\title{
后过渡金属配合物催化烯烃-极性单体共聚
}

\author{
李永清王凡曹育才* \\ (上海化工研究院有限公司 聚烯烃催化技术与高性能材料国家重点实验室 \\ 上海市聚烯烃催化技术重点实验 上海 200062)
}

\begin{abstract}
摘要 在非极性聚烯烃链中引入少量极性基团可明显改善聚烯烃材料性能. 依据配合物种类全面综述了 2010 年以来 后过渡金属配合物催化烯烃-极性单体共聚研究进展. 从 $\alpha$-二亚胺、膦酚和水杨醛亚胺型配合物到酮胺、膦磺酸、膦氧化膦和 $\mathrm{N}$-杂环卡宾型等多种新型骨架结构配合物, 总结了这些催化剂对催化活性、共聚物分子量、极性基团插入率、 共聚物微观结构和材料性能的有效调控. 尽管取得了许多重要进展, 这一领域产业化和商业化应用依然面临诸多限制 和挑战. 展望了应对这些挑战需要关注的问题.
\end{abstract}

关键词＼cjkstart催化剂; 聚合; 配合物; 烯烃; 极性单体; 后过渡金属

\section{Late Transition Metal Complexes for Olefin Copolymerization with Polar Monomers}

\author{
Li, Yongqing Wang, Fan Cao, Yucai* \\ (State Key Laboratory of Polyolefins and Catalysis, Shanghai Key Laboratory of Catalysis Technology for Polyolefins, \\ Shanghai Research Institute of Chemical Industry Co. Ltd., Shanghai 200062)
}

\begin{abstract}
Incorporation of small amounts of polar functional groups into non-polar polyolefins can dramatically improve properties of polyolefins. The development of late transition metal complexes for olefin copolymerization with polar monomers according to different types of complexes in the last decade is reviewed. With regard to $\alpha$-diimine, phosphino-phenolate, salicylaldimine, ketoamine, phosphine-sulfonate, bisphospnine monoxide, N-heterocyclic carbene complexes and more emerging catalysts, fine modulation of key copolymerization parameters (activity, molecular weight, polar monemer incorporation, etc.) and material properties of polyolefins in a controlled way are described in detail. Despite many recent advances and enticing characteristics of these catalysts, there still remains challenges for industrial and commercial application due to a variety of limitations. To overcome some of these challenges, a brief outlook on the future of issues should be focused on is provided.
\end{abstract}

Keywords catalyst; polymerization; complex; olefin; polar monomer; late transition metal

自 20 世纪 70 年代以来，单活性中心催化剂以其优 异的 “结构-性能” 调控特性, 成为继 Ziegler-Natta 催化 剂之后烯烃聚合领域又一革命性突破, 引起了学术界和 工业界的广泛关注 ${ }^{[1]}$. 从茂金属催化剂[2]到限制构型催 化剂[3]、非茂前过渡金属催化剂[4]和后过渡金属催化 剂 ${ }^{[5]}$, 高效催化剂的创新设计和发展, 极大推动了多种 商业化高性能聚烯烃产品的开发、生产和应用[6].

在饱和碳链组成的聚烯烃链中引入极性功能化基 团改善聚烯烃性能, 如黏结性、印刷性、染色性、流变 性、阻隔性、降解性以及其与其他高分子材料的相容性
和共混性等，是烯烃聚合领域长期以来极其重要又极具 挑战性的课题[7]. 引入少量极性基团(小于 $1 \%$ )便足以影 响材料性能 ${ }^{[8]}$. 工业界主要通过传统自由基聚合反应以 及基于化学或物理手段的多步后功能化等方法实现功 能化聚烯烃生产 ${ }^{[9]}$. 运用反应挤出接枝、辐射交联和支 化等各种后功能化方法(Scheme 1, f) 已经得到许多性能 优良的功能化聚合物, 并将其应用于水净化处理、药物 载体和生物薄膜等诸多领域; 然而复杂的反应步骤、较 低的接枝效率、较多的副反应(如链切断和交联)以及共 聚物结构及组成可控性差等缺点在不同程度上限制了

* Corresponding author. E-mail: caoyc@srici.cn

Received September 3, 2020; revised October 30, 2020; published online November 18, 2020.

Project supported by the Shanghai Professional and Technical Service Platform of Polyolefin Synthesis and Process Control (No. 19DZ2290900).

上海市聚烯烃合成技术及过程控制专业技术服务平台基金(No. 19DZ2290900)资助项目. 
这些材料的应用 $[10]$, 特别是针对非极性聚乙烯和聚丙 烯仅有有限的方法(如自由基接枝)可用. 通过共聚反应 先引入反应性基团再有选择性地进行进一步功能化或 接枝反应(Scheme 1, e), 可实现功能基团在不影响聚烯 烃主链结构的前提下有规律地分布在主链上; 这种方法 的关键在于满足特定条件的反应性单体的设计及适当 的共聚催化剂的使用 ${ }^{[11]}$. 传统自由基聚合(Scheme 1, a) 常常涉及苛刻条件并伴随大量副反应发生，易形成高支 化、宽分布和低结晶度共聚物; 极性单体对自由基中间 体敏感, 易导致共聚物中极性单体含量过高, 难以实现 对聚合物微观结构的精细调控 ${ }^{[0]}$. 活性自由基聚合 (Scheme 1, c) 可在一定程度上使聚合过程可控, 但目前 仍然面临许多工业化难题, 如催化效率不高、催化剂难 分离、自由基偶合终止及极性基团含量低等 ${ }^{[12]}$. 尽管环 状烯烃开环易位聚合(ROMP, Scheme 1, g) 和无环二烯烃 易位聚合(ADMET, Scheme 1, h) 也可实现极性共聚物的 精确调控, 但必要的后加氢及特定底物范围限制了该类 反应的大规模应用 ${ }^{[13]}$.

单活性中心催化剂催化烯烃-极性单体直接共聚, 可通过改变金属中心电子或空间结构精细控制聚合物 微观结构, 在较为温和的条件下形成极性单体插入率和 拓扑结构可控的共聚物 ${ }^{[14]}$. 最近 Marks 等 ${ }^{[15]}$ 综述了前过 渡金属催化的烯烃极性共聚(Scheme 1, b) 最新进展. 但 是, 前过渡金属具有较强的亲氧性, 易与极性单体中的 杂原子络合成稳定的鳌合物, 导致催化剂活性降低甚至 中毒失活. 通常需要采用一定保护措施降低极性基团或 杂原子对前过渡金属催化剂的影响(Scheme 1, d), 如使
用位阻较大的基团保护极性基团使催化剂活性中心受 到封闭 ${ }^{[16]}$, 使用大量甲基铝氧烷(MAO)或烷基铝等强 Lewis 酸预先与极性单体络合 ${ }^{[17]}$, 或者使用长链阻隔极 性基团与不饱和双键 ${ }^{[18]}$.

后过渡金属催化剂亲氧性弱, 使极性单体与烯烃直 接共聚(Scheme 1, b)成为可能 ${ }^{[19]}$. 以乙烯为例, 乙烯配 位插入到烷基金属键中，新形成的烷基金属中间体可以 与乙烯继续配位或者进行 $\beta-\mathrm{H}$ 消除和链转移; 在极性单 体存在时, 极性单体可以采用 $\sigma$-配位使催化剂中毒, 也 可以采用 $\pi$-配位然后以 1,2 或 2,1 形式插入到烷基金属 键中; 1,2 形式插入后的中间体若发生 $\beta$-极性基团 $(\beta-\mathrm{X})$ 消除, 也可能阻碍聚合反应继续进行(Scheme 2) ${ }^{[20]}$.

1987 年, Klabunde 等 ${ }^{[21]}$ 使用 SHOP (Shell Higher Olefin Process)催化剂(图 1)实现了乙烯与 “阻隔型” 极 性单体共聚. 1996 年, Brookhart 等 ${ }^{[22]}$ 首次将阳离子 $\alpha$-二 亚胺 Pd 配合物成功应用于乙烯或丙烯与丙烯酸酯的共 聚反应，由于独特的 “ $\beta-\mathrm{H}$ 消除” 和 “链行走” 特性，高 度支化的共聚物中极性基团大多位于链端，但其他工业 大宗单体，如醋酸乙烯酯和氯乙烯无法在该条件下与乙 烯共聚. 2000 年, Grubbs 等 ${ }^{[23]}$ 报道了对杂原子容忍性较 好的水杨醛亚胺中性 $\mathrm{Ni}$ 催化剂, 实现了乙烯和功能化 降冰片烯共聚形成高插入率线型共聚物，但对丙烯酸 酯、醋酸乙烯酯、氯乙烯和乙烯基醚等的共聚反应并不 显示催化活性 ${ }^{[24]}$. 相比之下, Drent 等 ${ }^{[25]} 2002$ 年报道 的电子不对称中性膦磺酸 Pd 催化体系则可以催化乙烯 与多种简单工业大宗极性单体(丙烯腈、醋酸乙烯酯、丙 烯酸和丙烯酸酯等)形成极性基团嵌入链中的线型

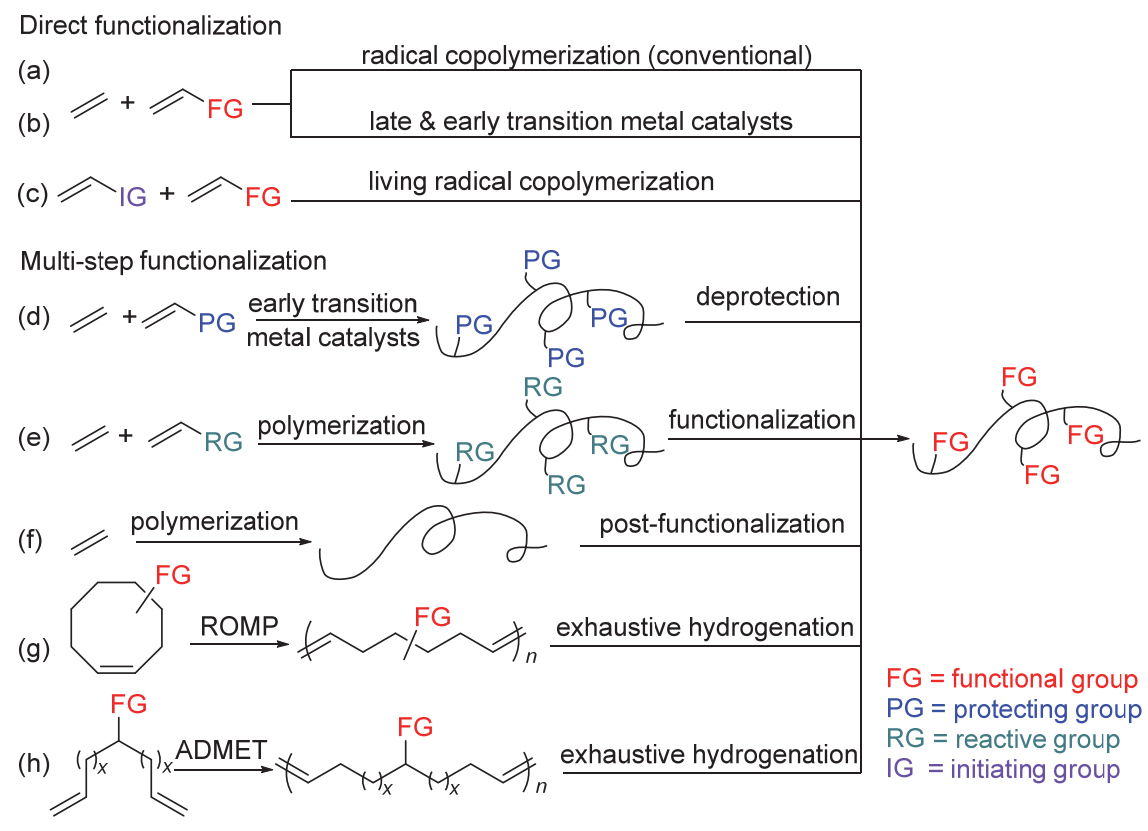

图式 1 在聚烯烃中引入极性基团的方法

Scheme 1 Approaches for synthesis of polyolefins containing polar group 


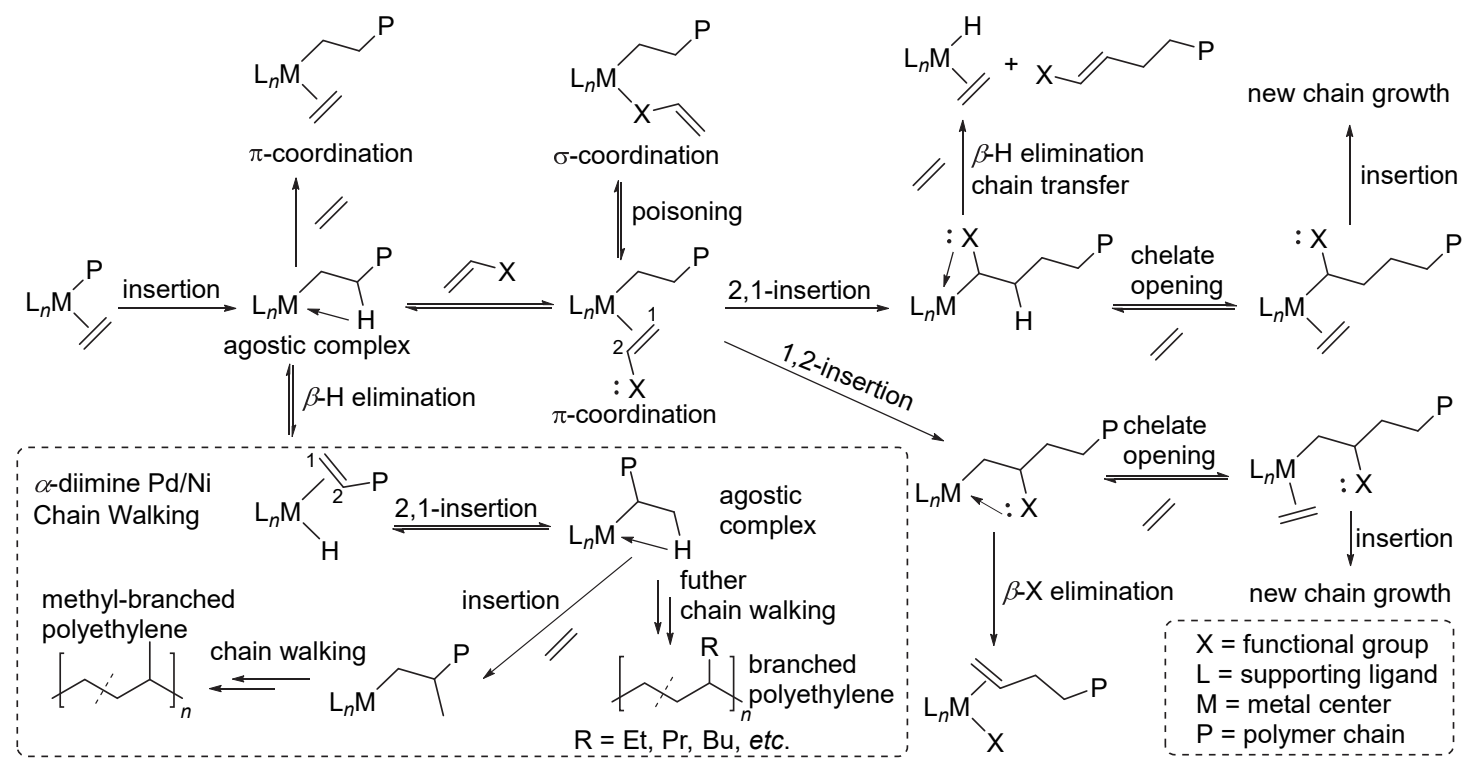

图式 2 后过渡金属催化乙烯-极性单体共聚及“链行走”的一般机理

Scheme 2 General mechanism for late transition metal catalyzed ethylene copolymerization with polar monomer and "chain walking”

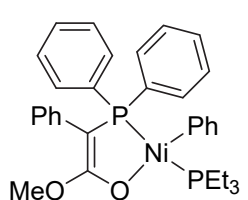

Klabunde 1987<smiles>[R][R]1([R])c2ccccc2O[N+]12CC1CCC2CC1</smiles>

$\mathrm{R}=\mathrm{Ph}, \mathrm{Cy},{ }^{i} \mathrm{Pr}$

Heinicke 2010

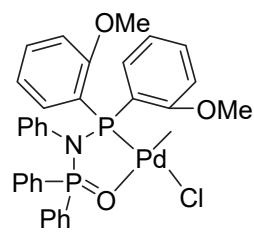

陈永乐 2018

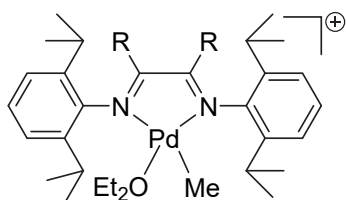

$\mathrm{R}=\mathrm{Me}, \mathrm{H}$

Brookhart 1996

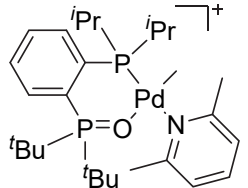

Nozaki 2012<smiles>C/C=C\c1cccc(CCC)c1N1C(c2ccccc2)=P(OCC)(OCC)O[NH+]1C</smiles>

陈永乐 2019

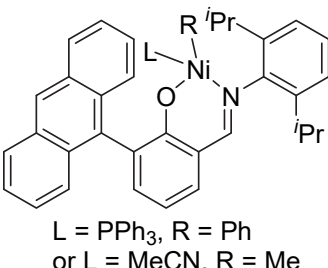

Grubbs 2000<smiles></smiles>

$\mathrm{R}^{1}=\mathrm{Dip}, \mathrm{R}^{2}=\mathrm{H}$ or $\mathrm{R}^{1}=$ Mes, $\mathrm{R}^{2}=\mathrm{H}$ Nozaki 2015<smiles>Cc1cc(C)c(C(C)C)c(C)c1</smiles>

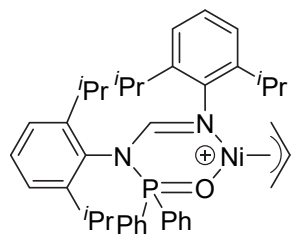

陈求乐 2019

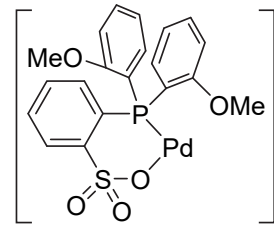

Drent 2002

$\mathrm{R}={ }^{t} \mathrm{Bu}$, Men

Nozaki 2018

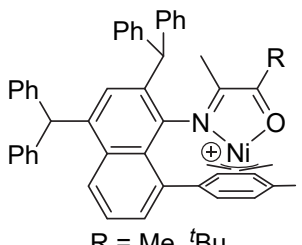

$\mathrm{R}=\mathrm{Me},{ }^{t} \mathrm{Bu}$

陈昶乐 2020

图 1 不同骨架的烯烃-极性单体共聚后过渡金属催化剂

Figure 1 Late transition metal catalysts with various backbones for olefin copolymerization with polar monomers

共聚物 ${ }^{[26]}$. 国内学者在该领域也取得了许多有价值的成

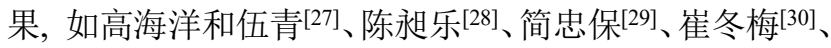
李悦生 ${ }^{[31]}$ 、孙文华 ${ }^{[32]}$ 、代胜瑜 ${ }^{[33]}$ 、贺晓慧 ${ }^{[7]}$ 和蔡正国 ${ }^{[34]}$ 等课题组.

自 Brookhart 等 ${ }^{[35]}$ 实现乙烯一丙烯酸酯直接共聚后 十多年时间里, 研究工作主要集中在对共聚物微观结
构、共聚机理和单体范围的探索. 2010 年以后, 特别是 近五年以来, 极性共聚领域发展迅速. 研究者们提出了 更科学理性的设计理念 ${ }^{[20 b]}$ 和多种聚合调控手段 ${ }^{[36]}$, 对 典型催化剂进行有目的的结构改进 ${ }^{[20 \mathrm{e}]}$, 多种新型骨架 催化剂(图 1)被合成出来并得到应用[20a,20d], 共聚单体范 围进一步拓展，共聚物材料性能的研究日渐增多，极大 
地提高了共聚物 “定制” 水平 $[31,37]$.

这些后过渡金属催化烯烃直接极性共聚的研究以 $\mathrm{Pd}$ 催化剂居多, $\mathrm{Ni}$ 催化剂次之, $\mathrm{Fe}$ 催化剂则仅有几例. $\mathrm{Pd}$ 催化剂比类似配体结构的 $\mathrm{Ni}$ 催化剂具有更好的极性 基团耐受能力, 因此也具有较好的可共聚极性单体范 围、更强的共聚物分子量及极性基团插入率调控能力. Pd 催化剂一般可催化简单大宗极性单体共聚, 而 $\mathrm{Ni}$ 催 化剂一般要求极性单体中存在一到多个亚甲基阻隔结 构.

苏碧云等 ${ }^{[19 b]}$ 于 2016 年介绍了膦磺酸 Pd 催化剂催 化极性共聚的研究进展, 侧重于机理探讨; 2018 年, 陈 昶乐 ${ }^{[28]}$ 和简忠保 ${ }^{[29]}$ 分别综述了各自课题组在极性共聚 领域的创新性工作. Nozaki 等 ${ }^{[38]}$ 发表的综述较为全面地 总结了 2009 年以前极性配位共聚研究进展. Guan 等 ${ }^{[39]}$ 也于 2010 年全面综述了单金属均相后过渡金属催化剂 的发展. 鉴于此后取得了许多重要成果, 以下将依据催 化剂种类全面综述 2010 年以来该领域的重要研究进展. 氧化还原调控共聚可参考陈永乐 ${ }^{[36 a-36 b]}$ 和 Long ${ }^{[36 c]}$ 发表 的相关综述. 为方便综述, 除非特别指明, 文中催化活 性、聚合物数均分子量和聚合物支化度单位分别为 $(\mathrm{g}$ polymer $) \cdot(\text { mol catalyst })^{-1} \cdot \mathrm{h}^{-1} 、 \mathrm{~g} \cdot \mathrm{mol}^{-1}$ 和 $\mathrm{br} / 1000 \mathrm{C}(\mathrm{br}=$ 支化链); 极性基团插入率以摩尔分数计, 文中以 $\%$ 表 示; 转化数(TON) 为每摩尔催化剂转化的底物摩尔数, 转化频率(TOF)为单位时间单位活性位上消耗反应物的 数目, $\mathrm{TOF}$ 单位为 $\mathrm{h}^{-1}$.

\section{1 用于共聚的极性单体概述}

在烯烃聚合反应中, 极性基团的存在会导致催化剂 聚合活性和聚合物分子量降低, 甚至导致催化剂完全失 活 ${ }^{[40]}$. 含有极性基团的单体较难与烯烃直接共聚, 这被 称为极性单体问题 ${ }^{[41]}$ : (1)极性基团与金属中心生成 $\sigma$-配 合物, 阻碍烯烃继续配位或使催化剂中毒(Scheme 3, a); (2)极性基团插入后形成稳定的金属-X 螯合物或发生 $\beta$ 极性基团消除, 降低聚合效率或使催化剂分解失活 (Scheme 3, b, c); (3)极性单体本身的缺电子特性导致与 金属中心的弱 $\pi$-配位, 显著降低极性基团插入率 (Scheme 3,d); (4) $\alpha$-极性基团取代的烷基乙烯中间体与 无取代中间体相比具有相对高的继续插入能垒, 也会导 致聚合效率降低(Scheme 3, e).

不同结构的极性单体在共聚反应中的插入形式有 很大差别 $[40 c, 42]$. 丙烯腈、丙烯酸酯和三氟甲基丙烯酸等 缺电子单体以 2,1 形式插入为主, 乙烯基乙醚和乙烯基 磷酸等富电子单体以 1,2 形式插入为主, 其他如醋酸乙 烯酯和醋酸烯丙酯等可以通过 1,2 形式插入也可以通过 2,1 形式插入. 降冰片烯有三种聚合形式: 开环易位聚

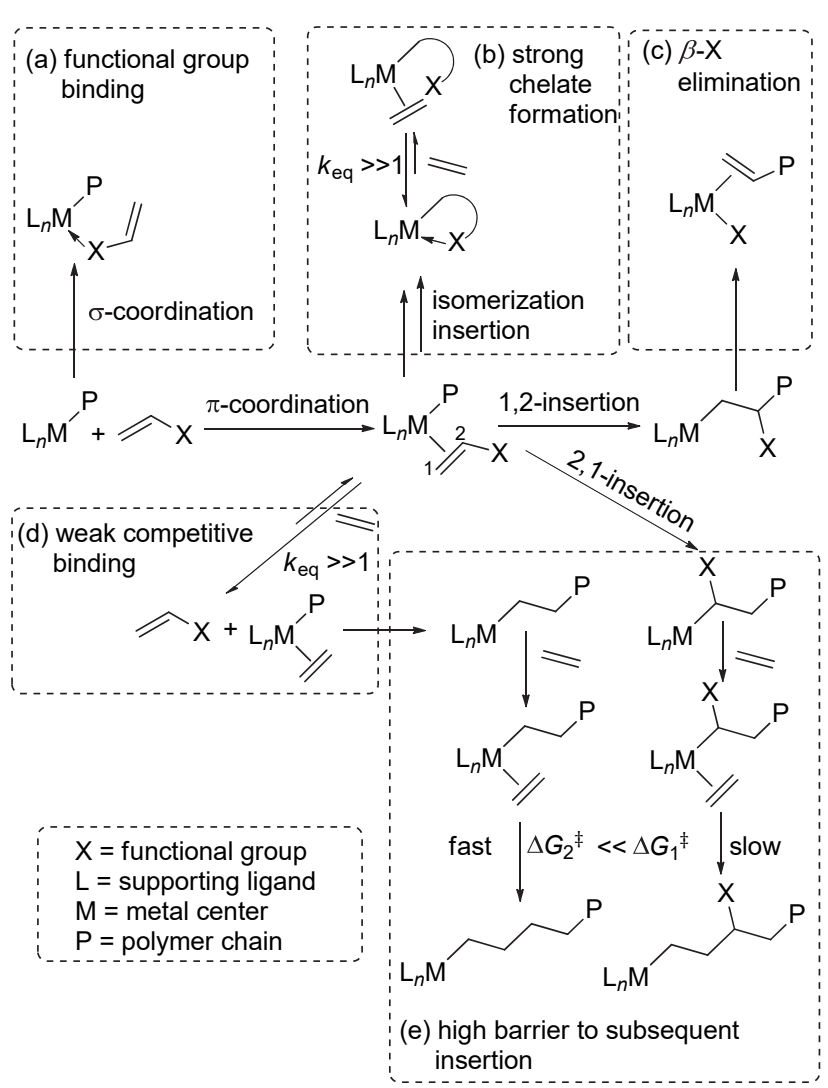

图式 3 极性单体问题

Scheme 3 Polar monomer problem

合、阳离子或自由基聚合和乙烯基聚合. 通过乙烯基聚 合, 聚合物通常具有高玻璃化转变温度、高光透性、低 介电常数和低双折射率 ${ }^{[43]}$. 迄今为止, 学术界已经实现 丙烯腈、丙烯酸甲酯、醋酸乙烯酯、醋酸烯丙酯、丙烯 酸、丙烯酰胺、烯丙基胺、乙烯叔丁基醚、乙烯基二乙 氧基硅烷、降冰片烯羧酸酯、十一烯酸甲酯、十一烯酸、 十一烯醇和烯已基氯等多种乙烯型(图 2), 烯丙基型和

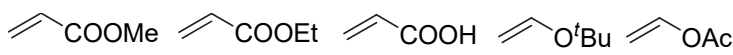

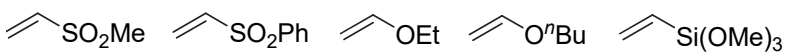
$\sim_{\mathrm{F}} \widehat{\mathrm{Cl}}_{\mathrm{Cl}} \widehat{\mathrm{CN}}_{\mathrm{CF}_{3}} \sim_{\mathrm{Si}(\mathrm{OEt})_{3}}$<smiles>C=CC(=O)NCCOC(=O)C=C</smiles>
$\lambda_{\mathrm{COOMe}} \int_{\mathrm{COOH}}^{\mathrm{CF}_{3}} \overbrace{\mathrm{COOEt}}^{\mathrm{CN}} \overbrace{\mathrm{COOH}}^{\mathrm{Br}}$<smiles>C=CCOCOC(=O)C=C</smiles>

图 2 乙烯型极性单体

Figure 2 Polar vinyl monomers 
长链阻隔型(图 3)和降冰片烯型(图 4)极性单体与非极性 烯烃(如乙烯、丙烯、高级 $\alpha$-烯烃或降冰片烯)直接共聚.

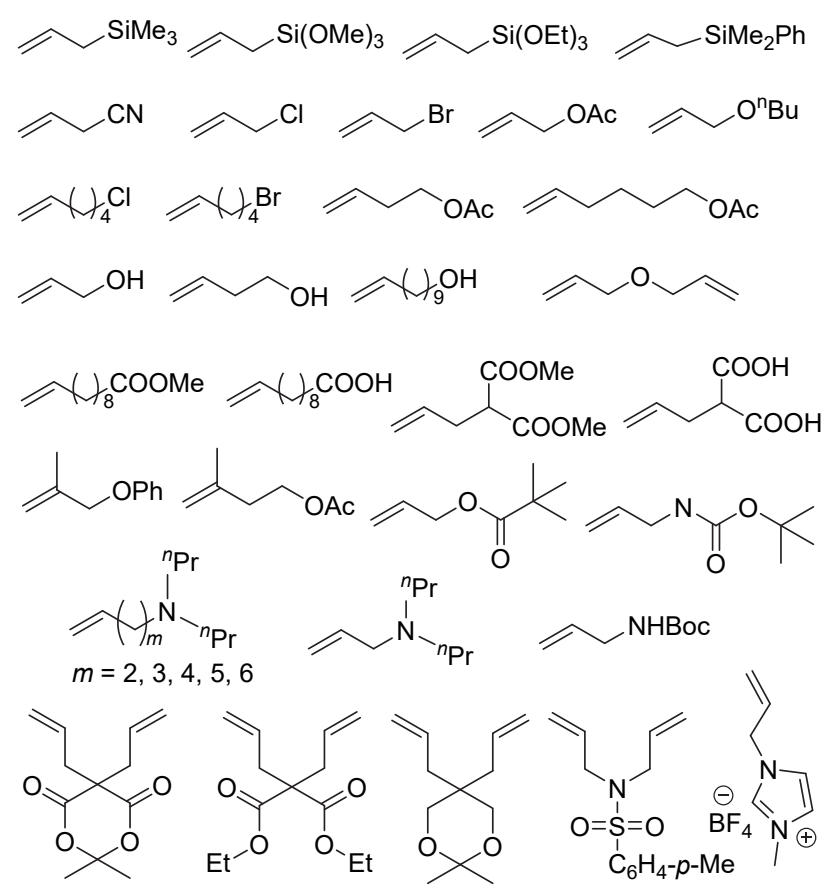

图 3 烯丙基型及长链阻隔型极性单体

Figure 3 Polar allyl monomers and monomers with methylene spacers
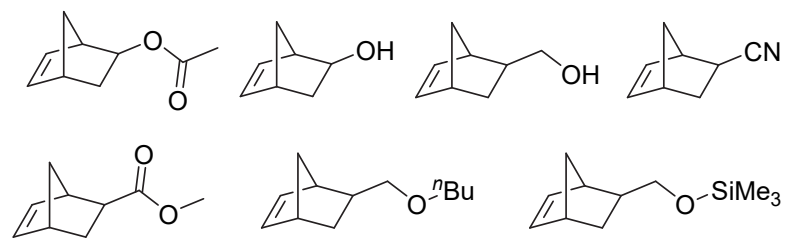<smiles>O=C1OC(=O)C2C3C=CC(C3)C12</smiles><smiles>O=C1C2C3C=CC(C3)C2C(=O)N1c1ccccc1</smiles>

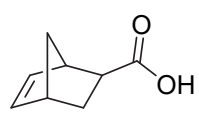

图 4 降冰片烯型极性单体

Figure 4 Polar norbornyl monomers

\section{$2 \alpha$-二亚胺型催化剂}

Brookhart 等 ${ }^{[22,44]}$ 最初报道的阳离子 $\alpha$-二亚胺 Pd 催 化剂 $1 \sim 5$ 在低温低压 $\left(35^{\circ} \mathrm{C}\right.$ 和 $\left.0.2 \mathrm{MPa}\right)$ 时, 催化乙烯与 丙烯酸酯共聚, 其中 4 催化得到共聚物分子量为 $1.1 \times$ $10^{4} \sim 8.8 \times 10^{4}$, 支化度为 $97 \sim 105$, 乙烯 $\mathrm{TON}$ 为 $455 \sim$ 7700 , 极性基团插入率为 $1 \% \sim 12 \%$ ，极性基团主要位于 支链链端. 功能化 $\alpha, \omega$-二烯烃 ${ }^{[45]}$ 和乙烯基三甲氧基硅 烷 ${ }^{[46]}$ 也可与乙烯共聚. 独特的链行走特性可以得到支化 和超支化聚合物, 但聚合物通常为无定形结构, 力学性 能差, 立构选择性共聚也非常困难; 高温时 $\left(60{ }^{\circ} \mathrm{C}\right)$ 由于

骨架垂直方向 $N$-芳基旋转增加, 配体发生 $\mathrm{C}-\mathrm{H}$ 活化及 链转移, 导致催化剂快速分解, 催化剂热稳定性差, 难以 在工业温度条件 $\left(70 \sim 110{ }^{\circ} \mathrm{C}\right)$ 下使用. 由于经 $\beta$-H 消除的 链转移速度增加, 高温时获得的聚合物通常只有较低的 分子量 ${ }^{[47]}$.
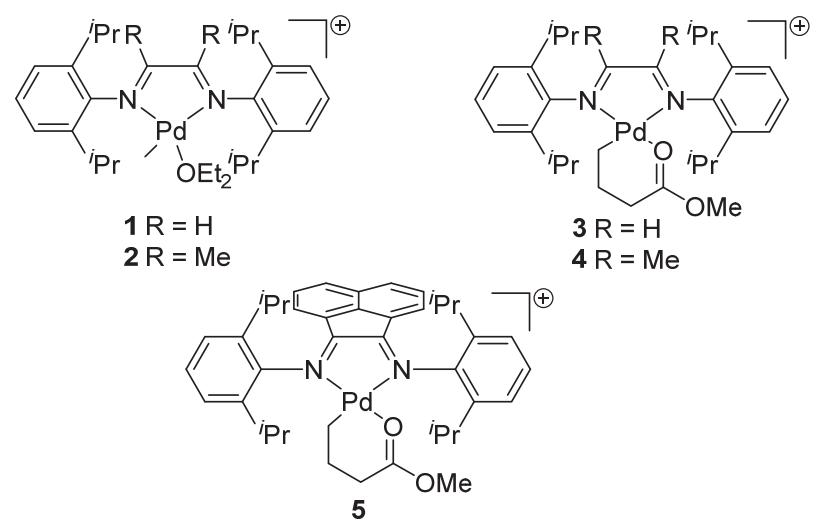

针对这些问题, 研究者们主要通过两种方式调整催 化剂结构 ${ }^{[48]}$ : 一是通过改变苯胺苯环取代基研究取代 基效应对聚合反应影响; 二是通过增加金属中心正方形 平面轴向位阻, 减少 $N$-芳基旋转, 抑制链转移和催化剂 失活, 提高催化剂稳定性, 从而获得高分子量共聚物. 通过调节催化剂结构和反应条件，催化剂热稳定性在一 定程度上得到提升, 原本受共聚条件影响较小的共聚物 支化度变得可控，极性基团在共聚物中的分布可由链端 转变为链中; 双金属催化剂金属中心的协同作用也会对 共聚行为产生影响.

\section{1 取代基效应}

高级 $\alpha$-烯烃(如 1-已烯)在 6 催化下分别与丙烯酸丁 酯和甲基丙烯酸甲酯共聚 ${ }^{[49]}$ 形成高度支化共聚物(支化 度为 $80 \sim 122$ ), 极性基团插入率为 $3.1 \% \sim 13.3 \%$, 分子 量为 $2.5 \times 10^{5} \sim 3.36 \times 10^{5}$. 1-癸烯与亚甲基阻隔的 1,1 二取代乙烯基极性单体在 7 催化共聚时得到中等支化度 共聚物 ${ }^{[50]}$; 由于极性基团与双键有亚甲基阻隔，使得烷 基金属中间体中极性基团位于 $\gamma$-位，不发生 $\beta$-极性基团 消除； $0{ }^{\circ} \mathrm{C}$ 时甲基烯丙基叔丁基醚和醋酸甲基烯丙基酯 分别参与共聚，极性基团插入率分别为 $9.7 \%$ 和 3.3\%, 共聚物分子量分别为 $1.87 \times 10^{4}$ 和 $1.54 \times 10^{4}$, 支化度分 别为 55 和 45 ; 极性单体有选择性地以 1,2 或 2,1 方式插 入, 进而使极性基团嵌入链端或者链中(Scheme 4).

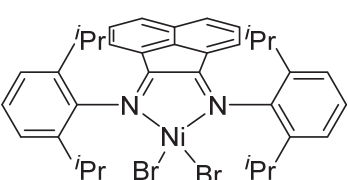

6

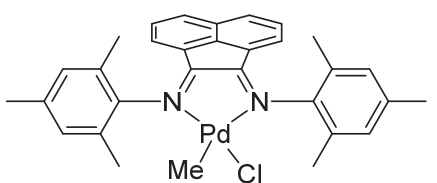

7 


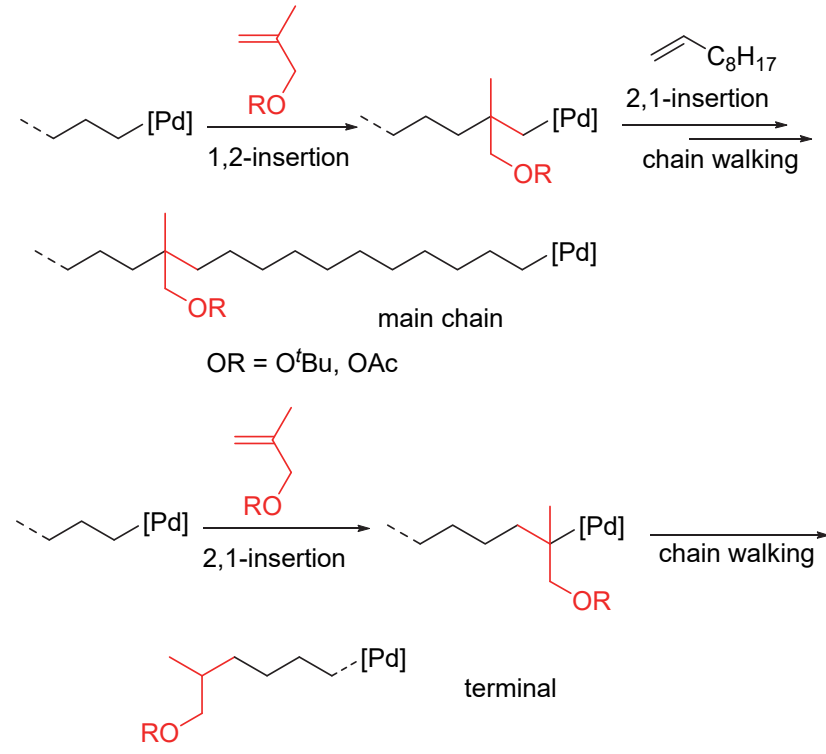

图式 47 催化共聚机理

Scheme 4 Mechanism for copolymerization catalyzed by 7

使用无取代的 1-菜结构替换典型催化剂(如 $\mathbf{1} \sim \mathbf{5}$ ) 中的苯环结构, 由于轴向位阻减小, Pd 催化剂 $8 \sim 11$ 在 $35{ }^{\circ} \mathrm{C}$ 和乙烯压力为 $0.25 \mathrm{MPa}$ 时, 仅能催化乙烯一丙烯酸 甲酯低聚共聚, 产物中还含有部分乙烯低聚物 ${ }^{[51]}$. 在荎 环上引入取代芳基形成夹心结构 Pd 催化剂 12, 轴向位 阻增加减缓链转移速率 [52]; 乙烯-丙烯酸甲酯共聚物分 子量较 $8 \sim 11$ 得以提升(最高为 $5.5 \times 10^{4}$ ), 但催化活性 (乙烯 $\mathrm{TON}=350 \sim 2930$ ) 仍低于典型催化剂 4, 支化度 $(114 \sim 124)$ 则高于 4 ; 需要指出的是, 典型催化剂 13 催 化乙烯-乙烯基三乙氧基硅烷共聚, 仅能在链端引入一 个硅基, 而 12 催化共聚极性单体以 1,2 形式插入 $\mathrm{Pd}-$ $\mathrm{Me}$ 键，在每条共聚物链中引入 $4 \sim 8$ 个硅基.

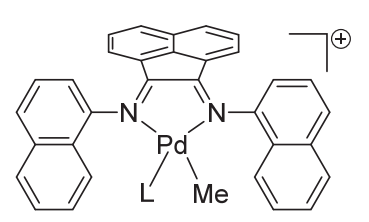

$8 \mathrm{~L}=\mathrm{MeCN}$

$9 \mathrm{~L}=\mathrm{DMSO}$

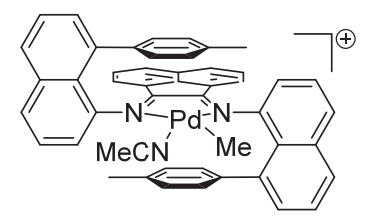

12

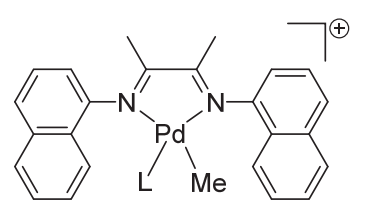

$10 \mathrm{~L}=\mathrm{MeCN}$

$11 \mathrm{~L}=\mathrm{DMSO}$

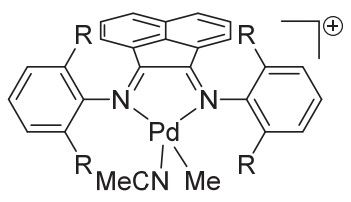

$13 \mathrm{R}={ }^{i} \mathrm{Pr}$

$14 \mathrm{R}=\mathrm{Me}$
与 $\mathrm{Pd}$ 催化剂形成乙烯钯烷基配合物休眠态不同, Brookhart 等 ${ }^{[53]}$ 发现类似的 $\mathrm{Ni}$ 催化剂催化乙烯-乙烯基 三乙氧基硅烷共聚形成的休眠态为硅烷 1,2 和 2,1 形式 插入到 $\mathrm{Ni}-\mathrm{R}$ 键中形成的四元和五元螯合环. 尽管发生 $\beta$-硅烷基消除, 但没有进一步链转移, 极性基团可分布 在链中和链端. Ni 催化剂 $\mathbf{1 5}$ 的活性高于 Pd 催化剂 13 (TOF 最高分别为 140000 和 362), 且 $\mathrm{Ni}$ 催化剂具有较好 的热稳定性，反应可在 $40 \sim 100{ }^{\circ} \mathrm{C}$ 时进行. 他们还发现, 极性基团分布规律受乙烯压力和温度影响: 温度升高, 链端硅烷量增加; 乙烯压力升高, 链中硅烷量增加. 15 催化反应得到高度支化共聚物(支化度 25 95), 而较小 空间位阻的 16 催化反应则的带低支化度共聚物(支化度 5 29), 且 16 的极性基团插入率较 $\mathbf{1 5}$ 高(3\% 10\% vs $0.37 \% \sim 2.2 \%$ ).

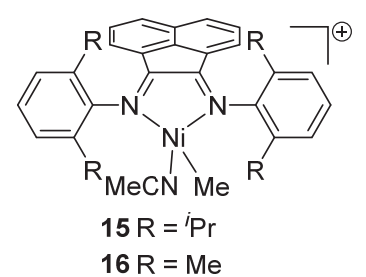

苯胺对位引入给电子基团，可在一定程度上提升金 属中心电子密度. 硅烷基团的引入使得 $\mathrm{Ni}$ 催化剂 18 在 极性基团环境中更加稳定, 与 17 相比催化活性更高 ${ }^{[54]}$. 加入 MAO 保护极性基团, 在较低极性单体浓度时, 18 催化乙烯-十一烯醇催化活性高达 $1.8 \times 10^{7}$, 但极性基 团插入率仅 $0.42 \%$; 增大极性单体浓度, 催化活性降低 至 $10^{4}$, 插入率则升高至 $4.3 \% .18$ 催化乙烯-甲基丙烯酸 甲酯共聚时极性基团插入率高达 $20 \% \sim 60 \%$.
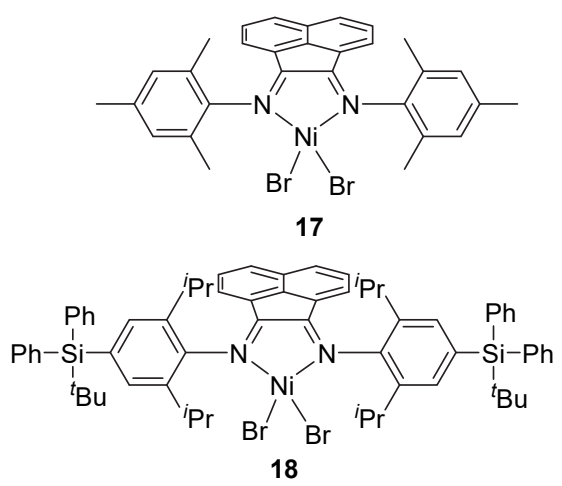

两个苯胺苯环上如果带有不同的取代基则形成电 子结构不对称催化剂, Milani 等 ${ }^{[5]}$ 研究了此类 Pd 催化剂 对乙烯一丙烯酸甲酯共聚反应的催化行为, 得到低分子 量高度支化共聚物，极性基团位于链端. 非对称电子结 构催化剂 19、20 比对称电子结构催化剂 21 23、26 具 有更高的催化活性和更高的极性单体插入率 $(6.6 \%$ $12.5 \%)$. Pd-DMSO 催化剂比 Pd-MeCN 催化剂活性更高, 24 催化共聚反应得到 $12.5 \%$ 插入率, 支化度也最高 (146), 催化活性约为 6800 . 改变配体结构, 在苯胺苯环 邻位引入甲氧基 ${ }^{[5]}, 27 \sim 32$ 催化乙烯-丙烯酸甲酯共聚 
活性与类似邻位甲基催化剂相比，极大降低，但是共聚 物极性基团插入率得到提高(6\% 38\%).

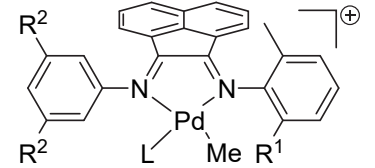

$19 \mathrm{~L}=\mathrm{MeCN}, \mathrm{R}^{1}=\mathrm{Me}, \mathrm{R}^{2}=\mathrm{CF}_{3}$

$20 \mathrm{~L}=\mathrm{DMSO}, \mathrm{R}^{1}=\mathrm{Me}, \mathrm{R}^{2}=\mathrm{CF}_{3}$

$21 \mathrm{~L}=\mathrm{MeCN}, \mathrm{R}^{1}=\mathrm{R}^{2}=\mathrm{Me}$

$22 \mathrm{~L}=\mathrm{DMSO}, \mathrm{R}^{1}=\mathrm{R}^{2}=\mathrm{Me}$

$27 \mathrm{~L}=\mathrm{MeCN}, \mathrm{R}^{1}=\mathrm{OMe}, \mathrm{R}^{2}=\mathrm{CF}_{3}$

$28 \mathrm{~L}=\mathrm{DMSO}, \mathrm{R}^{1}=\mathrm{OMe}, \mathrm{R}^{2}=\mathrm{CF}_{3}$

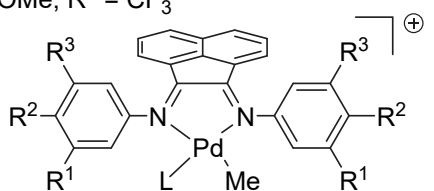

$23 \mathrm{~L}=\mathrm{MeCN}, \mathrm{R}^{1}=\mathrm{R}^{3}=\mathrm{Me}, \mathrm{R}^{2}=\mathrm{H}$

$24 \mathrm{~L}=\mathrm{MeCN}, \mathrm{R}^{1}=\mathrm{R}^{3}=\mathrm{CF}_{3}, \mathrm{R}^{2}=\mathrm{H}$

$25 \mathrm{~L}=\mathrm{DMSO}, \mathrm{R}^{1}=\mathrm{R}^{3}=\mathrm{CF}_{3}, \mathrm{R}^{2}=\mathrm{H}$

$26 \mathrm{~L}=\mathrm{MeCN}, \mathrm{R}^{1}=\mathrm{R}^{3}=\mathrm{R}^{2}=\mathrm{OMe}$

$\mathrm{Fu}$ 等 ${ }^{[57]}$ 也设计合成了非对称结构 $\mathrm{Pd}$ 催化剂 33 和 34, 在 $25 \sim 50{ }^{\circ} \mathrm{C}$ 和 $0.1 \mathrm{MPa}$ 乙烯压力时实现乙烯-丙烯 酸甲酯共聚，但催化活性非常低(150～907 vs 123 678), 33 还形成双峰分布共聚物. 34 在 $50{ }^{\circ} \mathrm{C}$ 时得到的共 聚物极性基团插入率最高(4\%), 此时的共聚物分子量为 $3.4 \times 10^{4}$.

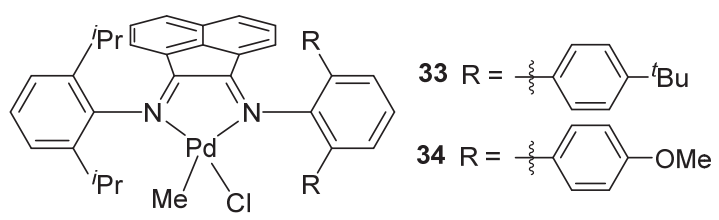

\section{2 轴向位阻效应}

轴向位阻增加可减少 $N$-芳基旋转, 抑制链转移和 催化剂失活, 影响催化活性和共聚行为, 如催化剂热稳 定性、极性基团插入率和共聚物分子量等. Guan 等 ${ }^{[58]}$ 利用环蕃结构增大轴向位阻, 在 $35{ }^{\circ} \mathrm{C}$ 时 35 催化乙烯丙烯酸甲酯共聚，极性基团插入率可提高至 14.4\% $21.8 \%$, 共聚物分子量 $6600 \sim 10000$, 但环蕃化合物合成 非常困难.

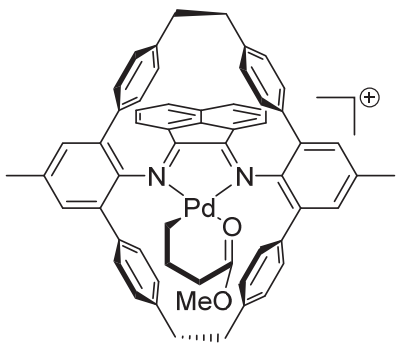

35
二苯甲基取代的 $\alpha$-二亚胺型配合物合成相对简单， 其独特的大体积结构也可在轴向带来较大位阻. Long 等 ${ }^{[59]}$ 首先将此类中性 $\mathrm{Ni}$ 催化剂在高温下 $\left(100{ }^{\circ} \mathrm{C}\right)$ 应用于 乙烯聚合，陈永乐等则对二苯甲基结构的 $\alpha$-二亚胺型催 化剂催化极性共聚进行了系统研究.

陈昶乐等 ${ }^{[60]}$ 首先合成了具有抑制 “链行走” 功能的 $\mathrm{Pd}$ 催化剂 36 和 37 , 在 $20{ }^{\circ} \mathrm{C}$ 和 $0.1 \mathrm{MPa}$ 乙烯压力下催化 乙烯一丙烯酸甲酯共聚, 催化活性高于典型催化剂 2 (3700 vs 330), 最高可达 $1.9 \times 10^{4}$; 共聚物分子量更高 （18900 vs 3100)，支化度更低(34 vs 93)，但极性基团插 入率较低 $(0.4 \%$ vs $3.2 \%)$. 值得注意的是, 高分子量和低 支化度使共聚物具有较高熔点 $\left(50 \sim 70{ }^{\circ} \mathrm{C}\right)$, 他们在 $\alpha$-二 亚胺型 $\mathrm{Pd}$ 催化剂催化的乙烯一丙烯酸甲酯共聚反应中首 次得到了半结晶固体共聚物，而非粘稠油状物。

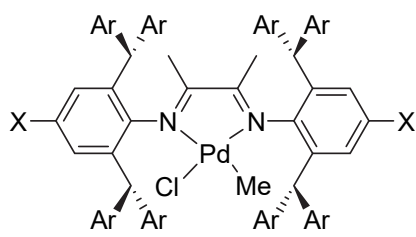

$36 \mathrm{X}=\mathrm{OMe}, \mathrm{Ar}=\mathrm{Ph}$

$37 \mathrm{X}=\mathrm{Me}, \mathrm{Ar}=\mathrm{Ph}$

减小轴向位阻，将二苯甲基中苯基替换为 $\mathrm{H}$ 和 $\mathrm{Me}$ 等，可对 $\mathrm{Pd}$ 催化的乙烯一丙烯酸甲酯共聚反应进行系统 调控 ${ }^{[8 c]}$. 乙烯压力 $0.1 \sim 0.8 \mathrm{MPa}, 30{ }^{\circ} \mathrm{C}$ 时加入自由基抑 制剂 Galvinoxyl，随着苯胺邻位位阻减小 $(37>42>41>$ 40 $>39>38$ ), 极性基团插入率升高(自 $0.4 \%$ 至 13.8\%), 分子量逐渐降低(自 70800 至 1100), 支化度升高(自 30 至 119).
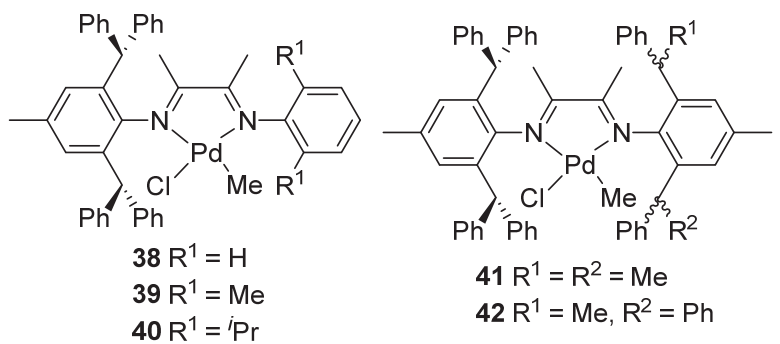

进一步增大轴向位阻，将二苯甲基苯环替换为荎基 和苯并噻吩基 ${ }^{[61]}, \mathrm{Pd}$ 催化剂 43 和 44 可以极大降低 “链 行走”, 得到低支化度 $(8 \sim 22)$ 的共聚物, 并可催化乙烯 与更多极性单体共聚，如烯丙基甲基醚、醋酸烯丙基酯、 十一烯基氯/溴、十一烯醇和十一烯酸甲酯等。但是，该 催化体系无法有效调和共聚物分子量和极性基团插入 率之间的矛盾，大位阻的引入可能造成金属中心过度拥 挤, 影响体积大的极性单体插入. 如 43 和 44 在乙烯压 力为 $0.8 \mathrm{MPa}$ 时, 催化乙烯一丙烯酸甲酯共聚, 共聚物分 
子量分别提升至 $4.4 \times 10^{5}$ 和 $2.8 \times 10^{6}$, 但是极性基团插 入率非常低 $(0.61 \%$ 和 $<0.1 \%)$. 即使催化乙烯-十一烯酸 甲酯共聚可获得分子量大于 $10^{6}$ 的超高分子量极性聚乙 烯，插入率也仅有 $0.12 \% \sim 1.21 \%$.

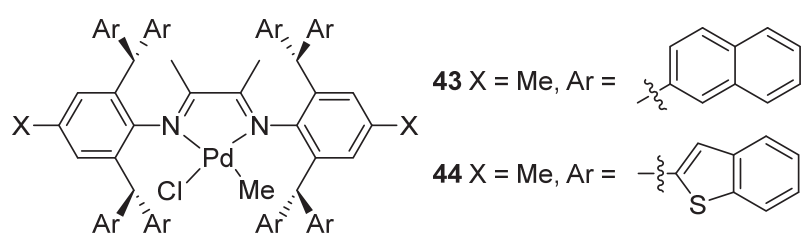

乙烯基叔丁基醚、醋酸乙烯酯、丙烯酸和丙烯腈无 法在该条件下与乙烯共聚, 丙烯一丙烯酸共聚仅能得到 插入率 $0.1 \%$ 的共聚物 ${ }^{[61,47 a]}$. 高级 $\alpha$-烯烃 1-辛烯与丙烯 酸共聚[47a]，37 44 仅有较低催化活性(1600 7700); 其 中 40 在 $20{ }^{\circ} \mathrm{C}$ 时得到最高分子量 $\left(4 \times 10^{4}\right)$ 共聚物, 极性 基团插入率为 $1.07 \% \sim 15.7 \%$. 随着轴向位阻增加, 极性 基团插入率降低，但对支化度影响较小 $(70 \sim 90)$.

降低反应体系乙烯压力至 $0.1 \mathrm{MPa}, 37 \sim 44$ 催化乙 烯一丙烯酸共聚[62]得到分子量为 $1200 \sim 54000$ 的共聚物, 极性基团插入率为 $0.5 \% \sim 7.3 \%$, 支化度为 $13 \sim 119$, 极 性基团位于链端. 37 催化乙烯-丙烯酸共聚, 产率和分 子量近似线性增加, 呈现出 “准” 活性共聚的特征. 37 催化含有亚甲基阻隔的乙烯一烯丙基乙酸和乙烯-十一 烯酸, 共聚活性大幅提高至 $2.19 \times 10^{5}$ 和 $1.06 \times 10^{5}$, 高 于丙烯酸-乙烯共聚活性(4100). 所有共聚物具有中等 支化度，且随轴向位阻增加呈降低趋势。

利用类似的轴向位阻调控思路, 范基骨架 $\mathrm{Ni}$ 催化 剂 45 49 催化乙烯-十一烯酸甲酯共聚, 轴向位阻对聚 合反应的影响无明显规律 ${ }^{[63]} .20{ }^{\circ} \mathrm{C}$ 时保持乙烯压力 0.2 $\mathrm{MPa}$, 以二乙基氯化铝为助催化剂, 共聚物具有中等支 化度(45 70), 47 具有最高的催化活性 $1.05 \times 10^{6}, 46$ 得 到最高插入率 $0.53 \%, 48$ 得到最高分子量 $2.4 \times 10^{5}$. 升高 反应温度至 $80{ }^{\circ} \mathrm{C}$ 时催化活性明显降低.

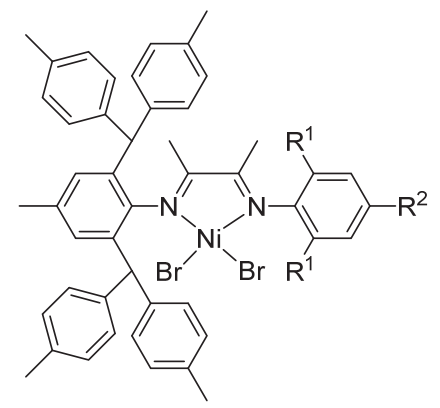

$$
\begin{aligned}
45 \mathrm{R}^{1} & =\mathrm{R}^{2}=\mathrm{H} \\
46 \mathrm{R}^{1} & =\mathrm{Me}, \mathrm{R}^{2}=\mathrm{H} \\
47 \mathrm{R}^{1} & =\mathrm{CH}(\mathrm{Me})_{2}, \mathrm{R}^{2}=\mathrm{Me} \\
48 \mathrm{R}^{1} & =\mathrm{CHMePh}, \mathrm{R}^{2}=\mathrm{Me} \\
49 \mathrm{R}^{1} & =\mathrm{CH}\left(\mathrm{C}_{6} \mathrm{H}_{4} \mathrm{Me}\right)_{2}, \mathrm{R}^{2}=\mathrm{Me}
\end{aligned}
$$

在 37 的苯胺苯环其他位点引入三个相同的吸电子 基团 $\mathrm{F}$ 或给电子基团 $\mathrm{OMe}$, 同步调节空间位阻和电子效 应, 51 可以催化乙烯均聚以及乙烯一丙烯酸甲酯、乙烯丙烯酸共聚, 而缺电子 50 甚至无法催化乙烯均聚 ${ }^{[64]}$.
可能由于增大的金属中心位阻更利于体积较小的丙烯 酸插入，在 $60{ }^{\circ} \mathrm{C}$ 和 $0.2 \mathrm{MPa}$ 乙烯压力时，丙烯酸甲酯和 丙烯酸插入率分别为 $0.2 \%$ 和 $1.2 \%$ ，共聚物支化度为 $48 \sim 56$.

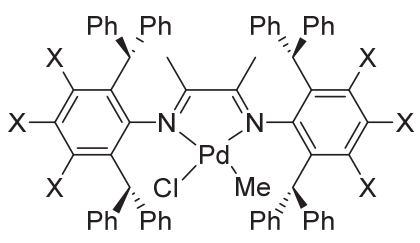

$50 \mathrm{X}=\mathrm{OMe} ; 51 \mathrm{X}=\mathrm{F}$

陈昶乐等[65]还尝试将二苯甲基中一个苯环用噻吩 替代, $\mathrm{Pd}$ 催化剂 52 在 $30{ }^{\circ} \mathrm{C}$ 和 $0.8 \mathrm{MPa}$ 乙烯压力下仅能 催化乙烯与阻隔型十一烯酸甲酯、十一烯酸、十一烯醇 和烯己基氯共聚，共聚物具有低支化度(14 46); 乙烯一 十一烯酸甲酯共聚分子量最高可达 $1.24 \times 10^{6}$, 催化活 性可达 $1.05 \times 10^{5}$, 但插入率仅为 $0.67 \%$.

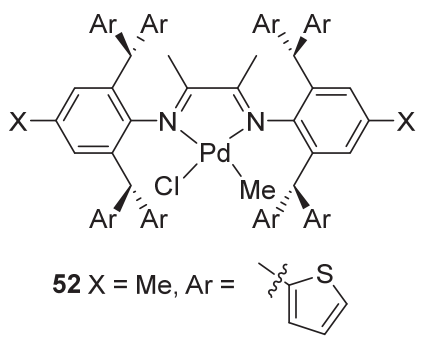

结构不对称型催化剂会对极性共聚反应产生影 响 ${ }^{[55]}$. 陈永乐等 ${ }^{[66]}$ 利用 $\mathrm{Pd}$ 催化剂 $53 \sim 57$ 对 $25{ }^{\circ} \mathrm{C}$ 和 0.1 $\mathrm{MPa}$ 乙烯压力下乙烯一丙烯酸甲酯的共聚反应进行了研 究. 除由 $\mathrm{NO}_{2}$ 造成金属中心亲电性增强的 56 不能催化 共聚外, 其他几种催化剂均可催化共聚反应, 但催化活 性较低(小于 1000), 共聚物分子量也较低(1800～5400). 53 催化乙烯-极性降冰片烯共聚[67]可得到高分子量共聚 物 $\left(2.16 \times 10^{4} \sim 1.25 \times 10^{5}\right)$, 但无法催化乙烯一氰基降冰 片烯共聚。近年来, Chen 等[68]还设计了非对称结构 $\mathrm{Ni}$

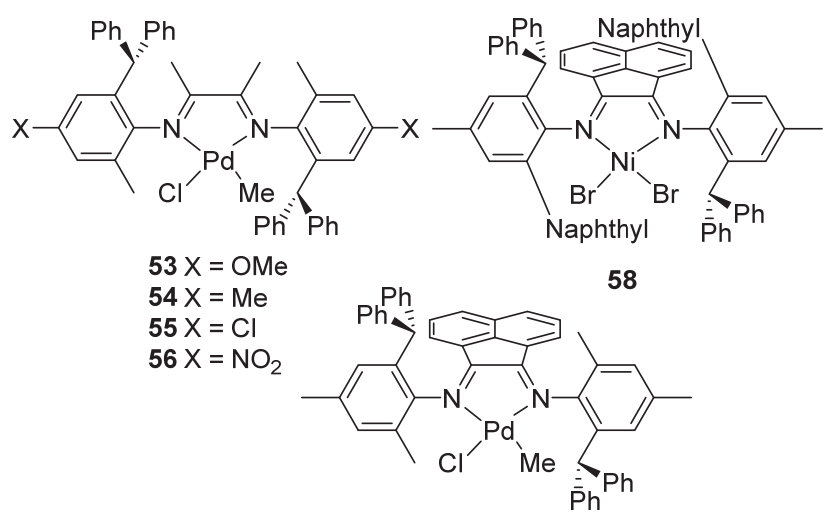

57

为助催化剂催化丙烯-十一烯酸甲酯和丙烯-十一烯醇 
催化剂 58, 在 $30{ }^{\circ} \mathrm{C}$ 和 $0.6 \mathrm{MPa}$ 丙烯压力时, 使用 $\mathrm{MAO}$ 共聚得到超支化结构共聚物(支化度为 $138 \sim 187$ ); 催化 活性可达 $4 \times 10^{4}$, 共聚物分子量高达 $10^{5}$, 插入率最高 分别为 $0.8 \%$ 和 $2.6 \%$.

在此基础上, 在苯胺对位再引入大位阻二苯甲基结 构, $\mathrm{Pd}$ 催化剂 $59 \sim 61$ 在 $30{ }^{\circ} \mathrm{C}$ 和 $0.18 \mathrm{MPa}$ 乙烯压力时, 催化乙烯一丙烯酸甲酯和乙烯一丙烯酸共聚[69]. 随着苯 胺邻位位阻增大 $(61>60>59)$, 极性基团插入率降低(分 别为 $1.0 \% \sim 4.7 \%$ 和 $1.1 \% \sim 2.7 \%$ ), 催化活性升高(分别 为 $1083 \sim 1583$ 和 $2306 \sim 3444$ ), 分子量升高(最高分别为 $1.4 \times 10^{4}$ 和 $\left.5.8 \times 10^{4}\right)$, 而支化度变化不大 $(50 \sim 62)$. 值 得注意的是, 可能由于空间位阻导致大体积极性单体插 入困难, 该催化体系对乙烯一丙烯酸共聚效果优于丙烯 酸甲酯.

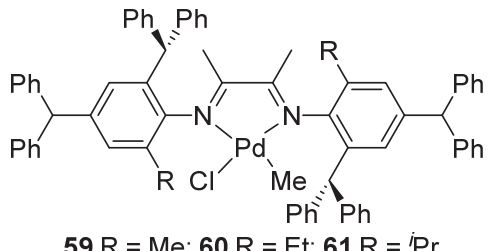

与二苯甲基结构相比，大体积五蝶烯结构更为刚 性, 尽管可在一定程度上增加轴向位阻, 但对共聚反应 的催化效果不及二苯甲基结构催化剂(如 37), 具体表现 在相对高的支化度(58～76 vs 22 25)、相对低的催化活 性和相对低的共聚物分子量. $\mathrm{Pd}$ 催化剂 $62 \sim 65$ 在 $30{ }^{\circ} \mathrm{C}$ 和 $0.4 \mathrm{MPa}$ 乙烯压力下催化乙烯-丙烯酸甲酯共聚[70], 催化活性随 $62 \sim 65$ 顺序增加 $\left(10^{3} \sim 10^{4}\right)$, 而插入率依次 降低 $(4.1 \% \sim 1 \%), 64$ 得到最高分子量共聚物 $\left(9 \times 10^{4}\right)$. Ni 催化剂 66 在 $25{ }^{\circ} \mathrm{C}$ 和 $0.1 \mathrm{MPa}$ 乙烯压力下, 以二乙基氯 化铝为助催化剂, 催化乙烯与长链阻隔型单体(如十一 烯酸甲酯、十一烯酸、十一烯氯(和烯己基醇)共聚 ${ }^{[71]}$; 极 性单体插入率为 $0.4 \% \sim 3.8 \%$, 共聚物分子量为 $9100 \sim$ 71600 .

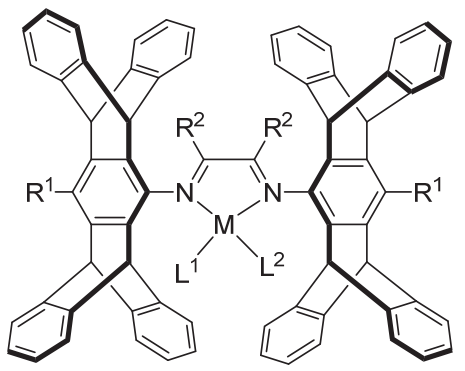

$62 \mathrm{R}^{1}=\mathrm{OH}, \mathrm{R}^{2}=\mathrm{An}, \mathrm{M}=\mathrm{Pd}, \mathrm{L}^{1}=\mathrm{Cl}, \mathrm{L}^{2}=\mathrm{Me}$ $63 \mathrm{R}^{1}=\mathrm{OMe}, \mathrm{R}^{2}=\mathrm{An}, \mathrm{M}=\mathrm{Pd}, \mathrm{L}^{1}=\mathrm{Cl}, \mathrm{L}^{2}=\mathrm{Me}$ $64 \mathrm{R}^{1}=\mathrm{OH}, \mathrm{R}^{2}=\mathrm{Me}, \mathrm{M}=\mathrm{Pd}, \mathrm{L}^{1}=\mathrm{Cl}, \mathrm{L}^{2}=\mathrm{Me}$ $65 \mathrm{R}^{1}=\mathrm{OMe}, \mathrm{R}^{2}=\mathrm{Me}, \mathrm{M}=\mathrm{Pd}, \mathrm{L}^{1}=\mathrm{Cl}, \mathrm{L}^{2}=\mathrm{Me}$ $66 \mathrm{R}^{1}=\mathrm{OBu}, \mathrm{R}^{2}=\mathrm{Me}, \mathrm{M}=\mathrm{Ni}, \mathrm{L}^{1}=\mathrm{L}^{2}=\mathrm{Br}$
最近，简忠保等 ${ }^{[72]}$ 将五蝶烯结构与二苯甲基结构 结合，制备了非对称 $\mathrm{Pd} / \mathrm{Ni}$ 催化剂. 以二乙基氯化铝为 助催化剂, $\mathrm{Ni}$ 催化剂 67 在 $30{ }^{\circ} \mathrm{C}$ 和乙烯压力 $0.2 \sim 0.8$ $\mathrm{MPa}$ 时，催化乙烯-十一烯酸甲酯共聚得到超支化结构 共聚物（支化度 $120 \sim 138$ )，极性基团插入率很低 $(0.05 \% \sim 0.2 \%)$, 催化活性为 $2.8 \times 10^{4} \sim 11.4 \times 10^{4}$, 共聚 物分子量为 $5.1 \times 10^{4} \sim 15.1 \times 10^{4}$. Pd 催化剂 68 在 $70{ }^{\circ} \mathrm{C}$ 时催化乙烯一丙烯酸甲酯、丙烯酸和戊烯酸共聚，插入率 分别为 $2.87 \% 、 1.26 \%$ 和 $2.15 \%$ ，共聚物分子量较低 (1900 8400), 支化度为 $71 \sim 73$.

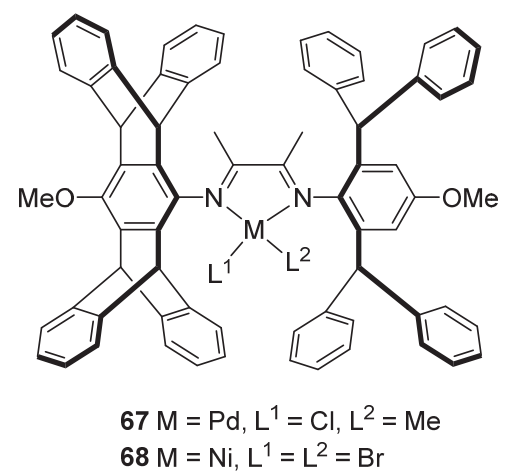

\section{3 次级配位效应}

除了对配体的取代基效应和轴向位阻进行调控，还 可在苯胺苯环远端引入基团，增加空间位阻或利用杂原 子和氢键影响配体与金属的配位作用，进而对共聚行为 产生影响. 2016 年, 陈昶乐等 ${ }^{[73]}$ 利用次级配位策略设计 合成了一系列含有氧杂葸结构的 $\mathrm{Pd}$ 催化剂 69 72, 可 在 $20{ }^{\circ} \mathrm{C}$ 和 $0.1 \mathrm{MPa}$ 乙烯压力时, 催化乙烯-丙烯酸甲酯 共聚. 69 72 催化活性和共聚物分子量均高于类似的典 型催化剂，但插入率小于典型催化剂 13 (0.64\% 1.59\% vs $2.53 \%$ ), 其中 69 催化活性最高为 2130 ; 共聚物高度 支化(支化度 $97 \sim 108$ ), 分子量最高为 $9.8 \times 10^{4}$. 当催化 乙烯-醋酸降冰片烯酯共聚时, 69 催化活性最高为 1.35 $\times 10^{4}, 71$ 和 72 则无催化活性.

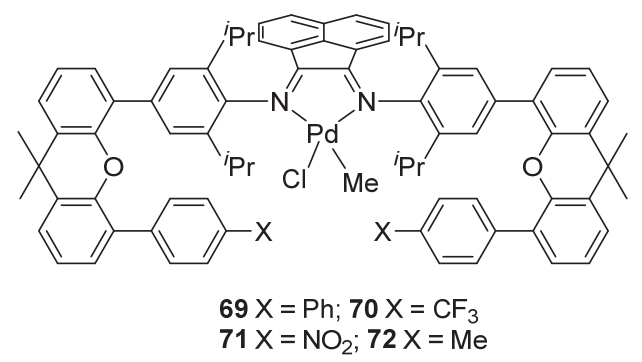

陈昶乐等 $[47 \mathrm{~b}]$ 还制备了一系列含 $\mathrm{N}$ 原子次级配位催 化剂 73 和 74. 73 可在 $0.8 \mathrm{MPa}$ 乙烯压力和 $\mathrm{MAO}$ 存在时 室温催化乙烯一丙烯酸甲酯共聚，催化活性较低(800 1000), 插入率为 $7.5 \%$, 共聚物分子量较低(4500). 73 催 
化十一烯酸甲酯、醋酸烯丙基酯和己烯基氯分别与乙烯 共聚, 所有共聚物均为半结晶态, 拥有低支化度 $(5 \sim$ $11)$, 极性基团插入率低 $(0.4 \sim 1.3 \%)$. 74 催化乙烯与烯丙 基氯、烯丙醇、烯丙基乙醚和醋酸烯丙酯分别共聚, 则 得到无定形共聚物.

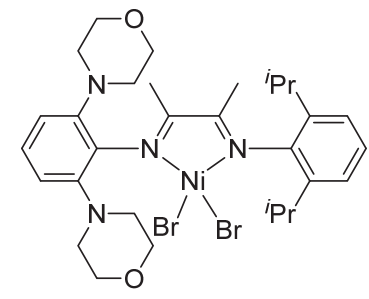

73

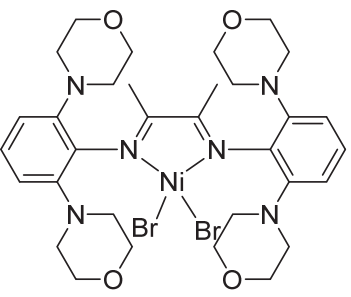

74
2017 年, Jordan 等 ${ }^{[74]}$ 利用氢键的次级配位效应设计 制备了苯胺苯环邻位为酰胺结构的 Pd 催化剂 75 和 76. 室温及 $0.1 \mathrm{MPa}$ 乙烯压力下催化乙烯-丙烯酸甲酯共聚, 同时作为氢键给体和受体的 75 催化活性(乙烯 $\mathrm{TON}=$ $1060)$ 和分子量 $\left(8.1 \times 10^{3}\right)$ 高于只作为氢键受体的 76 及 不含酰胺基团的 40 , 插入率最高为 $2.4 \%$. 在自由基抑 制剂 galvinoxyl 存在时, 75、76 和 40 催化乙烯一丙烯酸 共聚，极性基团插入率分别为 $1.5 \% 、 0.88 \%$ 和 $0.45 \%$, 但 75 和 76 的催化活性和分子量低于 40, 三者乙烯 TON 分 别为 210、190 和 4600, 共聚物分子量分别为 3000、3200 和 65300. 所有共聚反应极性基团主要位于支链链端, 聚合物支化度为 $73 \sim 82$.

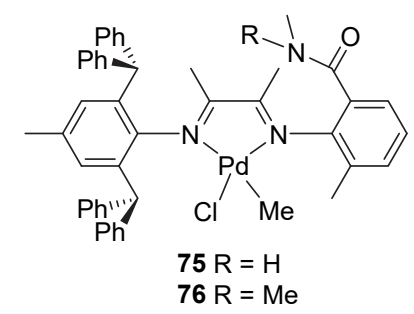

\section{4 骨架调整}

二亚胺氮原子间的骨架的结构改变也可以在轴向 形成一定位阻, 减少配体苯环旋转, 从而达到抑制链转 移和稳定催化剂的效果. 陈昶乐等 ${ }^{[75]}$ 采用范基骨架 $\mathrm{Pd}$ 催化剂, 研究了范基不同位置甲氧基取代基对乙烯一丙 烯酸甲酯共聚反应的影响. $77 \sim 81$ 催化反应在 $30{ }^{\circ} \mathrm{C}$ 和 $0.1 \mathrm{MPa}$ 乙烯压力时极性单体插入率类似 $(3.5 \%$ \% $7.9 \%)$. 与苯胺邻位引入甲氧基 ${ }^{[56]}$ 导致共聚活性下降不同, 范 基骨架带有给电子甲氧基的 79 和 81 , 共聚物分子量均 高于典型催化剂 82 (17000/18500 vs 8000). 共聚物支化 度几乎不受取代基影响(102 116).

Milanni 等 ${ }^{[76]}$ 将范基形成的五元环改变为菲基形成 的六元环, 在 2,2,2-三氟乙醇中进行乙烯-丙烯酸甲酯共

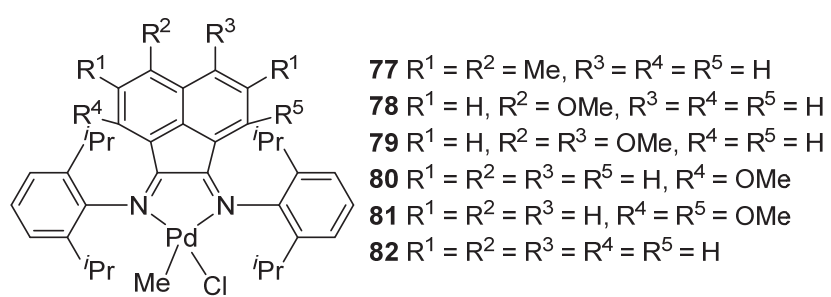

聚得到棕色油状共聚物. 反应在 $35{ }^{\circ} \mathrm{C}$ 和 $0.25 \mathrm{MPa}$ 乙烯 压力下进行, 苯胺苯环上取代基位阻对共聚反应有重要 影响. 83 具有最高的催化活性, 而 85 则不显示共聚活 性. 相同实验条件下, 83 和 84 共聚物分子量高于典型催 化剂 14(分别为 33000、10000 和 3200), 但极性基团插 入率低于 14 (分别为 $0.3 \% 、 2.4 \%$ 和 $4.4 \%$ ). 83 可得到最 高共聚物分子量 $\left(3.7 \times 10^{4}\right), 84$ 可得到最高极性基团插 入率(5.3\%). 值得注意的是, 极性基团除位于链端外还 可嵌入链中.

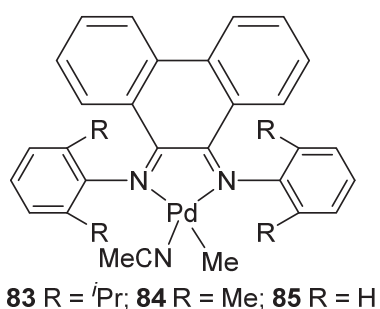

伍清和高海洋等也通过引入不同的大位阻基团, 研 究了骨架调整对共聚行为的影响. 茨基骨架配合物 86 容易合成, 在 $0.1 \mathrm{MPa}$ 乙烯压力和 $35{ }^{\circ} \mathrm{C}$ 时催化乙烯一丙 烯酸甲酯共聚 ${ }^{[48 c]}$, 插入率为 $1.2 \%$, 共聚物分子量为 $1.2 \times 10^{4}$. 体积更小的典型催化剂 4 共聚效果与 86 类似 (分子量为 $1.2 \times 10^{4}$, 插入率为 $0.52 \%$ ), 但是 4 活性更高 $(T O F=66$ vs 11). 相比苯胺苯环上的空间位阻, 大体积 骨架对共聚行为的影响规律并不明显.

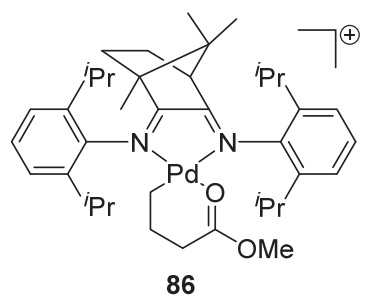

二苯并桶烯骨架阳离子 $\mathrm{Pd}$ 催化剂 87 在 $15 \sim 50{ }^{\circ} \mathrm{C}$ 和 $0.02 \mathrm{MPa}$ 乙烯压力时, 不使用助催化剂催化乙烯一丙 烯酸甲酯共聚 ${ }^{[77]}, 25{ }^{\circ} \mathrm{C}$ 时共聚物分子量最高可达 $3.63 \times 10^{4}$. 温度升高, 极性基团插入率从 $1.35 \%$ 增加至 4.64\%, 支化度则从 100 降低至 91. 共聚物支化度几乎 不受乙烯压力影响, 但共聚物拓扑结构可以通过乙烯压 力进行调控. 乙烯压力从 $0.02 \mathrm{MPa}$ 增大至 $2 \mathrm{MPa}$, 超支 化结构向线型结构转变. 最近他们还研究了不同反应温 
度对 87 和 88 催化乙烯一丙烯酸糠酯共聚反应的影响 ${ }^{[78]}$, 发现反应温度小于 $35{ }^{\circ} \mathrm{C}$ 时, 87 的活性、产率、分子量和 支化度均高于 $\mathbf{8 8}$, 而在大于 $35{ }^{\circ} \mathrm{C}$ 时 $\mathbf{8 8}$ 的活性高于 $\mathbf{8 7}$, 显示出 88 更好的热稳定性.

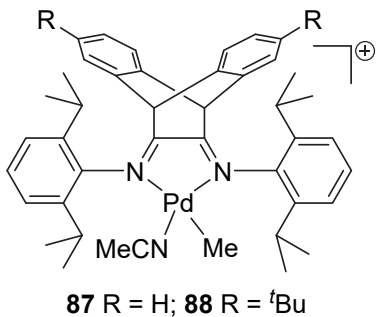

二苯并桶烯骨架 $\mathrm{Ni}$ 催化剂 89 和 90 在 $20 \sim 50{ }^{\circ} \mathrm{C}$ 和 $0.02 \mathrm{MPa}$ 乙烯压力下, 使用二乙基氯化铝为助催化剂, 可实现乙烯一十一烯酸甲酯具有活性聚合特点的共 聚 ${ }^{[79]}$, 所得共聚物支化度为 $81 \sim 89$. 与典型 $\alpha$-二亚胺 $\mathrm{Ni}$ 催化剂 6 相比, 89 和 90 得到分子量较高 $\left(5.3 \times 10^{3} \sim\right.$ $\left.1.32 \times 10^{5}\right)$ 的共聚物，但极性基团插入率偏低 $(0.41 \sim$ $1.4 \%)$, 相同聚合条件下 6 所得共聚物分子量和极性基 团插入率分别为 1600 和 $2.3 \%$.

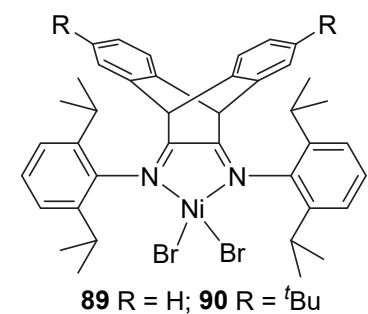

贺晓慧等[43]使用两种二苯并桶烯骨架 $\alpha$-二亚胺 $\mathrm{Ni}$ 催化剂, 在 $60{ }^{\circ} \mathrm{C}$ 时催化降冰片烯-醋酸降冰片烯酯共 聚, 共聚活性为 $1.6 \times 10^{5} \sim 5.8 \times 10^{5}$, 苯胺邻位具有更大 位阻的 89 活性高于 91 ; 共聚物分子量达 $0.2 \times 10^{5} \sim$ $2.8 \times 10^{5}$, 极性基团插入率为 $6.1 \% \sim 10.2 \%$, 分解温度 高达 321 408 ${ }^{\circ} \mathrm{C}$, 玻璃化转变温度达 265 304 ${ }^{\circ} \mathrm{C}$. 使 用萗基代替苯基进一步增大骨架位阻, $\mathrm{Ni}$ 催化剂 92 也 可催化共聚 ${ }^{[80]}$, 且具有更高的催化剂活性和共聚物分 子量(分别为 $7.6 \times 10^{5}$ 和 $3.6 \times 10^{5}$ ), 极性单体插入率为 $10 \% \sim 48 \%$. 在苯胺苯环对位引入强吸电子基 ${ }^{[81]}$ 的 $\mathrm{Ni}$ 催 化剂 93 具有优秀的高温稳定性, 催化降冰片烯-甲基丙 烯酸丁酯共聚可在 $100{ }^{\circ} \mathrm{C}$ 高温下进行, 极性单体浓度变 化对共聚物分子量(约为 $3 \times 10^{4}$ )影响不明显; 极性基团 插入率可在 $6 \% \sim 78 \%$ 较宽范围内调节, 但插入率较高 时产率和催化活性明显降低. Ni 催化体系均需使用 $\mathrm{B}\left(\mathrm{C}_{6} \mathrm{~F}_{5}\right)_{3}$ 为助催化剂.

类似结构的 $\mathrm{Pd}$ 催化剂 94 97 在 $30{ }^{\circ} \mathrm{C}$ 时催化降冰 片烯-降冰片烯羧酸甲酯的共聚 ${ }^{[82]}$, 不同取代基对共聚

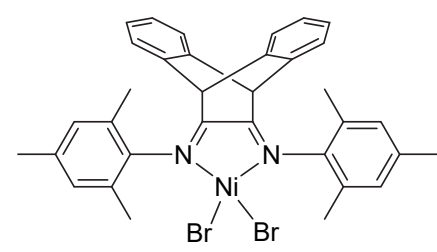

91

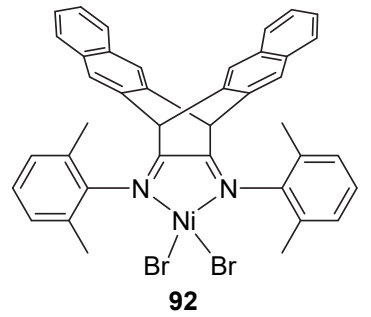

92

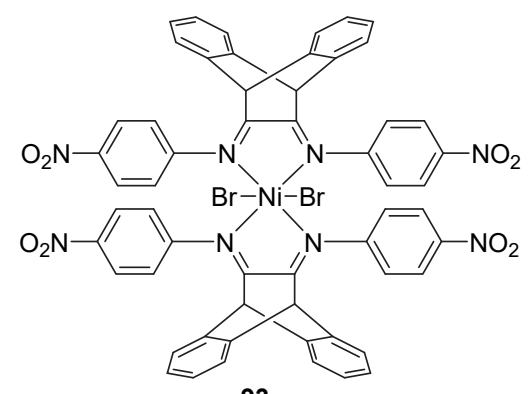

93

反应有重要影响, 苯胺邻位具有更大位阻的 95 活性和 共聚物分子量均最高(分别为 $2 \times 10^{5}$ 和 $2.2 \times 10^{5}$ ), 94 活 性最低; 相同极性单体浓度条件下极性基团插入率基本 一致 $(9 \%$ ～25.6\%). 该催化体系需要使用助催化剂 $\mathrm{B}\left(\mathrm{C}_{6} \mathrm{~F}_{5}\right)_{3}$. 当使用 $\mathrm{MAO}$ 为助催化剂, $\mathrm{Pd}$ 催化剂 97 可催 化降冰片烯与 2-丁氧基甲基降冰片烯的乙烯基类型共 聚 ${ }^{[83]}$, 极性单体插入率在 $9.8 \% \sim 62 \%$ 可控, 催化活性降 低不明显。

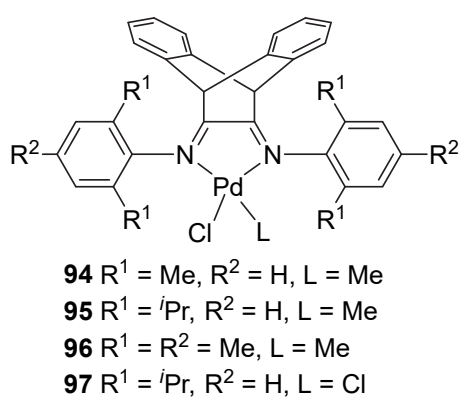

Coates 等[84]在二苯并桶烯骨架基础上在苯胺苯环 邻位引入了大位阻基团, 制备了 $\mathrm{Ni}$ 催化剂 98, MAO 为 助催化剂催化乙烯一十一烯酸甲酯共聚, $0.17 \mathrm{MPa}$ 乙烯 压力 $20{ }^{\circ} \mathrm{C}$ 反应共聚物分子量 $6.2 \times 10^{4}$, 极性基团插入 率为 $1 \%$. 降低乙烯压力至 $0.07 \mathrm{MPa}$ 同时降温至 $-20{ }^{\circ} \mathrm{C}$ 反应，产率提升 4 倍，极性基团插入率不变，但共聚物

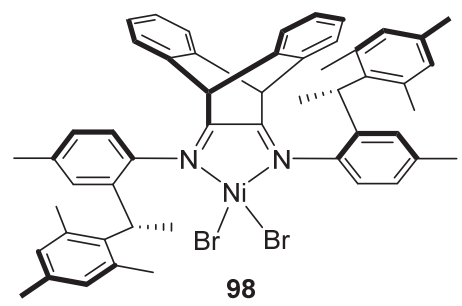


分子量降低为 $2.7 \times 10^{4}$.

伍清和高海洋等 ${ }^{[85}$ 还通过改变骨架杂化方式, 将 极性基团更多地嵌入链中. 他们设计合成了阳离子 $\mathrm{sp}^{2}-\mathrm{sp}^{3}$ 胺-亚胺 $\mathrm{Pd}$ 催化剂 99 和 100 , 催化乙烯一丙烯酸 甲酯共聚得到高度支化(支化度 $89 \sim 99$ ) 共聚物. $25{ }^{\circ} \mathrm{C}$ 和 $0.034 \mathrm{MPa}$ 乙烯压力下共聚, 大位阻 99 得到的共聚物分 子量为 $1.18 \times 10^{4}$, 极性基团插入率为 $2 \%$, 其中 $42 \%$ 的 极性基团位于链中. 具有较小空间位阻的 100 得到的共 聚物分子量降低至 $7.3 \times 10^{3}$, 极性基团插入率升高至 $5.7 \%$, 其中 $36 \%$ 位于链中. 典型催化剂 101 催化反应 TON 达 3010 (催化剂 99 为 326), 分子量也较高 $(5.3 \times$ $10^{4}$ ), 但极性基团插入率仅为 $0.7 \%$, 且全部位于链端. $\mathrm{sp}^{3}-\mathrm{sp}^{3}$ 杂化骨架 $\mathrm{Pd}$ 催化剂 102 也可催化降冰片烯分别 与降冰片烯羧酸甲酯和醋酸降冰片烯酯共聚 ${ }^{[86]}$, 以 MAO 为助催化剂, 在 $50{ }^{\circ} \mathrm{C}$ 时较 $\mathrm{sp}^{2}-\mathrm{sp}^{3}$ 杂化骨架 103 展 现出更高的催化活性 $\left(2.8 \times 10^{4}\right)$ 、分子量 $\left(3.1 \times 10^{4}\right)$ 和极 性基团插入率(15.7\%). $\mathrm{sp}^{2}-\mathrm{sp}^{2}$ 杂化典型催化剂 104 催化 活性、共聚物分子量和极性基团插入率则均低于 102 和 103.
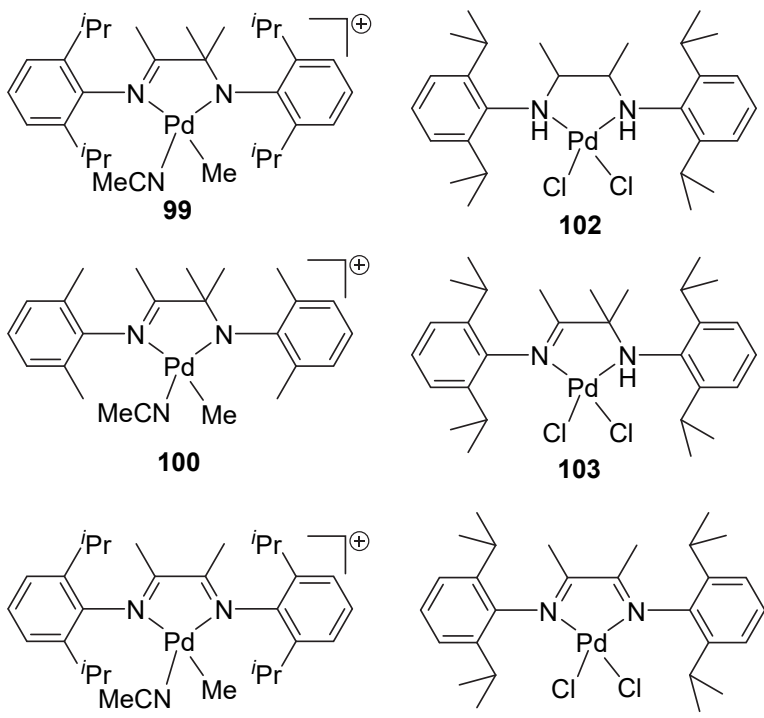

101

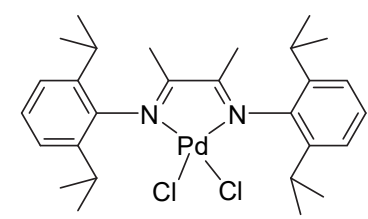

104

由于存在 $\beta-\mathrm{X}$ 消除终止聚合, 二亚胺吡啶 $\mathrm{Fe}$ 催化剂 一直无法成功催化极性共聚。烯丙基类单体中亚甲基将 双键和极性基团阻隔，可能成为有效共聚单体. 2015 年， Nozaki 等 ${ }^{[87]}$ 制备了二亚胺吡啶 Fe 催化剂 105, 以改性甲 基铝氧烷(MMAO)为助催化剂, 在 $0 \sim 30{ }^{\circ} \mathrm{C}$ 时成功催化 丙烯分别与烯丙基三甲基硅烷、烯丙基二甲基苯基硅烷 和烯丙基三乙氧基硅烷共聚, 极性基团插入率分别为 $2.1 \% 、 1.7 \%$ 和 $0.3 \%$, 极性基团大多位于链端, 催化活性 和共聚物分子量不高, 三个共聚反应中共聚活性分别为 $4500 、 2100$ 和 1300, 共聚物分子量分别为 1300、2000
和 3200 .

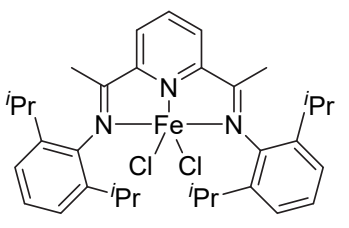

105

\section{5 双金属催化剂}

陈昶乐等 ${ }^{[88}$ 在范基骨架基础上制备了共轭 $\alpha$-二亚 胺双金属 Pd 配合物 106 和 107, 室温下催化乙烯-丙烯 酸甲酯共聚得到超支化共聚物. 共轭桥连基团对双金属 中心间的协同作用影响较弱，共聚物分子量均较低 (1400 和 4600).

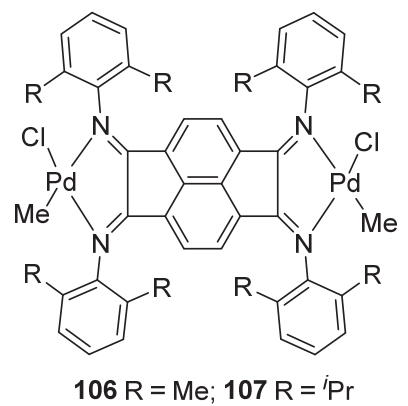

单桥双金属 Pd 配合物 $108 \sim 110$ 无法在 $20{ }^{\circ} \mathrm{C}$ 和 0.9 $\mathrm{MPa}$ 乙烯压力条件下有效催化乙烯一丙烯酸甲酯共 聚 ${ }^{[89]}$, Takeuchi 等 ${ }^{[7 \mathrm{~d}]}$ 设计的刚性双桥 $\alpha$-二亚胺双金属 $\mathrm{Pd}$ 催化体系 112, 在催化乙烯-丙烯酸酯共聚则展现出有 效的双金属协同作用. 在 $1 \mathrm{MPa}$ 乙烯压力和 $40{ }^{\circ} \mathrm{C}$ 时, 112 得到的共聚物较单金属催化剂 7 支化度低, 极性基 团插入率高. 不同极性单体对共聚物微观结构有重要影 响. 112 催化乙烯-丙烯酸甲酯共聚物插入率和分子量可 达 $9.3 \%$ 和 $6.3 \times 10^{4}$, 极性基团大多位于链中; 升高乙烯 压力, 极性基团更多嵌入链中(链中链端比例 $85: 15$ ). 112 催化乙烯-丁烯酸叔丁基酯共聚, 插入率和分子量 可达 $3.9 \%$ 和 $1.09 \times 10^{4}$, 但是大多极性基团位于链端(链 中链端比例 $12: 88$ ). 112 还可催化乙烯一戊烯酸乙酯共 聚，插入率和分子量可达 $7.3 \%$ 和 $2.35 \times 10^{4}$, 但分子量 分布非常宽(12.1). 值得注意的是, 112 催化乙烯-丙烯酸 叔丁基酯共聚，插入率可达 $3.3 \%$, 分子量可达 $1.25 \times$ $10^{5}$ ，支化度为 48 ，极性基团几乎全部嵌入链中 $(>99 \%)$; 该共聚物及其水解后的乙烯一丙烯酸共聚物杨氏模量从 $1.6 \mathrm{MPa}$ 提高至 $4.6 \mathrm{MPa}$, 熔点分别为 $8 \sim 29{ }^{\circ} \mathrm{C}$ 和 $16 \sim$ $35{ }^{\circ} \mathrm{C}$, 均可形成可拉伸的柔软膜. 苯胺苯环邻位缺少取 代基的 Pd 配合物 111 无法有效催化共聚反应. 

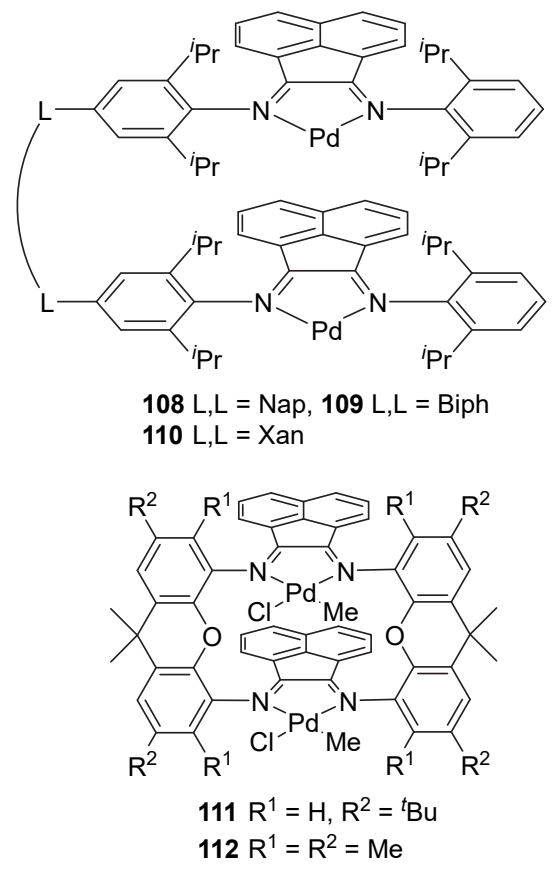

\section{6 负载催化剂}

贺晓慧等 ${ }^{[00]}$ 将三维立体结构 $\alpha$-二亚胺 $\mathrm{Ni}$ 催化剂负 载在多层碳纳米管上, 考察了 113 在降冰片烯与丙烯酸 正丁基酯的共聚反应中的催化活性, 采用三甲基铝和 $\mathrm{B}\left(\mathrm{C}_{6} \mathrm{~F}_{5}\right)_{3}$ 双助催化剂时, 共聚活性比单独使用 $\mathrm{B}\left(\mathrm{C}_{6} \mathrm{~F}_{5}\right)_{3}$ 高约 2 倍. 极性基团插入率最高可达 $44.8 \%$, 同时催化 活性可达 $1.7 \times 10^{5}$.

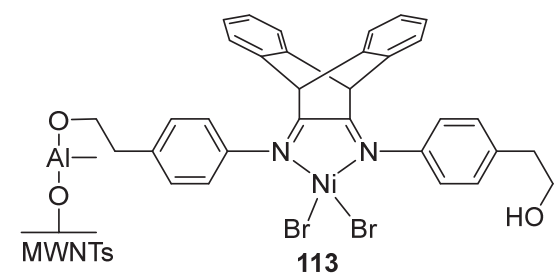

Conley 等 ${ }^{[91]}$ 将二亚胺 $\mathrm{Ni}$ 催化剂负载在硫化氧化锆 上, 在 $0.31 \mathrm{MPa}$ 乙烯压力和 $40{ }^{\circ} \mathrm{C}$ 时, 114 催化乙烯-十 一烯酸甲酯共聚, 催化活性非常低, TOF 仅为 180 , 共聚 物分子量 $2.97 \times 10^{4}$. 他们还将大体积 $\mathrm{Pd}$ 催化剂负载在 硫化氧化锆上 ${ }^{[2]}$, 在 $0.55 \mathrm{MPa}$ 乙烯压力和 $25 \sim 60{ }^{\circ} \mathrm{C}$ 时, 115 催化乙烯一丙烯酸甲酯共聚, 催化活性达 $1.5 \times 10^{4}$,
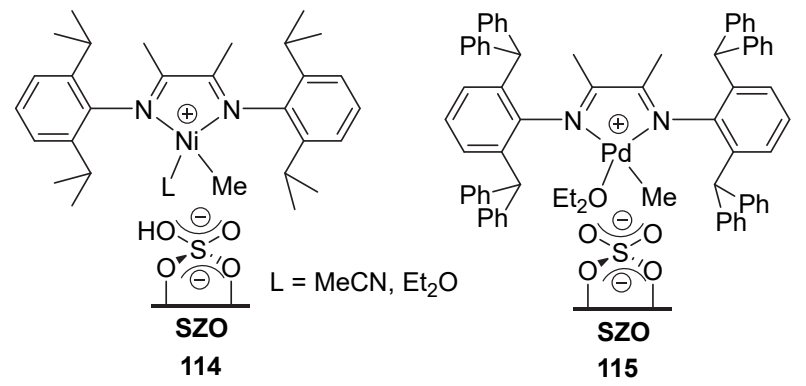

极性基团插入率仅为 $0.46 \%$; 共聚物分子量为 $4.4 \times 10^{4}$, 具有低支化度 $(31 \sim 39)$.

$\alpha$-二亚胺型催化剂是极性共聚领域最具代表性的 进展, 为极性共聚反应的长远发展奠定了基础, 为高支 化或超支化聚烯烃和极性聚烯烃材料的可控制备提供 了可能. 陈永乐等运用轴向位阻效应, 通过在配体中引 入二苯甲基基团, 并以其为基础，通过多种不同体积取 代基的组合，将极性共聚反应共聚物分子量、支化度和 插入率的系统精确调控推向了更高水平，高分子量、低 支化度极性共聚物的获得亦极大推动了直接极性共聚 物材料性能的研究. 但需要指出, 高分子量的获得是以 极大增加轴向位阻减少 $N$-芳基旋转为基础的, 金属中 心周围大空间位阻的存在实际上限制了极性单体插入， 损失了极性基团插入率. 这一策略使得分子量与插入率 之间的矛盾更为明显和突出, 且对极性共聚反应中催化 剂的热稳定性提升作用并不明显，反应一般只能在室温 或 $30 \sim 35{ }^{\circ} \mathrm{C}$ 时进行. 相比之下, 伍清和高海洋等通过 催化剂骨架的调整对催化剂热稳定性的提升作用更为 显著. 二苯并桶烯骨架和 $\mathrm{sp}^{2}-\mathrm{sp}^{3}$ 杂化骨架催化剂催化共 聚反应最高可在 $50{ }^{\circ} \mathrm{C}$ 时进行. 更高温度 (大于 $50{ }^{\circ} \mathrm{C}$ )下 进行的共聚反应仅有少数报道. 尽管有所提高, $\alpha$-二亚 胺型催化剂在极性共聚中的热稳定性仍然不及在烯烃 均聚中的表现, 大多数共聚反应是在室温下发生的. 催 化剂热稳定性已成为影响其实用性的最重要限制因素 之一。

\section{3 水杨醛亚胺/酮胺型催化剂}

水杨醛亚胺/酩胺型催化剂在烯烃均聚及与非极性 烯烃共聚反应中取得了巨大成功, 然而将其应用于烯烃 极性共聚反应中时，催化活性受极性基团的抑制非常严 重. 研究者们通过双金属中心协同作用设计了双金属催 化剂, 可在适当条件下实现阻隔型极性单体参与共聚.

\section{1 双金属催化剂}

单/双金属中性 $\mathrm{Ni}$ 催化剂容易被胺抑制活性 ${ }^{[41 a]}$, 胺 单体参与的共聚反应通常需要额外保护机制. Agapie 等 ${ }^{[93]}$ 设计了一系列三联苯骨架的双金属中心 $\mathrm{Ni}$ 催化剂 116 120, 其中 116 和 118 互为阻转异构体 (atropisomer), 117 和 119 互为阻转异构体. 在 $25^{\circ} \mathrm{C}$ 和 $0.69 \mathrm{MPa}$ 压力下, 乙烯可直接与未保护的烯丙基、烯丁基、烯戊基、烯己 基、烯庚基和烯辛基二正丙基胺分别共聚. 烯基与胺基 间阻隔越大，催化剂聚合活性越高，但极性单体插入率 相差不大 $(0.1 \% \sim 0.7 \%)$. 由于临近 $\mathrm{Ni}$ 中心的双金属效 应, $\mathrm{Ni}$ 中心间空间拥挤, 胺单体同时与双 $\mathrm{Ni}$ 中心配位困 难, 催化剂构型对催化活性有影响较大, 顺式催化剂 (116、117 和 120)催化活性高于反式催化剂(118 和 119). 


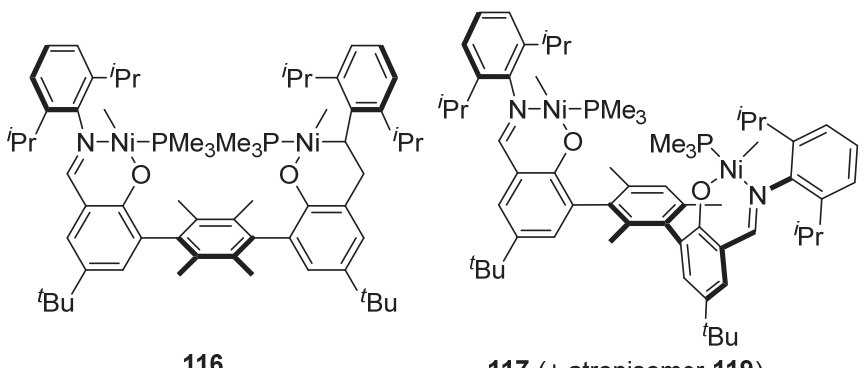

116
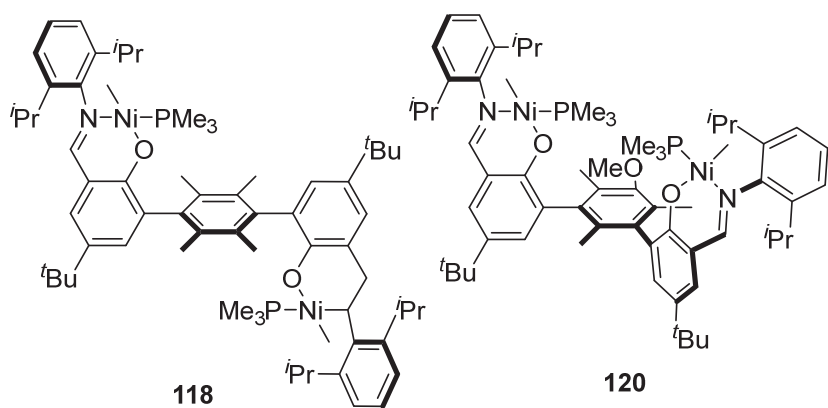

$\mathrm{MPa}$ 时, 127 129 催化乙烯与醋酸乙烯酯、醋酸烯丙基 酯和三甲基乙酸乙烯酯分别共聚，可能由于发生 $\beta-\mathrm{X}$ 消 除导致所得聚合物中均没有极性基团嵌入. 他们发现, 随着两个金属中心之间的距离越来越远，聚合反应产 率、反应活性和聚合物分子量均降低, 距离最大的 129 不能催化聚合; 极性单体的加入使乙烯均聚支化度明显 降低(29～67 降低至 24 32), 可能催化剂空位被极性单 体占据，导致 $\beta-\mathrm{H}$ 迁移得到一定程度抑制.
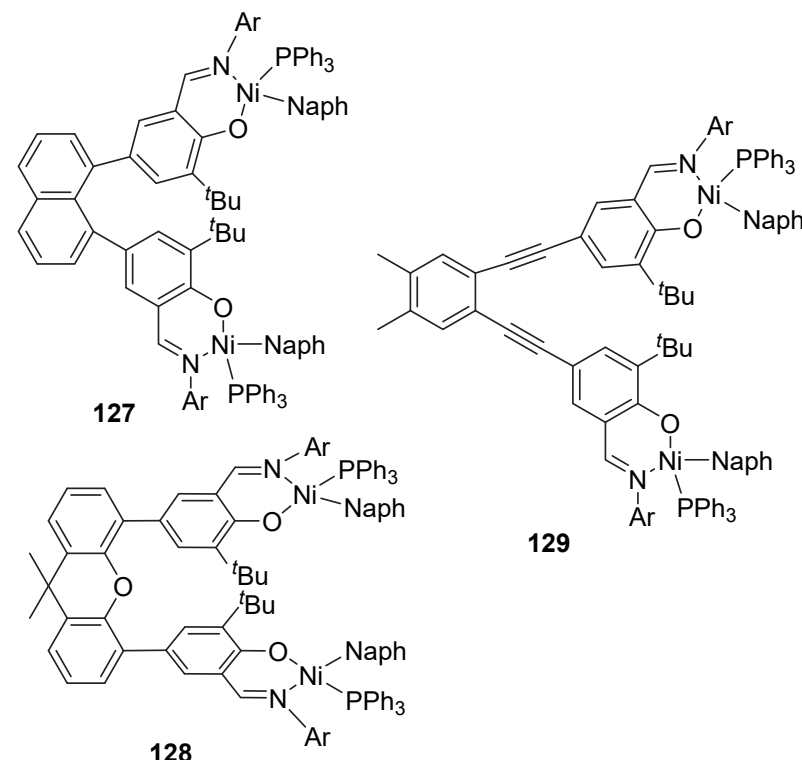

129

\section{2 双酮胺配体催化剂}

降冰片烯作为烯烃-极性单体共聚中的非极性单体 研究较少. Sen 等 ${ }^{[97]}$ 采用水杨醛亚胺型 Pd 配合物 130 催 化降冰片烯一丙烯酸甲酯的共聚反应，极性基团插入率 可达 $21.5 \%$. 但是加入自由基抑制剂 galvinoxyl 后，只得 到乙烯均聚物, 他们认为 130 催化降冰片烯与丙烯酸甲 酯共聚经由自由基历程.

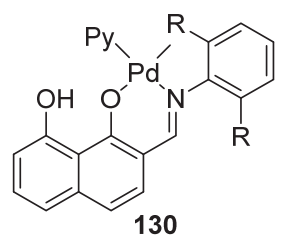


贺晓慧等对双酮胺型催化剂催化的降冰片烯-极性 单体共聚反应进行了较为深入的研究, 降冰片烯-极性 降冰片烯共聚反应中极性基团插入率在较宽范围内可 控，催化剂活性及共聚物分子量得到提升.

使用双酮胺 $\mathrm{Ni}$ 催化剂 131 催化降冰片烯-醋酸降冰 片烯酯进行乙烯型共聚反应 ${ }^{[98]}$, 共聚极性单体浓度从 $30 \%$ 增加至 $90 \%$, 极性单体插入率相应增加 $(7.6 \%$ $54.1 \%$ ), 但催化剂活性从 10000 急剧降低至 950 , 共聚物 分子量为 $1.98 \times 10^{4} \sim 3.45 \times 10^{4}$. 该反应必须使用助催 化剂三乙基铝和 $\mathrm{B}\left(\mathrm{C}_{6} \mathrm{~F}_{5}\right)_{3}$, 不加入三乙基铝时催化活性 和极性单体插入率则呈现降低趋势 ${ }^{[99]}$.

带有强吸电子性三氟甲基的 132 催化降冰片烯-降 冰片烯羧酸甲酯共聚 ${ }^{[100]}$, 只需 $\mathrm{B}\left(\mathrm{C}_{6} \mathrm{~F}_{5}\right)_{3}$ 一种助催化剂 即可实现高活性聚合; 调节极性单体浓度, 极性基团插 入率可控 $\left(7.9 \% \sim 77.6 \%\right.$ ), 催化活性从 $2.7 \times 10^{5}$ 降低至 $7.6 \times 10^{4}$, 共聚物分子量从 $2.7 \times 10^{5}$ 降低到 $6 \times 10^{4}$. 单酮 胺 $\mathrm{Pd}$ 催化剂 133 在 $60{ }^{\circ} \mathrm{C}$ 时催化该反应 ${ }^{[101]}$, 催化活性高 达 $2.8 \times 10^{6}$, 极性基团插入率可达 $21 \%$. 只有 $\mathrm{B}\left(\mathrm{C}_{6} \mathrm{~F}_{5}\right)_{3}$ 一种助催化剂存在时, 131 和 132 还可催化降冰片烯-甲

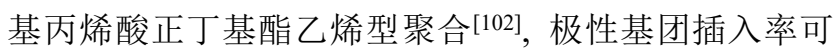
达 7.29\%; 共聚物具有良好的热稳定性, 分解温度大于 $400{ }^{\circ} \mathrm{C}$.

$$
\mathrm{R}_{\mathrm{R}^{2}}^{\mathrm{R}^{2}}
$$

$131 R^{1}=R^{2}=M e, R^{3}=$ Naphthyl

$132 \mathrm{R}^{1}=\mathrm{CF}_{3}, \mathrm{R}^{2}=\mathrm{Me}, \mathrm{R}^{3}=$ Naphthyl

进一步的取代基效应研究发现，带有不同取代基的 双酮胺 $\mathrm{Ni}$ 催化剂 134 138, 在助催化剂三乙基铝和 $\mathrm{B}\left(\mathrm{C}_{6} \mathrm{~F}_{5}\right)_{3}$ 存在时催化降冰片烯-降冰片烯甲醇共聚 ${ }^{[103]}$,

135、136 和 138 无法有效催化共聚反应进行. 131、134 和 137 催化共聚活性和共聚物分子量类似，但极性基团 插入率相差较大，分别为 $41.1 \% 、 9.5 \%$ 和 $22.7 \%$.

$$
\begin{aligned}
& 134 \mathrm{R}^{1}=\mathrm{R}^{2}=\mathrm{Me}, \mathrm{R}^{3}=\text { Phenyl } \\
& 135 \mathrm{R}^{1}=\mathrm{Phenyl}, \mathrm{R}^{2}=\mathrm{Me}, \mathrm{R}^{3}=\mathrm{Naphthyl} \\
& 136 \mathrm{R}^{1}=\mathrm{R}^{2}=\mathrm{Me}, \mathrm{R}^{3}=2,6-\mathrm{Me}_{2} \mathrm{C}_{6} \mathrm{H}_{3} \\
& 137 \mathrm{R}^{1}=\mathrm{R}^{2}=\mathrm{Me}, \mathrm{R}^{3}=2,6{ }^{-} \mathrm{Pr}_{2} \mathrm{C}_{6} \mathrm{H}_{3} \\
& 138 \mathrm{R}^{1}=\text { Phenyl, } \mathrm{R}^{2}=\mathrm{Me}, \mathrm{R}^{3}=2,{ }^{-}{ }^{-} \mathrm{Pr}_{2} \mathrm{C}_{6} \mathrm{H}_{3}
\end{aligned}
$$

基于苯并环己基双酮胺骨架的 $\mathrm{Ni}$ 催化剂 $\mathbf{1 3 9}$ 用于
降冰片烯-醋酸降冰片烯酯的乙烯型共聚 ${ }^{[104]}$, 反应活性 $\left(2 \times 10^{5}\right)$ 和共聚物分子量 $\left(2.5 \times 10^{5}\right)$ 较 131 均有提升, 极 性基团插入率为 $5.8 \% \sim 12 \%$. Pd 催化剂 140 催化性能相 对较低. 该体系只使用 $\mathrm{B}\left(\mathrm{C}_{6} \mathrm{~F}_{5}\right)_{3}$ 一种助催化剂.

$\mathrm{N}$ 原子上连接更大体积的荎基和芴基取代基的 $\mathrm{Ni} / \mathrm{Pd}$ 催化剂 $141 \sim 144$, 在 $\mathrm{B}\left(\mathrm{C}_{6} \mathrm{~F}_{5}\right)_{3}$ 存在时催化降冰片 烯一降冰片烯羧酸甲酯共聚 ${ }^{[105]}$, 极性基团插入率为 20.9\% 42.5\%. 两种取代基的 Ni 催化剂在催化活性、 共聚物分子量及极性基团插入率上催化效果基本一致, 相应 Pd 催化剂活性比 $\mathrm{Ni}$ 催化剂差. 此外, 141 还能催化 降冰片烯一降冰片烯甲氧基三甲基硅烷的共聚反应 ${ }^{[106]}$ 。

随后，贺晓慧等通过调整取代基团种类进一步研究 了位阻和电子效应对苯并环已基双酮胺骨架催化剂催 化行为的影响. 145 148 催化降冰片烯-降冰片烯羧酸 甲酯的共聚[107], 邻位给电子基的 145 催化活性高于吸 电子基的 147, 邻位双取代的 147 催化活性高于单取代 的 148, Ni 催化剂活性高于相应 Pd 催化剂. 催化降冰片 烯-甲基丙烯酸正丁酯共聚时 ${ }^{[108]}, 145$ 催化活性、插入率 和共聚物溶解性能均优于 147. 149 152 催化降冰片烯降冰片烯羧酸甲酯乙烯型共聚 ${ }^{[109]}$, 吸电子基团的存在 可提升催化活性，催化活性按 152、151、150 和 149 的 顺序依次降低.

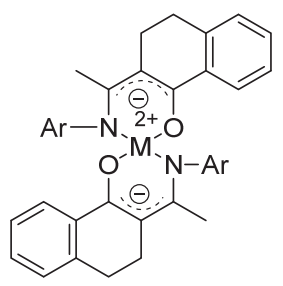

$139 \mathrm{Ar}=$ Phenyl, $\mathrm{M}=\mathrm{Ni} ; 140 \mathrm{Ar}=$ Phenyl, $\mathrm{M}=\mathrm{Pd}$

$141 \mathrm{Ar}=$ Naphthyl, $\mathrm{M}=\mathrm{Ni} ; 142 \mathrm{Ar}=$ Naphthyl, $\mathrm{M}=\mathrm{Pd}$

$143 \mathrm{Ar}=$ Fluorenyl, $\mathrm{M}=\mathrm{Ni}$; $144 \mathrm{Ar}=$ Fluorenyl, $\mathrm{M}=\mathrm{Pd}$

$145 \mathrm{Ar}=2,6-\mathrm{Me}_{2} \mathrm{C}_{6} \mathrm{H}_{3}, \mathrm{M}=\mathrm{Ni} ; 146 \mathrm{Ar}=2,6-\mathrm{Me}_{2} \mathrm{C}_{6} \mathrm{H}_{3}, \mathrm{M}=\mathrm{Pd}$

$147 \mathrm{Ar}=2,6-\mathrm{Cl}_{2} \mathrm{C}_{6} \mathrm{H}_{3}, \mathrm{M}=\mathrm{Ni} ; 148 \mathrm{Ar}=2-\mathrm{ClC}_{6} \mathrm{H}_{4}, \mathrm{M}=\mathrm{Ni}$

$149 \mathrm{Ar}=4-\mathrm{MeC}_{6} \mathrm{H}_{4}, \mathrm{M}=\mathrm{Ni} ; 150 \mathrm{Ar}=4-\mathrm{PhC}_{6} \mathrm{H}_{4}, \mathrm{M}=\mathrm{Ni}$

$151 \mathrm{Ar}=4-\mathrm{FC}_{6} \mathrm{H}_{4}, \mathrm{M}=\mathrm{Ni} ; 152 \mathrm{Ar}=4-\mathrm{CF}_{3} \mathrm{C}_{6} \mathrm{H}_{4}, \mathrm{M}=\mathrm{Ni}$

此外，贺晓慧等 ${ }^{[110]}$ 设计合成了双芴桥连结构的双酮 胺 $\mathrm{Ni}$ 催化剂, 153 和 154 催化降冰片烯-降冰片烯甲基丁 基醚共聚行为基本一致，催化活性可达 $8.6 \times 10^{5}$, 共聚物 分子量达 $2.98 \times 10^{5}$, 极性基团插入率为 $65 \% \sim 94 \%$.

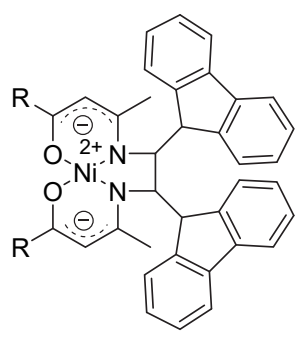

$153 \mathrm{R}=\mathrm{Me} ; 154 \mathrm{R}=\mathrm{CF}_{3}$ 


\section{3 新型骨架催化剂}

多种新型 N,O 骨架催化剂可有效催化乙烯与阻隔 型极性单体共聚. 但是用于乙烯与简单大宗工业极性单 体共聚时, 共聚活性、共聚物分子量及极性基团插入率 普遍不高, 甚至无法催化多个种类的单体共聚.

轴向位阻较大的苯胺䒺醌骨架 $\mathrm{N}, \mathrm{O}$ 型 $\mathrm{Ni}$ 催化剂 155 , 在 $40{ }^{\circ} \mathrm{C}$ 和 $1 \mathrm{MPa}$ 乙烯压力下以干燥的改性甲基铝 氧烷( $\mathrm{dMMAO}$ ) 为助催化剂, 催化乙烯-醋酸己烯酯共聚 [111], 催化活性为 $3 \times 10^{6}$, 但极性基团插入率低 $(0.76 \%)$, 共聚物分子量亦较低(7660), 分子量分布高达 9.77; $80{ }^{\circ} \mathrm{C}$ 不能发生共聚. $\mathrm{SiO}_{2}$ 负载催化剂 157 催化该反应催 化活性高达 $4.7 \times 10^{6}$, 极性基团插入率 $0.56 \%$, 共聚物 分子量提升至 $1.08 \times 10^{5} ; 80{ }^{\circ} \mathrm{C}$ 时催化活性仍能保持 $1.2 \times 10^{6}$. 156 无法在 $40{ }^{\circ} \mathrm{C}$ 时催化乙烯一醋酸己烯酯共 聚, 但将其负载在 $\mathrm{SiO}_{2}$ 上形成的负载催化剂 $\mathbf{1 5 8}$, 催化 活性却高达 $3.8 \times 10^{6}, 80{ }^{\circ} \mathrm{C}$ 催化活性下降至 $10^{5}$. 与此不 同的是, 157 催化无亚甲基阻隔乙烯一醋酸烯丙酯共聚活 性, 仅为 155 的一半.

随后, 蔡正国等 ${ }^{[12]}$ 使用类似的 Pd 催化剂 159 和 160 在 $40{ }^{\circ} \mathrm{C}$ 和 $0.07 \sim 0.21 \mathrm{MPa}$ 乙烯压力时, 催化乙烯丙烯酸甲酯共聚, 159 具有最高的催化活性 $\left(5.5 \times 10^{4}\right)$, 同时具有最高共聚物分子量(9380), 但此时极性基团插 入率最低(仅为 $0.07 \%$ ). 空间位阻较小的 $\mathbf{1 6 0}$ 催化共聚 插入率可提升至 3.54\%, 但共聚物分子量仅有 1260 , 催 化活性也低至 $3 \times 10^{3}$.
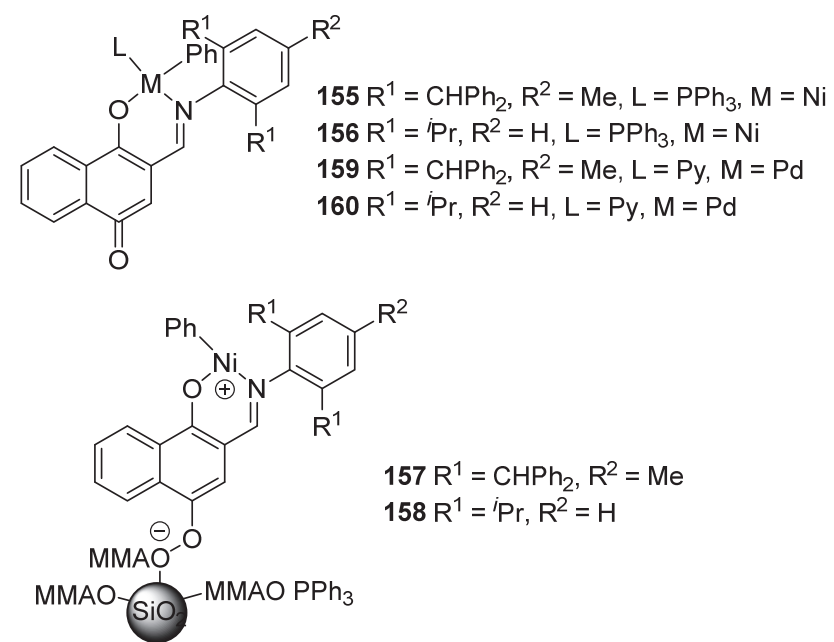

苯胺苯甲酸甲酯骨架 $\mathrm{N}, \mathrm{O}$ 型 $\mathrm{Ni}$ 催化剂 161, 在 $40{ }^{\circ} \mathrm{C}$ 和 $1.5 \mathrm{MPa}$ 乙烯压力时, 以 $\mathrm{dMMAO}$ 为助催化剂, 催化乙烯-醋酸己烯酯共聚活性为 $2.77 \times 10^{5}$, 共聚物分 子量和极性基团插入率较 155 均有提升(分别为 19700 和 $0.35 \% \sim 1.33 \%)^{[113]} .161$ 还可催化乙烯-醋酸降冰片烯 酯共聚, 但是不能实现乙烯一丙烯酸甲酯、醋酸乙烯酯的 共聚.

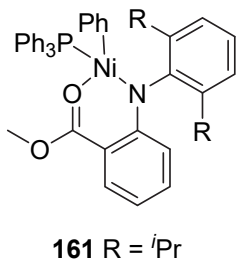

最近，蔡正国等 ${ }^{[34]}$ 制备了芳醚咪唑啉亚胺骨架的 $\mathrm{Ni}$ 催化剂 162 164, 可催化降冰片烯与亚甲基阻隔的 醋酸烯丙酯、烯丙基乙醚、十一烯醇、十一烯氯、烯己 基溴、烯己醇和十一烯酸甲酯分别共聚. 以 $\mathrm{B}\left(\mathrm{C}_{6} \mathrm{H}_{5}\right)_{3}$ 为 助催化剂, $40 \sim 60{ }^{\circ} \mathrm{C}$ 时, 苯环上带有二苯甲基取代基的 164 催化活性最高，除醋酸烯丙酯 $(1 \%$ 3\%) 外，其他共 聚反应中极性单体插入率普遍较低 $(0.35 \% \sim 0.7 \%)$. 该 催化体系无法催化降冰片烯与丙烯酸甲酯、丙烯酸丁 酯、烯丙基氯和醋酸乙烯酯等大宗工业单体共聚.
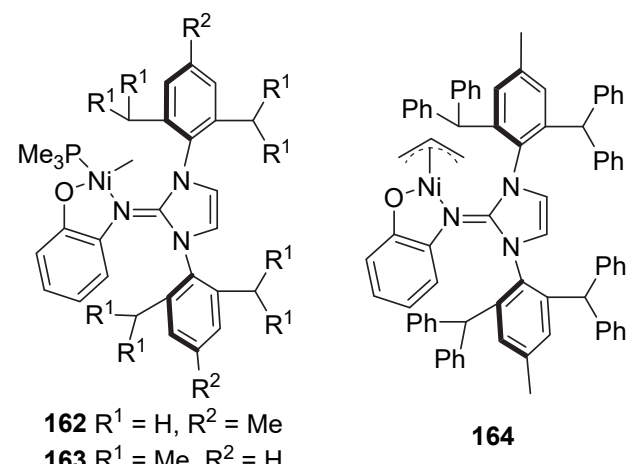

陈昶乐等 ${ }^{[114]}$ 基于亚胺吡啶氧化物骨架结合二苯甲 基结构制备了两种 $\mathrm{Ni}$ 催化剂 $\mathbf{1 6 5}$ 和 $\mathbf{1 6 6}$, 在 $20{ }^{\circ} \mathrm{C}$ 和 0.2 $\mathrm{MPa}$ 乙烯压力下, 使用 MAO 为助催化剂, 可催化乙烯十一烯酸甲酯共聚. 165 催化活性可达 $3.24 \times 10^{5}$, 共聚 物分子量最高可达 $5 \times 10^{4}$, 使用 166 催化共聚物分子量 可提升至 $1.2 \times 10^{6}$. 两种催化剂极性单体插入率均不高 $(0.1 \% \sim 1.5 \%)$.

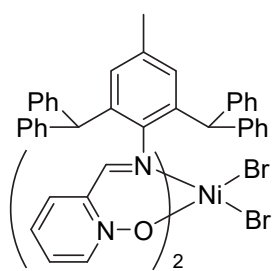

165

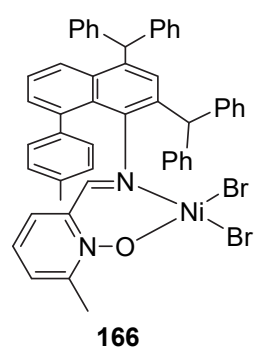

166
尽管较难有效催化简单大宗工业单体参与极性共 聚, 阻隔型极性单体及极性降冰片烯单体却可在对催化 剂进行调整后参与共聚，这些调整包括协同作用双金属 催化剂的设计、双配体催化剂的设计和催化剂骨架的调 整. 贺晓慧等设计了一系列双酮胺配体催化剂, 在助催 
化剂存在时用于催化降冰片烯与极性降冰片烯共聚, 共 聚物分子量和极性基团插入率可在很宽范围内调控. 但 是，这些降冰片烯一极性降冰片烯共聚反应的机理和共 聚物微观结构并未有深入研究, 并不能明确了解此类共 聚反应的途径及类型.

\section{4 膦酚型催化剂}

SHOP 催化剂一般催化乙烯齐聚制备高级 $\alpha$-烯烃, 聚合物分子量相对偏低, 在 Keim 等 ${ }^{[5]}$ 报道后的 20 多年 里, 一直未在烯烃-极性单体共聚领域得到重视. 后续 研究发现 SHOP催化剂也可催化乙烯与乙烯基极性单体 共聚, 但是极性单体的极性基团与不饱和双键间常常需 要多个亚甲基阻隔 ${ }^{[21,115]}$.

Heinicke 等[116]在 2010 年报道了膦酚型 $\mathrm{Ni}$ 催化剂 167 169, 催化乙烯分别与阻隔型十一烯酸乙酯和 9-癸 烯醇在 $100{ }^{\circ} \mathrm{C}$ 时共聚, 具有大空间位阻的 168 催化共聚 物分子量约为 167 的 6 倍. 甲基丙烯酸甲酯、丙烯酸正 丁基酯、醋酸乙烯酯和丙烯腈等大宗工业单体均无法参 与共聚. 膦端配体及苯环上(特别是氧端邻位)的取代基 不同的电子效应和空间效应均为催化性能调控提供了 可能.

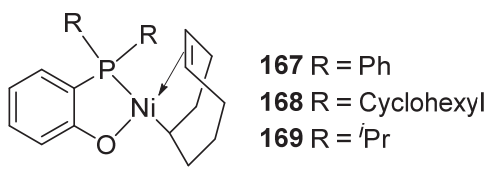

膦端具有结构调控灵活性, 可通过改变膦端取代基 才以调节活性中心周围轴向空间位阻, 进而调控催化剂 性能和共聚物性能. Nozaki、Shimizu 和李悦生等通过对 膦端取代基的一系列研究, 已经实现了膦酚型 $\mathrm{Ni}$ 催化 剂催化烯烃与丙烯酸酯等大宗工业单体共聚.

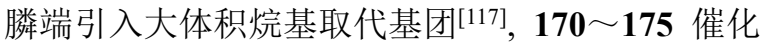
丙烯均聚和共聚, 对丙烯均聚有较高催化活性, 可得到 高分子量均聚物的 174 催化丙烯与烯丁醇、醋酸烯丁酯 和烯丙基氨基甲酸叔丁酯分别共聚，可得到插入率为 $0.39 \% \sim 2.4 \%$ 的共聚物，分子量为 $2700 \sim 7000$. 共聚物 微观结构分析发现, 三种共聚物中极性基团分布有很大

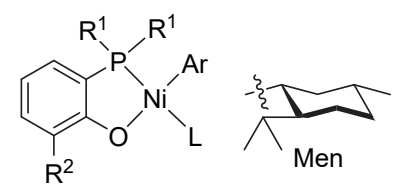

$170 \mathrm{R}^{1}=\mathrm{Ph}, \mathrm{R}^{2}=\mathrm{H}, \mathrm{Ar}=\mathrm{Ph}, \mathrm{L}=\mathrm{PEt}_{3}$

$171 \mathrm{R}^{1}={ }^{t} \mathrm{Bu}, \mathrm{R}^{2}=\mathrm{H}, \mathrm{Ar}=\mathrm{Ph}, \mathrm{L}=\mathrm{PEt}_{3}$

$172 \mathrm{R}^{1}=$ Men, $\mathrm{R}^{2}=\mathrm{H}, \mathrm{Ar}=4-\mathrm{FC}_{6} \mathrm{H}_{4}, \mathrm{~L}=\mathrm{PEt}_{3}$

$173 \mathrm{R}^{1}={ }^{t} \mathrm{Bu}, \mathrm{R}^{2}=\mathrm{C}_{6} \mathrm{~F}_{5}, \mathrm{Ar}=4-\mathrm{FC}_{6} \mathrm{H}_{4}, \mathrm{~L}=\mathrm{Py}$

$174 \mathrm{R}^{1}={ }^{t} \mathrm{Bu}, \mathrm{R}^{2}={ }^{t} \mathrm{Bu}, \mathrm{Ar}=4-\mathrm{FC}_{6} \mathrm{H}_{4}, \mathrm{~L}=\mathrm{Py}$

$175 \mathrm{R}^{1}=$ Men, $\mathrm{R}^{2}={ }^{t} \mathrm{Bu}, \mathrm{Ar}=4-\mathrm{FC}_{6} \mathrm{H}_{4}, \mathrm{~L}=3,5-\mathrm{Br}_{2} \mathrm{Py}$
区别，烯丁醇极大部分位于链端，醋酸烯丁酯嵌入链中， 而烯丙基氨基甲酸叔丁酯在同时存在于链端和链中. 使 用对丙烯均聚等规度较好 $([\mathrm{mm}]=60 \%)$ 的 175 催化丙烯醋酸烯丁酯共聚, 共聚物等规度也较高 $([\mathrm{mm}]=61 \%)$.

膦端引入甲氧基或苯氧基苯基 ${ }^{[118] ， 176 １ 84 ~}$ 可实 现乙烯与一系列丙烯酸酯共聚得到高度线型共聚物，分 子量最高可大于 $10^{5}$, 极性基团可全部嵌入主链中. 极 性单体位阻增大或增加配体中苯氧基的个数, 催化剂活 性和共聚物分子量均增加, 极性单体插入率下降. 位阻 更大的 177 与 176 相比, 共聚物有更少的支链(支化度 $0.5 \mathrm{vs} 4$ )、更高的分子量以及更少的链端极性基团. 他们 认为，高分子量源于甲氧基在聚合过程中与金属中心短 暂配位，有利于极性基团插入后乙烯再插入这一决速步 骤; 同时, 177 上的 $\beta-\mathrm{H}$ 消除更慢, 或者 $\beta-\mathrm{H}$ 消除后形成 的大分子单体更多地以 1,2 形式再插入，而不是 2,1 形 式.

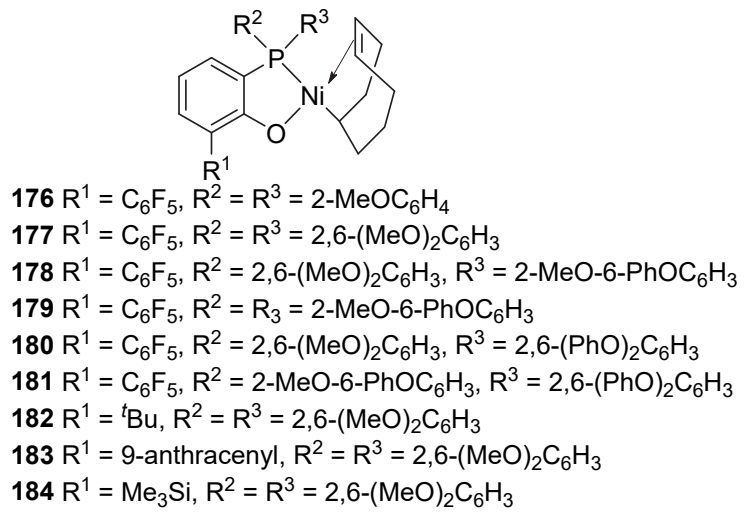

膦端引入联苯基团，进一步增大 $\mathrm{P}$ 原子上的空间位

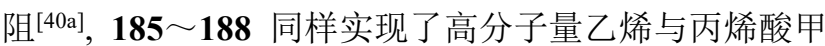
酯、丙烯酸丁酯和 $N, N$-二甲基丙烯酰胺分别共聚，共聚 物为不含支链的线性结构，大部分极性基团位于链中， 插入率为 $3.3 \% \sim 7.7 \%$. 拥有最大位阻的 188 显示出最高 共聚活性 $\left(10^{5}\right)$, 催化乙烯一丙烯酸甲酯共聚物分子量可 达 $10^{5}$. 膦端的大位阻取代基阻挡了 $\mathrm{d}\left(\mathrm{sp}^{2}\right)$ 杂化 $\mathrm{Ni}$ 中心 $\mathrm{p}_{z}$ 空轨道，共聚单体无法从轴向靠近金属中心，同时拥 挤空间还可减少双分子失活，从而有效抑制 2,1 方式插 入后 $\beta-\mathrm{H}$ 消除和链转移, 增加共聚物分子量. 当保持单

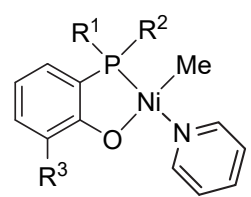

$185 R^{1}=R^{2}=P h, R^{3}={ }^{t} B u$

$186 \mathrm{R}^{1}=\mathrm{Ph}, \mathrm{R}^{2}=2-\left(2,6-(\mathrm{MeO})_{2} \mathrm{C}_{6} \mathrm{H}_{3}\right) \mathrm{C}_{6} \mathrm{H}_{4}, \mathrm{R}^{3}={ }^{{ } \mathrm{Bu}}$

$187 \mathrm{R}^{1}=\mathrm{Ph}, \mathrm{R}^{2}=2-\mathrm{PhC}_{6} \mathrm{H}_{4}, \mathrm{R}^{3}={ }^{\mathrm{B}} \mathrm{Bu}$

$188 \mathrm{R}^{1}=\mathrm{R}^{2}=2-\mathrm{PhC}_{6} \mathrm{H}_{4}, \mathrm{R}^{3}={ }^{t} \mathrm{Bu}$ 
体浓度不变, 增大乙烯压力, 极性单体插入率降低, 共 聚物产率升高; 当保持乙烯压力不变, 升高单体浓度, 极性单体插入率升高, 共聚物产率降低.

氧端邻位取代基结构也可对催化性能产生重要影 响. 李悦生等 ${ }^{[119]}$ 在联苯基团系列催化剂基础上又系统 研究了氧端邻位不同取代基 186 和 189 195 催化的乙 烯一丙烯酸甲酯共聚, 在 $60{ }^{\circ} \mathrm{C}$ 和 $1 \mathrm{MPa}$ 乙烯压力时反应, 194 具有最高的催化活性 $\left(1.28 \times 10^{5}\right)$ 、最高分子量 $\left(1.54 \times 10^{5}\right)$ 和最低插入率 $(0.7 \%)$. 提高极性单体浓度或 降低乙烯压力, 极性基团插入率可提高至 3.9\%, 催化活 性也可提升至 $2.1 \times 10^{5}$, 但分子量降低至 $1.8 \times 10^{4}$. 在 电子效应(吸电子)和空间效应(大位阻)共同作用下, 催 化剂活性和共聚物分子量按 194、192、193、191、190、

$189 / 186$ 和 195 的顺序依次降低. 194 还可以催化乙烯与 丙烯酸丁酯、 $N, N$-二甲基丙烯酰胺、丙烯酸乙二醇单甲 醚酯和十一烯酸甲酯分别共聚, 极性基团插入率为 $1 \% \sim 3 \%$.

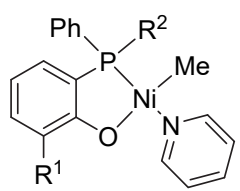

$189 \mathrm{R}^{1}=\mathrm{H}, \mathrm{R}^{2}=2-\left(2,6-(\mathrm{MeO})_{2} \mathrm{C}_{6} \mathrm{H}_{3}\right) \mathrm{C}_{6} \mathrm{H}_{4}$

$190 \mathrm{R}^{1}=\mathrm{F}, \mathrm{R}^{2}=2-\left(2,6-(\mathrm{MeO})_{2} \mathrm{C}_{6} \mathrm{H}_{3}\right) \mathrm{C}_{6} \mathrm{H}_{4}$

$191 \mathrm{R}^{1}=\mathrm{Me}, \mathrm{R}^{2}=2-\left(2,6-(\mathrm{MeO})_{2} \mathrm{C}_{6} \mathrm{H}_{3}\right) \mathrm{C}_{6} \mathrm{H}_{4}$

$192 \mathrm{R}^{1}=\mathrm{CF}_{3}, \mathrm{R}^{2}=2-\left(2,6-(\mathrm{MeO})_{2} \mathrm{C}_{6} \mathrm{H}_{3}\right) \mathrm{C}_{6} \mathrm{H}_{4}$

$193 \mathrm{R}^{1}=\mathrm{Ph}, \mathrm{R}^{2}=2-\left(2,6-(\mathrm{MeO})_{2} \mathrm{C}_{6} \mathrm{H}_{3}\right) \mathrm{C}_{6} \mathrm{H}_{4}$

$194 \mathrm{R}^{1}=\mathrm{C}_{6} \mathrm{~F}_{5}, \mathrm{R}^{2}=2-\left(2,6-(\mathrm{MeO})_{2} \mathrm{C}_{6} \mathrm{H}_{3}\right) \mathrm{C}_{6} \mathrm{H}_{4}$

$195 \mathrm{R}^{1}={ }^{t} \mathrm{Bu}, \mathrm{R}^{2}=2-\left(2,6-\mathrm{F}_{2} \mathrm{C}_{6} \mathrm{H}_{3}\right) \mathrm{C}_{6} \mathrm{H}_{4}$

膦酚型催化剂还可以催化乙烯与极性降冰片烯、降 冰片烯与极性降冰片烯共聚. 使用单组分催化剂 196 和 197 在较高乙烯压力下 $(10 \mathrm{MPa})$, 乙烯与醋酸降冰片烯 酯可在 $85^{\circ} \mathrm{C}$ 时共聚[115a], 催化活性最高达 $1.94 \times 10^{5}$, 共 聚物分子量 4000 5000, 极性基团插入率 1\% 3\%. 使 用 $\mathrm{B}\left(\mathrm{C}_{6} \mathrm{~F}_{5}\right)_{3}$ 为助催化剂, $\mathrm{Ni}$ 催化剂 198 和 199 可在 $60{ }^{\circ} \mathrm{C}$ 时催化降冰片烯与醋酸降冰片烯酯、降冰片烯羧酸甲酯

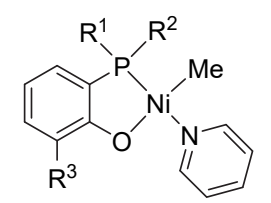

$196 R^{1}=R^{2}=R^{3}=P h$ $197 \mathrm{R}^{1}=\mathrm{Ph}, \mathrm{R}^{2}=\mathrm{R}^{3}={ }^{t} \mathrm{Bu}$

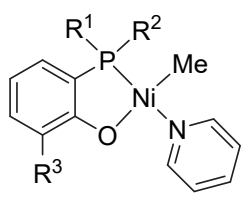

$198 \mathrm{R}^{1}=\mathrm{R}^{2}=\mathrm{Ph}, \mathrm{R}^{3}={ }^{t} \mathrm{Bu}$ $199 \mathrm{R}^{1}=\mathrm{C}_{6} \mathrm{~F}_{5}, \mathrm{R}^{2}=\mathrm{R}^{3}=\mathrm{Ph}$<smiles></smiles>

和降冰片烯甲醇分别共聚[120], 催化活性可达 $10^{6}$, 共聚 物分子量大于 $3 \times 10^{5}$, 极性基团插入率可在较宽范围内 调控(7.2\% 37.6\%); Pd 催化剂 200 在 $60{ }^{\circ} \mathrm{C}$ 催化降冰片 烯一降冰片烯羊酸甲酯和降冰片烯一降冰片烯甲醇共 聚 ${ }^{[121]}$, 前者共聚物分子量 $6400 \sim 11000$, 极性基团插入 率为 $2.5 \% \sim 15.4 \%$, 后者共聚活性大幅下降, 共聚物分 子量仅为 3500, 极性基团插入率为 $8.9 \%$.

最近，简忠保等使用不同辅助配体 Ni 催化剂 201 和 202 实现了 $50{ }^{\circ} \mathrm{C}$ 和 $0.8 \mathrm{MPa}$ 乙烯压力时乙烯与乙烯 基三甲氧基硅烷、烯己基氯和烯丙基丁基醚分别共 聚 ${ }^{[122]}$, 使用吡啶骨架 $\mathrm{Ni}$ 催化剂 203 催化乙烯-十一烯酸 甲酯 $90{ }^{\circ} \mathrm{C}$ 时的共聚 ${ }^{[123]}$, 得到较低支化度 $(<10)$ 共聚物, 极性基团插入率偏低 $(0.2 \% \sim 1.2 \%)$; 除乙烯-烯已基氯 共聚物分子量稍高 $\left(2.33 \times 10^{4}\right)$, 其他共聚物分子量偏低 (1433 7400).<smiles>CC(C)(C)c1cccc2c1O[N+](C)(P)P2(Br)(c1ccccc1)c1c(O)cc(Oc2ccccc2)cc1O</smiles>

201

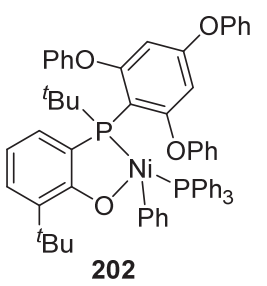

202<smiles>COc1ccccc1[PH]1(c2ccccc2OC)N2CCC(CC2)ON1C(C)(C)C</smiles>

203
膦酚型催化剂为 $\mathrm{Ni}$ 催化剂, 与 $\alpha$-二亚胺型 $\mathrm{Ni}$ 催化 剂和水杨醛亚胺/酮胺型 $\mathrm{Ni}$ 催化剂相比, 热稳定性更高. 共聚反应可在较高温度 $\left(60 \sim 80{ }^{\circ} \mathrm{C}\right)$ 下进行, 接近工业应 用温度区间，实用性更强. 通过对膦端和氧端邻位取代 基结构调整, 膦酚型催化剂可共聚极性单体范围已从多 阻隔型转变为烯丙基型, 甚至在催化双键与极性基团直 接相连的乙烯型单体共聚时, 依然可以得到高分子量 (大于 $10^{5}$ )共聚物. 但是此时极性基团插入率相对偏低, 共聚物分子量与插入率间的矛盾关系较为突出, 在保证 较高分子量前提下的极性基团插入率调控能力有待加 强.

\section{5 膦磺酸型催化剂}

在 Drent 等报道了膦磺酸钯催化剂催化乙烯一丙烯 酸酯共聚之后, 其出色的共聚性能以及共聚物的独特结 构使其共聚单体种类进一步拓宽，不仅丙烯酸酯 ${ }^{[124]}$,

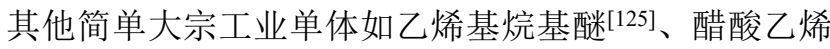
酯 $[126]$ 、丙烯腈 ${ }^{[127]}$ 和氟乙烯 ${ }^{[128]}$ 等都可与乙烯共聚得到线 型共聚物. 催化剂具有较好的热稳定性，可在 80 $100{ }^{\circ} \mathrm{C}$ 的相对高温环境中进行共聚; 在这些共聚反应中, 极性基团大多以 2,1-方式嵌入链端和链中, 氟乙烯插入 率一般为 $0.09 \% \sim 0.14 \%$, 其他极性基团插入率为 $1 \%$ $10 \%$; 共聚物分子量一般不高(1000 10000), 催化剂活 
性一般也较低(100～1000); 机理研究发现, 极性单体插 入金属中心后形成螯合物，烯烃分子再插入较为缓慢， 螯合物容易发生 $\beta-\mathrm{H}$ 或 $\beta-\mathrm{X}$ 消除，导致链转移.

迄今为止, 膦磺酸型催化剂中膦端配体研究繁多, 多种多样的取代基团展现出各异的催化性能, 大量研究 证实膦磺酸型催化剂的高效性和普遍适用性, 对该类催 化剂的应用研究也逐渐深入. 以下将从配体类型的角度 对膦磺酸 $\mathrm{Pd}$ 催化剂进行综述, 并介绍膦磺酸 $\mathrm{Ni}$ 催化剂 研究进展.

\section{1 双 2-甲氧基苯基膦 Pd 催化剂}

辅助配体 $\mathrm{L}$ 与金属中心的配位强度对共聚活性有 非常大的影响. 在 $\left(\mathrm{P}^{\wedge} \mathrm{O}\right) \mathrm{PdR}(\mathrm{L})+$ monomer $=$ $\left(\mathrm{P}^{\wedge} \mathrm{O}\right) \mathrm{PdR}$ (monomer) $+\mathrm{L}$ 这一平衡中, 强配位作用倾向 于平衡向稳定的 $\left(\mathrm{P}^{\wedge} \mathrm{O}\right) \mathrm{PdR}(\mathrm{L})$ 移动. 目前经常使用的单 配位辅助配体主要有 2,6-二甲基吡啶(207)、三苯基膦 (205)、四甲基乙二胺(208)、吡啶(206)和二甲亚砜(204) 等 ${ }^{[129]}$. 与 $\mathrm{N}$ 或 $\mathrm{P}$ 配体相比, 二甲亚砜(DMSO)与金属中 心配位较弱 ${ }^{[130]}$, 能快速和烯烃单体交换, 可在较低乙 烯压力下形成具有较高极性基团插入率 ${ }^{[26]}$ 的共聚物, Mecking 等使用 DMSO 为配体的双 2-甲氧基苯基 Pd 膦 催化剂 204 开展了大量出色的工作. 在实际应用中, 催 化活性和分子量还受到溶剂效应、轴向配位效应和催化 剂聚集态等因素影响[131].

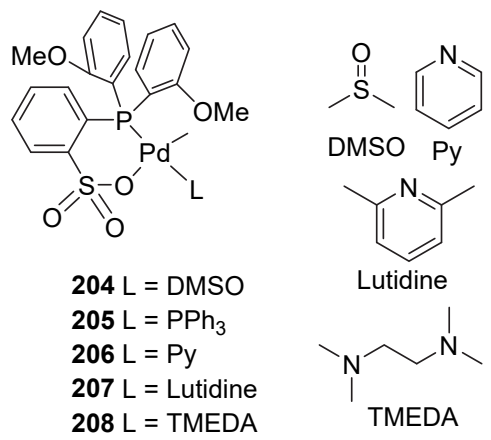

\section{1 .1 催化丙烯酸、丙烯酸酯类单体共聚}

丙烯酸属于大宗化工产品, 但是对过渡金属配合物 的毒化作用明显, 实现乙烯与丙烯酸的直接共聚难度很 大. Claverie 等[132]利用 209 催化乙烯与丙烯酸叔丁酯共 聚再水解的方法间接制备出了链中含丙烯酸基团的聚 合物. 2010 年, Mecking 等 ${ }^{[41 b]}$ 使用 204 首次实现了乙烯丙烯酸直接共聚. 加入少量自由基抑制剂 2,6-二叔丁基 对甲酚(BHT), 在 $0.5 \mathrm{MPa}$ 乙烯压力和 $95{ }^{\circ} \mathrm{C}$ 时反应, 极 性基团插入率可达 $9.6 \%$, 且大多位于链中(不同于乙烯醋酸乙烯和乙烯一丙烯腈共聚反应中位于链端). 共聚物 为线性结构(支化度 3), 但该体系的催化活性和聚合物 分子量都很低. 此后, Claverie 等 ${ }^{[133]}$ 使用 210 也实现了
乙烯一丙烯酸直接共聚，极性基团插入率为 5\%; 他们还 使用 206 催化乙烯一降冰片烯二酸酐共聚，插入率达 $11 \%$, 分子量为 8000 ; 当 206 催化乙烯一马来酸酐共聚 时, 需要加入 $\mathrm{BF}_{3}$ 才能有效提高马来酸酐的插入率至 2\% 9\%, 且共聚物分子量很低(1800 2800).

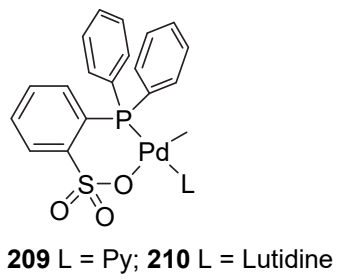

Mecking 等 ${ }^{[134]}$ 通过实验和密度泛函理论(DFT)研究 发现，在一系列不同电子效应和空间效应催化剂 211 222 中, 缺电子催化剂催化乙烯一丙烯酸甲酯共聚活性 更高, 但也观察到其快速分解; P 上苯环邻位带有双给 电子基团(如甲氧基)的催化剂 214 和 220 可在较低丙烯 酸甲酯浓度时得到高极性基团插入率共聚物; 此外, 增 大空间位阻可提高共聚物分子量. 进一步研究发现, 223 226 和 204 室温下催化共聚丙烯酸甲酯以 2,1 形式 插入 $\mathrm{Pd}-\mathrm{Me}$ 的速度非常快 ${ }^{[135]}$, 且单体向缺电子催化剂 223 的 $\mathrm{Pd}-\mathrm{Me}$ 键插入活性更高; 但是, 极性基团插入率 (3.7\% 21\%)、共聚物分子量(1000 5400)和链端结构与 配体电子效应无明显关联; 膦端芳基烷基混合配体 227 和 228 显示出类似活性, 227 可得到最高的共聚物分子 量 $\left(1.2 \times 10^{4}\right)$.

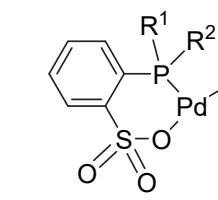

$211 \mathrm{R}^{1}=\mathrm{R}^{2}=2-\mathrm{PhC}_{6} \mathrm{H}_{4}$

$212 R^{1}=R^{2}=2-\left(2,6-(\mathrm{MeO})_{2} \mathrm{C}_{6} \mathrm{H}_{3}\right) \mathrm{C}_{6} \mathrm{H}_{4}$

$213 R^{1}=R^{2}=2,5-M_{2}-6-M_{e O C} \mathrm{H}_{2}$

$214 \mathrm{R}^{1}=\mathrm{R}^{2}=2,6-(\mathrm{MeO})_{2} \mathrm{C}_{6} \mathrm{H}_{3}$

$215 \mathrm{R}^{1}=\mathrm{R}^{2}=2-\mathrm{CyOC}_{6} \mathrm{H}_{4}$

$216 \mathrm{R}^{1}=\mathrm{R}^{2}=2-\mathrm{MeOC}_{6} \mathrm{H}_{4}$

$217 \mathrm{R}^{1}=\mathrm{R}^{2}=2-\mathrm{CF}_{3} \mathrm{C}_{6} \mathrm{H}_{4}$

$218 \mathrm{R}^{1}=\mathrm{R}^{2}=2,4,6-(\mathrm{MeO})_{3} \mathrm{C}_{6} \mathrm{H}_{2}$

$219 \mathrm{R}^{1}=\mathrm{R}^{2}=2,6-\left({ }^{i} \mathrm{PrO}\right)_{2} \mathrm{C}_{6} \mathrm{H}_{3}$

$220 \mathrm{R}^{1}=2-\left(2,6-(\mathrm{MeO})_{2} \mathrm{C}_{6} \mathrm{H}_{3}\right) \mathrm{C}_{6} \mathrm{H}_{4}, \mathrm{R}^{2}=2,6-(\mathrm{MeO})_{2} \mathrm{C}_{6} \mathrm{H}_{3}$

$221 \mathrm{R}^{1}=2-\mathrm{CyOC}_{6} \mathrm{H}_{4}, \mathrm{R}^{2}=2,6-(\mathrm{MeO})_{2} \mathrm{C}_{6} \mathrm{H}_{3}$

$222 \mathrm{R}^{1}=\mathrm{Me}, \mathrm{R}^{2}=2,4,6-(\mathrm{MeO})_{3} \mathrm{C}_{6} \mathrm{H}_{2}$

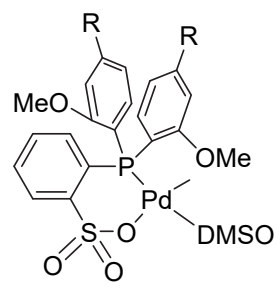

$223 \mathrm{R}=\mathrm{CF}_{3}$

$224 \mathrm{R}=\mathrm{Cl}$

$225 \mathrm{R}=\mathrm{Me}$

$226 \mathrm{R}=\mathrm{OMe}$

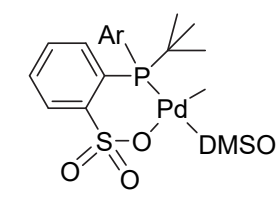

$227 \mathrm{Ar}=2,4,6-(\mathrm{MeO})_{3} \mathrm{C}_{6} \mathrm{H}_{2}$

$228 \mathrm{Ar}=\mathrm{Ph}$ 
提高聚合体系中乙烯压力可实现乙烯一丙烯酸甲酯 高插入率共聚 ${ }^{[136]}$, 极性基团插入率最高可达 52\%, 但 共聚物分子量偏低(1800 4200). 分析插入率大于 $30 \%$ 时的共聚物微观结构发现, 链中存在丙烯酸甲酯孤立重 复单元、丙烯酸甲酯-乙烯一丙烯酸甲酯交替序列和连续 的丙烯酸甲酯单元.

陈永乐等 ${ }^{[137]}$ 在膦端引入聚乙二醇基团取代基, 提 高丙烯酸甲酯插入率的同时还可保持较高共聚物分子 量. 229 232 均可催化乙烯一丙烯酸甲酯共聚, 其中 231 在得到 $20 \%$ 较高极性基团插入率时, 共聚物分子量为 $1.9 \times 10^{4}$. 与乙烯一丙烯酸甲酯共聚相同, 乙烯-丙烯酸 正丁酯共聚时, 催化活性、极性基团插入率、共聚物分 子量和熔点按照氧原子个数从多到少按 231 、230 和 229 的顺序降低, 长烷基链结构 232 极性基团插入率低于 229. 231 还可催化乙烯与丙烯酸、十一烯羧酸、降冰片 烯羧酸、十一烯醇、丙烯酸乙二醇酯和 $N$-异丙基丙烯酰 胺分别共聚; 类似结构的 $\mathrm{Ni}$ 催化剂 234 和 235 可以催化 乙烯一十一烯醇共聚, 但是活性、插入率和分子量远低于 相应 Pd 催化剂; 233 和 236 则无法催化乙烯-十一烯醇 共聚.
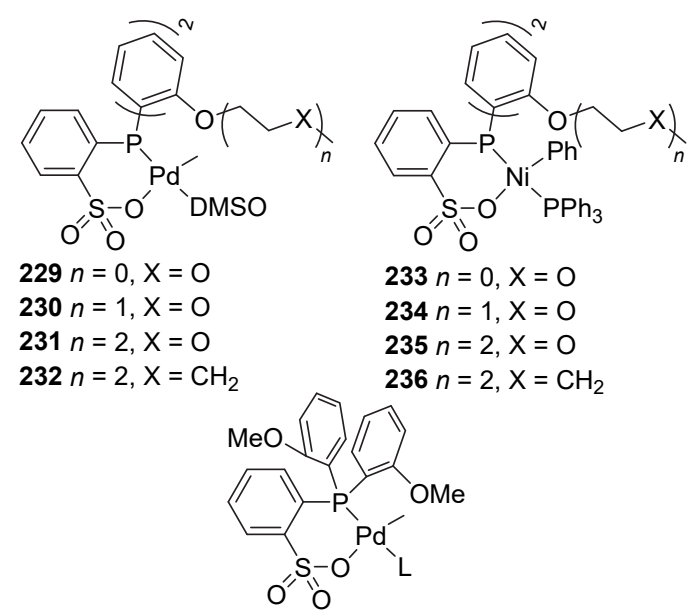

$237 \mathrm{~L}=\mathrm{MeCN}$

\section{1 .2 催化二乙烯基极性单体共聚}

二乙烯基单体在参与共聚反应时, 可优先连续二次 插入，抑制 $\beta-\mathrm{H}$ 消除，实现聚合性能提升，并可在共聚 物链中引入环状极性基团. Claverie 等 ${ }^{[138]}$ 使用 206 和 209
催化乙烯-丙烯酸烯丙基酯共聚(Eq. 1), 共聚物链中包 含环状 $\delta$-戊内酯(Scheme 5, C) 和 $\gamma$-丁内酯(Scheme 5, B) 单元. 他们证实, 烯丙基端双键一般以 1,2 形式插入，丙 烯酸酯端双键一般以 2,1 形式插入，但是当空间拥挤时 丙烯酸酯端双键则选择 1,2 形式插入. 聚合性能和聚合 物分子量相对于乙烯-丙烯酸酯体系并未有明显提高.

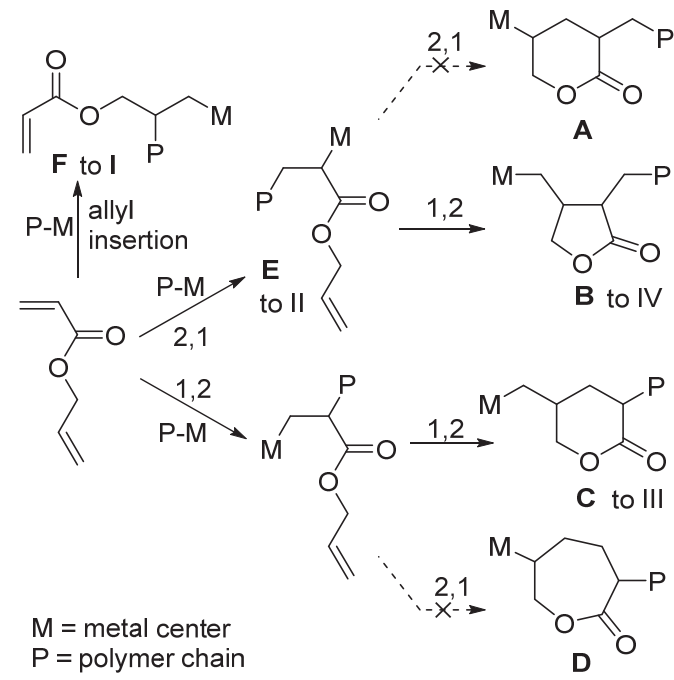

图式 5 可能的乙烯-丙烯酸烯丙基酯共聚机理

Scheme 5 Possibile mechanism for copolymerization of ethylene and allyl acrylate

为了提高共聚物分子量, Mecking 等 ${ }^{[139]}$ 尝试使用对 称二乙烯基单体与乙烯共聚. 204 和 227 在 $65 \sim 95{ }^{\circ} \mathrm{C}$ 和 $0.5 \mathrm{MPa}$ 乙烯压力时, 催化乙烯一丙烯酸酐共聚(Eq. 2), 极性基团插入率高达 $25.1 \%$, 共聚物分子量(最高 $\left.2.7 \times 10^{4}\right)$ 较相同插入率的乙烯一丙烯酸酯共聚物提高一 个数量级. 极性基团以四种形式嵌入高度线型共聚物链 中, 以环状马来酸酐结构为主 $(>90 \%)($ Scheme 6, B). 丙 烯酸酐第一个双键以 2,1 形式插入后, 第二个双键马上 以 1,2 形式快速插入, $\beta-\mathrm{H}$ 消除和链转移得到抑制. 204 还可催化乙烯一马来酸酐共聚，但极性基团插入率 (1.7\%)和共聚物分子量(3500)均不高. 乙烯一丙烯酸酐共 聚进行后修饰的方法为乙烯一马来酸酐、丙烯酸、丙烯 酸酯共聚物及乙烯一丙烯酰胺共聚物等的制备提供了新 途径.

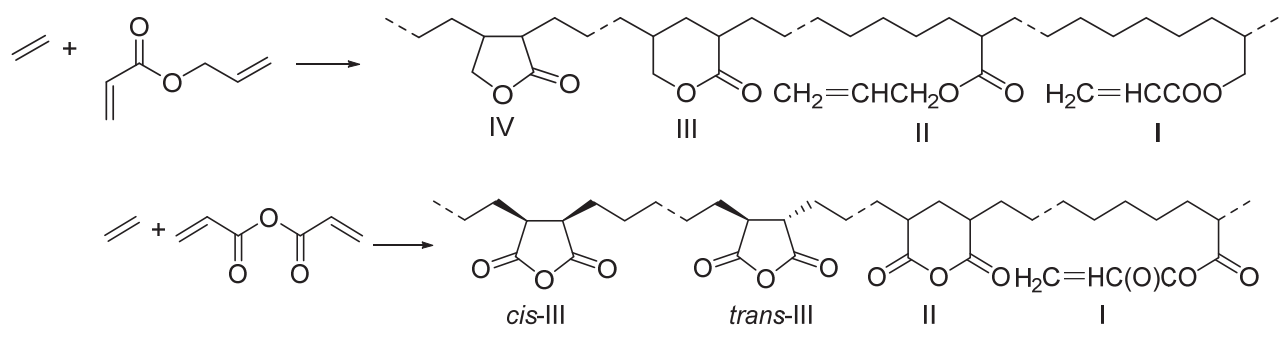




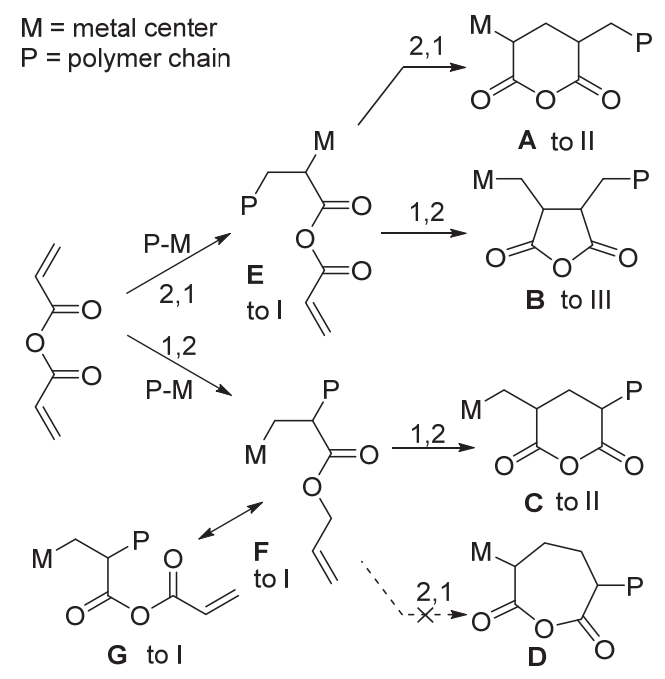

图式 6 可能的乙烯-丙烯酸酐共聚机理

Scheme 6 Possibile mechanism for copolymerization of ethylene and acrylic anhydride

使用 204 催化乙烯一二烯丙基醚共聚[140], 极性基团 插入率最高可达 $20.4 \%$; 随着插入率升高, 共聚物熔点 自 $118{ }^{\circ} \mathrm{C}$ 降低到 $52{ }^{\circ} \mathrm{C}$, 共聚物分子量自 5900 降低到 2300. 共聚物中极性基团以成环和非环两种形式存在, 其中 $96 \% \sim 99 \%$ 成环，且以五元环为主 $(60 \%)$. 他们认 为, 极性单体首先以 1,2 形式插入, 随着链增长活性中 心的位阻增大, 极性基团由 1,2 插入快速转变为为 2,1 插入.

204 还可催化乙烯-二乙烯基缩甲醛共聚[141]得到高 度线型共聚物, 极性基团一般位于链起始端, 极性基团 插入率最高达 $12.5 \%$, 但是共聚物分子量较低(1200 3000). 共聚物中 $98 \%$ 以上极性基团以五元环或六元环 形式存在. 2,1-1,2 连续插入 $\mathrm{Pd}-\mathrm{H}$ 键形成五元环, 1,2-1,2 连续插入形成六元环. 两种成环倾向类似, 五元 环和六元环比例接近.

\section{1 .3 催化 1,1 -二极性取代单体共聚}

氧基丙烯酸乙酯是世界上产量最大的粘合剂之一, 市场销售的产品中最广为所知的就是 502 , 但是该单体 中 1,1 位上同时含有两个极性基团, 较难进行极性共聚 反应. Chikkali 等 ${ }^{[142]}$ 首次报道了乙烯与此类工业相关 1,1-二极性取代单体的共聚反应，一次性在链中一个位 点上同时引入两个极性基团. 237 催化乙烯-氧基丙烯酸 乙酯和三氟甲基丙烯酸共聚, 极性单体插入率分别为 $6.5 \%$ 和 $3.0 \%$ ，相应共聚物分子量分别为 $5.8 \times 10^{3}$ 和 $2.8 \times 10^{3}$. Nozaki 等 ${ }^{[143]}$ 认为该聚合反应并非配位聚合, 而是离子聚合或自由基聚合 ${ }^{[144]}$.

随后, Chikkali 等[40c]将共聚 1,1 二二极性取代单体的 范围进一步拓宽，乙酰氨基丙烯酸甲酯可以 1,2 或 2,1
形式插入, 1,2 形式稍占优; 缺电子 2-三氟甲基丙烯酸则 全部以 2,1 方式插入. 乙酰氨基丙烯酸、2-溴丙烯酸、 烯丙基丙二酸甲酯和烯丙基丙二酸也可进行共聚反应, 极性基团插入率为 $1.3 \% \sim 11.8 \%$ ，分子量一般不高.

\section{1 .4 催化极性苯乙烯单体共聚}

由于苯乙烯与乙烯有完全不同的竞聚率，乙烯一极 性苯乙烯共聚也很难进行. 尽管前过渡金属催化乙烯一 极性苯乙烯已经可以实现，但后过渡金属催化的研究还 很少 ${ }^{[145,16]}$. Sen 等 ${ }^{[146]}$ 尝试使用 206 催化乙烯与 4-乙酰氧 基苯乙烯和 4 -氟苯乙烯分别共聚，催化活性很低 $(1.28 \times$ $10^{4}$ 和 $\left.1.61 \times 10^{4}\right)$, 极性基团插入率分别为 $2.8 \%$ 和 $4.5 \%$.

最近, 陈昶乐和简忠保等 ${ }^{[147]}$ 系统研究了乙烯-极性 苯乙烯共聚反应. $90{ }^{\circ} \mathrm{C}$ 和 $0.9 \mathrm{MPa}$ 乙烯压力时, 使用 204 可有效催化乙烯与多达 14 种极性苯乙烯单体共聚, 特 别是多种富有挑战性的邻位取代单体. 极性基团插入率 为 $0.9 \% \sim 4.7 \%$, 共聚物分子量为 $2400 \sim 8400.204$ 催化 乙烯-邻氟、对氟和邻氯取代单体时活性较高 $\left(2.4 \times 10^{5}\right)$, 催化乙烯与邻羧基和邻醛基取代单体时活性则较低 $\left(10^{4}\right)$. 有趣的是，极性基团在共聚物分子链饱和链端、 链中和不饱和链端的分布较为平均.

\section{1 .5 催化其他简单极性单体共聚}

膦磺酸型催化剂极大拓展了极性共聚单体范围，除 了以上介绍的各种极性单体和使用条件外，更多其他种 类的极性单体也可以在膦磺酸型催化剂催化下实现共 聚, 且共聚反应一般均可在高温 $\left(80 \sim 95{ }^{\circ} \mathrm{C}\right)$ 和较低乙 烯压力 $(0.5 \mathrm{MPa} \sim 2 \mathrm{MPa})$ 时进行. Jordan 等使用新设计 的含苯基磺酸盐取代基的 $\mathbf{2 3 8}$ 和 239 将乙烯基氟插入率 从 $0.14 \% \%^{[128]}$ 提高到 $3.6 \%{ }^{[148]}$, Rieger 等 ${ }^{[149]}$ 使用 204 和三 氟甲基乙烯单体进一步实现了高氟插入率线型共聚. 三 氟甲基插入率最高可达 $8.9 \%$, 单独计算 $\mathrm{F}$ 的插入率为 $15 \%$; 极性基团以 1,2 和 2,1 方式嵌入链中(少量链端), 其中 1,2 方式稍占优. $3 \mathrm{MPa}$ 乙烯压力时，三氟甲基插入 率最低仅为 $0.3 \%$, 此时的共聚物分子量最高为 $1.5 \times 10^{4}$.

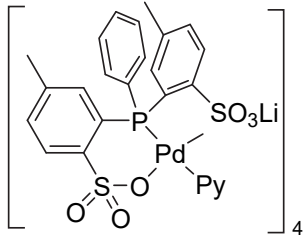

238

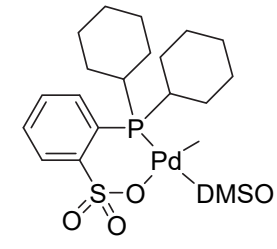

239
Mecking 等 ${ }^{[150]}$ 首次报道 204 催化乙烯-取代乙烯基 砜共聚得到高度线型共聚物，甲基乙烯基砜和苯基乙烯 基砜插入率分别可达 $13.9 \%$ 和 $7.2 \%$, 共聚物分子量偏低 (最高分别为 3600 和 4550). Tritto 等 ${ }^{[151]}$ 使用 204 实现了 
乙烯与极性降冰片烯共聚, 含有乙酰基和羟基的降冰片 烯单体插入率分别可达 $30.2 \%$ 和 $22.4 \%$, 相对应的共聚 物分子量分别为 $3.7 \times 10^{4}$ 和 $7.4 \times 10^{3}$. Mecking 等 ${ }^{[152]}$ 还 使用 204、212、228 和 239 实现了乙烯-烯丙基咪唑盐 共聚, 位阻较大的 212 极性基团插入率仅为 $0.04 \%$, 其 他催化剂极性基团插入率为 $0.2 \% \sim 0.23 \%$; 共聚物为高 度线型结构, 极性基团嵌入主链和饱和起始链端, 但分 子量仅为 1600 . 最近, Chen 等 ${ }^{[153]}$ 研究了 204 催化的乙烯 与一系列 1,2-二取代极性单体共聚反应, 乙烯与反式巴 豆酸甲酯和反式巴豆酸乙酯分别共聚, 两者共聚活性 $\left(1 \times 10^{4} \sim 1.8 \times 10^{4}\right)$ 与分子量 $(5200 \sim 9300)$ 类似, 后者插 入率稍高 $(2.5 \%$ vs 3.4\%); 乙烯也可与反式 3-戊烯-2-酮、 反式丙烯基乙醚和肉桂酸乙酯分别共聚, 插入率为 $1.2 \% \sim 2.9 \%$; 乙烯与顺丁烯二酸二甲酯共聚得到 $1.1 \%$ 插入率的共聚物, 但催化活性非常低(仅为 800); 反丁 烯二酸二甲酯和油酸甲酯无法参与共聚.

酰胺基团与金属原子配位作用与丙烯酸酯相比更 强, 丙烯酰胺对乙烯共聚活性抑制作用更加明显. Mecking 等 ${ }^{[26]}$ 系统研究了 204 催化乙烯-丙烯酰胺共聚 反应的机理, 丙烯酰胺主要采用 2,1 形式插入, $N$-异丙基 丙烯酰胺、 $N, N$-二甲基丙烯酰胺和 2-乙酰胺基乙基丙烯 酸酯分别与乙烯共聚的插入率可达 $3.1 \% 、 3.6 \%$ 和 $6.9 \%$, 共聚物分子量则非常低(分别为 2400、1200 和 700). 极 性基团一方面阻塞配位中心, 限制乙烯插入速率; 另一 方面与配位中心鳌合. 前者导致极性基团插入率和共聚 产率间存在固有矛盾, 且无法通过增大共聚单体浓度进 行调和. 保持丙烯酰胺浓度不变, 增大乙烯压力, 极性 单体插入率降低, 共聚物产率升高; 保持乙烯压力不变, 升高丙烯酰胺浓度, 极性单体插入率升高, 共聚物产率 降低.

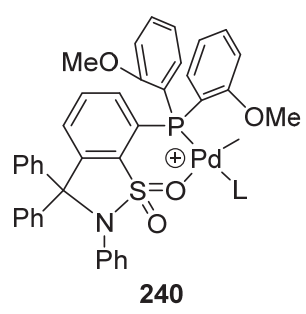

膦磺酸型催化剂通常得到高度线型极性共聚物, 而 Ziegler-Natta 或茂金属催化剂可以通过乙烯一低级 $\alpha$-烯 烃共聚得到具有短支链结构的聚乙烯, 后过渡金属催化 一锅法串联反应仅使用乙烯和极性单体便可得到带有 短烷基支链结构且极性基团嵌入主链的乙烯极性共聚 物 ${ }^{[154]}$. 首先使用阳离子膦-磺内酰胺 $\mathrm{Pd}$ 催化剂 240 进行 乙烯齐聚, 再用 204 或 239 进行极性共聚. 一次性加入 240 和 204, 缺电子乙烯基单体(如丙烯酸甲酯)共聚支链 全部为乙基结构, 支化度为 13 , 极性基团插入率为

$8.2 \%$; 先加入 240 反应完成后再加入 204 , 共聚物支链 也全部为乙基结构, 支化度为 22 , 极性基团插入率为 5.4\%. 使用 $N$-异丙基丙烯酰胺、甲基乙烯砜和丙烯腈为 共聚单体, 催化活性和极性基团插入率均明显降低. 富 电子乙烯基单体(如乙烯基乙醚和醋酸乙烯酯)极性基团 插入率非常低 $(0.2 \%)$. 乙烯-烯丙基溴共聚仅可以在 $\mathbf{2 4 0}$ 和 239 催化时发生，插入率仅有 $0.8 \%$. 所有共聚物分子 量均不高(1100 2900).

\section{2 取代芳基-苯基膦 $\mathrm{Pd}$ 催化剂}

取代芳基-苯基膦 Pd 催化剂(如 241) 可有效催化乙 烯与极性降冰片烯单体或阻隔型极性单体共聚. 陈昶乐 等 ${ }^{[67]}$ 使用 $\mathrm{Pd}$ 催化剂 241 成功催化了乙烯与氰基降冰片 烯、醋酸降冰片烯酯和 $N$-苯基马来酰亚胺的分别共聚, 共聚物分子量分别为 $1.49 \times 10^{4} 、 9.12 \times 10^{4}$ 和 $1.1 \times 10^{5}$, 其中醋酸降冰片烯酯可同时保持 $14.3 \%$ 的极性基团插入 率. 随后他们使用 241 催化乙烯与一系列阻隔型极性单 体(如十一烯酸甲酯、十一烯酸、十一烯醇和烯己基氯) 共聚 ${ }^{[65]}$, 形成类似线型低密度聚乙烯(LLDPE) 的共聚 物。催化活性较高 $\left(10^{5}\right)$, 极性基团插入率高 $(1.9 \%$ $10.7 \%)$, 共聚物分子量较高 $\left(3.8 \times 10^{4} \sim 19.4 \times 10^{4}\right)$.

通过催化剂配体结构优化, 简单工业化大宗单体也 可与乙烯共聚得到高分子量共聚物. 保持膦端一个苯基 不变, 在另一配体苯环中引入边臂基团, 242 245 可催 化乙烯一丙烯酸甲酯共聚 ${ }^{155]} .243$ 和 244 具有更高活性和 分子量, 可在保持高分子量(分别为 $2.16 \times 10^{4}$ 和 $8.25 \times$ $10^{4}$ ) 同时维持较高的极性基团插入率(15.2\%和 6.1\%). 这是较少的同时具备高分子量和高插入率的体系之一. 242 244 得到的共聚物极性基团嵌入主链, 但 245 得到 的共聚物中有 $30 \%$ 极性基团位于链终止端，说明 245 易 发生链转移. 244 催化乙烯一烯丙基腈和乙烯一醋酸烯丙 酯共聚时, 催化活性和插入率相对较低, 类似结构的 $\mathrm{Ni}$ 催化剂不能催化极性共聚.

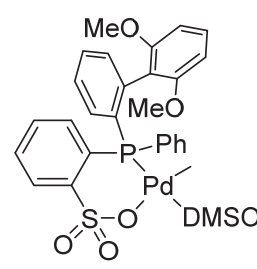

241
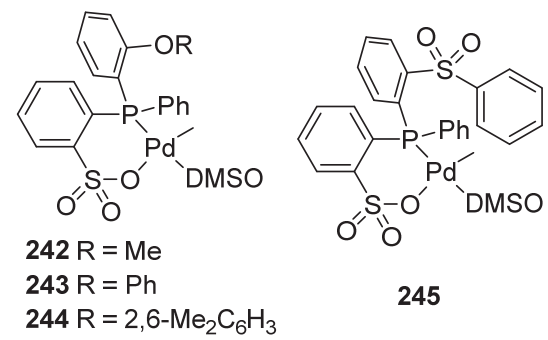

在膦端一个苯环上引入杂环取代基, 也可调控共聚 性能和共聚物性能. 含呋喃和苯并呋喃的催化剂 246 和 247 催化乙烯与丙烯酸甲酯、丙烯酸丁酯、己烯基氯、 十一烯醇和十一烯酸分别共聚 ${ }^{[156]}$, 极性基团插入率为 $3 \% \sim 9 \%$, 催化活性为 $1.5 \times 10^{4} \sim 8 \times 10^{4}$, 共聚物分子量 
为 $5000 \sim 14400$; 极性基团嵌入主链的共聚物为半结晶 态, 熔点为 $86 \sim 112{ }^{\circ} \mathrm{C}$. 含咔唑的催化剂 248 催化乙烯 与丙烯酸甲酯和丙烯酸共聚分别得到高度线型(支化度 3 )和低支化度(支化度 32)共聚物 ${ }^{[157]}$, 活性约为 $4 \times 10^{4}$, 共聚物分子量为 $4.2 \times 10^{4} \sim 4.5 \times 10^{4}$, 极性基团插入率 最高分别为 $9.3 \%$ 和 $6.3 \% ; 248$ 催化有阻隔型烯已基氯、 十一烯酸和十一烯醇共聚活性明显升高; 以路易斯酸 $\mathrm{B}\left(\mathrm{C}_{6} \mathrm{H}_{5}\right)_{3}$ 为助催化剂, 乙烯一烯己基氯共聚活性进一步 提高到 $1.55 \times 10^{5}$, 极性基团插入率从 $1.1 \%$ 升高到 $2.5 \%$; 类似的 $\mathrm{Ni}$ 催化剂 249 可催化乙烯分别与十一烯酸甲酯 和烯已基氯共聚，但活性大幅降低。

膦端含苯磺酸取代基的非对称膦阴离子 Pd 催化剂 250 在 $80 \sim 100{ }^{\circ} \mathrm{C}$ 时, 催化乙烯与丙烯酸甲酯、丙烯腈 和醋酸乙烯酯等大宗工业单体分别共聚 ${ }^{[158]}$, 受限于催 化剂的多聚结构, 乙烯一丙烯酸甲酯共聚得到双峰分布 的共聚物, 其中包含高分子量聚乙烯; 乙烯一丙烯腈则 显示较好的单活性中心共聚性能(分子量分布 1.7), 极性 基团插入率为 $4.5 \%$; 乙烯-醋酸乙烯酯的共聚反应则没 有发生，聚合物全部为高分子量聚乙烯.
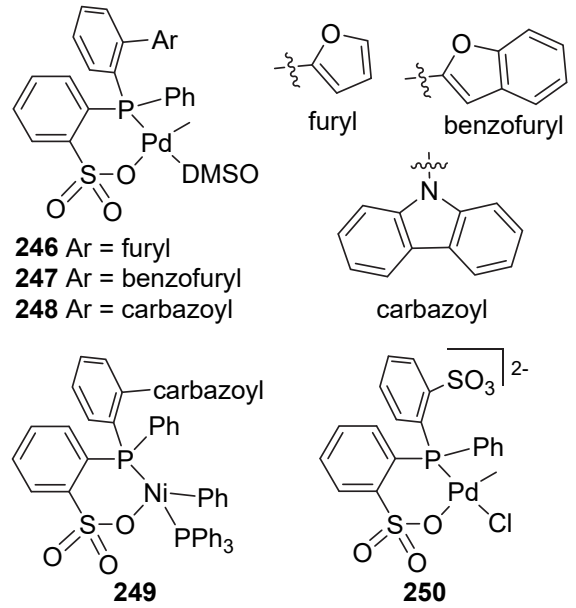

\section{3 双杂芳基膦 $P d$ 催化剂}

膦端配体中的杂原子可能会与金属中心产生弱的 相互作用, 进而影响聚合反应. Mecking 等 ${ }^{[130]}$ 把膦端取 代基全部设计为杂环取代基, 251 254 催化乙烯-丙烯 酸甲酯共聚生成极性基团嵌入链中的高度线型共聚物。 与典型催化剂相比, 所有杂环催化剂活性和极性基团插<smiles>[R]P1([R])(C)OS(=O)(=O)c2ccccc21</smiles>

$251 \mathrm{R}=\mathrm{a}, \mathrm{L}=\mathrm{Py}$ $252 \mathrm{R}=\mathrm{b}, \mathrm{L}=\mathrm{Py}$ $253 \mathrm{R}=\mathrm{c}, \mathrm{L}=\mathrm{Py}$ $254 \mathrm{R}=\mathrm{d}, \mathrm{L}=\mathrm{Py}$ $255 \mathrm{R}=\mathrm{a}, \mathrm{L}=\mathrm{DMSO}$

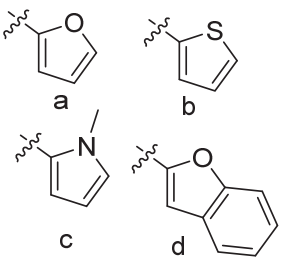

入率均偏低. 各种杂原子基团和辅助配体对极性基团的 插入率影响较小; 辅助配体对催化活性影响较大, 吡啶 为辅助配体时, 乙烯 TOF 为 $204 \sim 507$, 以弱连接的 DMSO 为辅助配体乙烯 TOF 提升约 5 倍.

\section{4 含烷基膦 $\mathrm{Pd}$ 催化剂}

2013 年, Mecking 等 ${ }^{[159]}$ 使用膦端含烷基取代基的催 化剂 256、257 和 239, 首次实现了后过渡金属催化乙 烯一氯乙烯配位共聚，极性基团插入率非常低 $(0.03 \%$ $0.1 \%)$. 他们还尝试将催化剂负载在聚苯乙烯上，非均 相催化剂 258 260 催化乙烯-丙烯酸甲酯共聚 $[160]$, 所 得高度线型结构共聚物分子量不高 $\left(3 \times 10^{3}\right)$, 可能由于 258 膦端叔丁基体积影响导致极性基团插入率降低, 与 259 催化 $(2.2 \% \sim 2.7 \%)$ 相比极性单体插入率仅为 $0.2 \%$ $0.8 \%$.

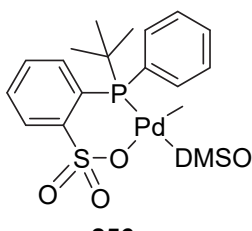

256
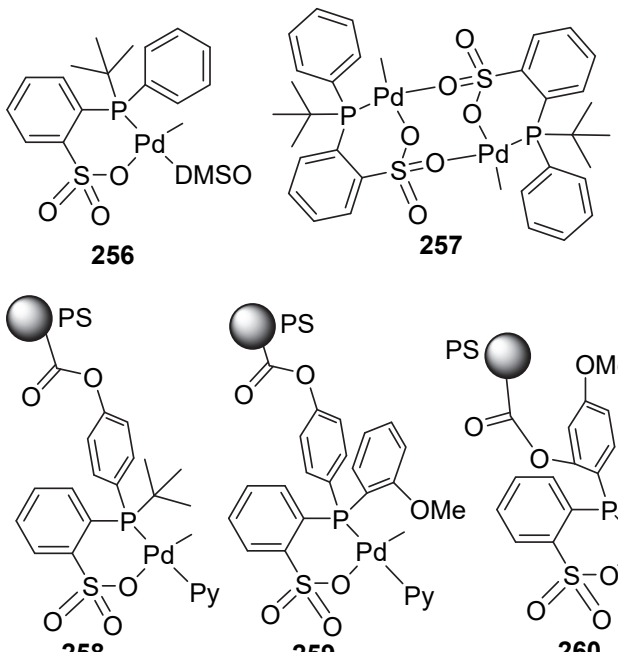

258
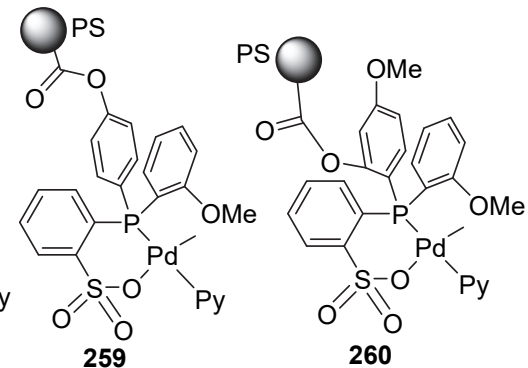

一般需要降低乙烯压力以获得较高丙烯酸甲酯插 入率, Claverie 等 ${ }^{[131]}$ 采用膦端叔丁基和苯基结合的方式, 以 2,6-二甲基吡啶为辅助配体，在不降低乙烯压力 $(0.7$ $\mathrm{MPa}$ )时, 261 催化乙烯一丙烯酸甲酯共聚拥有较高的极 性基团插入率 $(28 \%)$ 和较高的催化活性 $\left(5 \times 10^{4}\right)$, 同时还 拥有较高的共聚物分子量 $\left(1.2 \times 10^{4}\right)$. 值得注意的是, 与 Mecking 等 ${ }^{[136]}$ 的同等插入率(30\%)结果相比, Claverie 等 获得的共聚物分子量更高. 膦端引入双叔丁基的 262 催 化共聚可能由于较大的位阻影响极性单体的插入, 导致 共聚物分子量和极性基团插入率均远小于 261 .

Nozaki 等 ${ }^{[161]}$ 采用双环已基膦磺酸 Pd 催化剂 263 催 化乙烯-烯丙基极性单体共聚，80 ${ }^{\circ} \mathrm{C}$ 和稍高的乙烯压力 (1.5 5 MPa)条件下, 醋酸烯丙基酯、烯丙醇、烯丙基氯 和烯丙基澳均可参与共聚, 形成链中嵌入极性基团的高 度线型共聚物，插入率为 $1.1 \% \sim 7.9 \%$, 共聚活性普遍较 低.

膦磺酸型催化剂催化极性共聚分子量偏低, Nozaki 
等 ${ }^{162]}$ 利用 Sterimol B5 参数量化空间效应系统研究了双 烷基膦磺酸 Pd 催化剂空间效应与共聚物分子量的关系. 在 $80 \sim 100{ }^{\circ} \mathrm{C}$ 和 1 3 MPa 乙烯压力下, 262 267 催化 乙烯与丙烯腈、丙烯酸乙酯、烯丙基氯、乙烯基叔丁基 醚、醋酸乙烯酯和醋酸烯丙酯等乙烯基和烯丙基单体分 别共聚, 共聚物分子量较典型催化体系高. Sterimol B5 值最高即轴向位阻最大的带有双薄荷基催化剂 267 催化 乙烯-醋酸烯丙酯共聚分子量最高 $\left(1.77 \times 10^{5}\right)$, 但是极 性基团插入率非常低( $0.6 \%)$. 增大金属中心空间位阻不 完全有利于单体插入, 共聚物分子量和极性基团插入率 之间存在平衡和矛盾的关系. 丙烯与丙烯酸甲酯、烯丙 基氯、烯丙腈和醋酸烯丙酯的共聚可在带有双薄荷基且 磺酸邻位存在三甲基硅基的 268 催化下进行 ${ }^{[163] ;} 50{ }^{\circ} \mathrm{C}$ 时, 催化活性为 $200 \sim 830$, 极性基团嵌入主链, 插入率 为 $1.3 \% \sim 3.3 \%$, 共聚物分子量为 $2.9 \times 10^{3} \sim 1.1 \times 10^{4}$; 结晶全同立构共聚物中存在 $1 \%$ 的 $1,2 / 2,1$ 定向结构缺陷; 除丙烯酸甲酯以 2,1 形式插入外, 其他单体以 1,2 形式插 入.

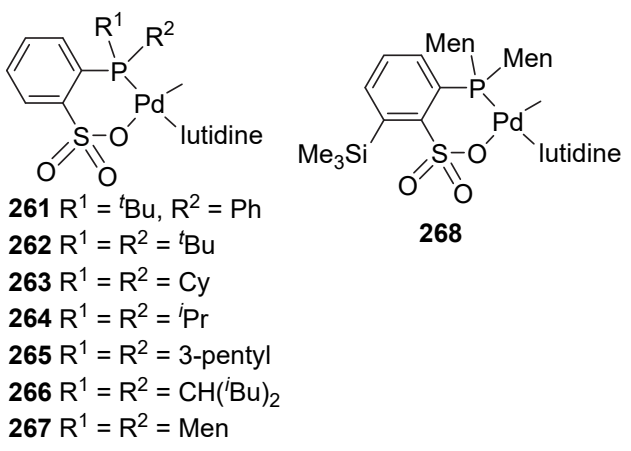

最近，简忠保等 ${ }^{[164]}$ 结合薄荷基和大体积芳基或联 芳基设计制备的 $\mathrm{Pd}$ 催化剂 $\mathbf{2 6 9} \sim \mathbf{2 7 2}$, 在 $90{ }^{\circ} \mathrm{C}$ 和 0.14 $\mathrm{MPa}$ 乙烯压力时, 催化乙烯一丙烯酸甲酯共聚形成高度 线型共聚物. 具有薄荷基及 2,4,6-三甲氧基苯取代基的 272 同时具有最高的产率、催化活性 $\left(3.48 \times 10^{5}\right)$ 、极性 基团插入率 $(1.1 \%)$ 和共聚物分子量 $\left(7.5 \times 10^{4}\right)$; 降低乙烯 压力并增大极性单体浓度, 极性基团插入率最高可达 5.7\%. 272 催化乙烯-丙烯酸丁酯、丙烯酸、 $N$-异丙基丙 烯酰胺、乙烯基丁基醚和丙烯腈共聚的催化性能降低, 极性基团插入率一般小于 $1 \%$.
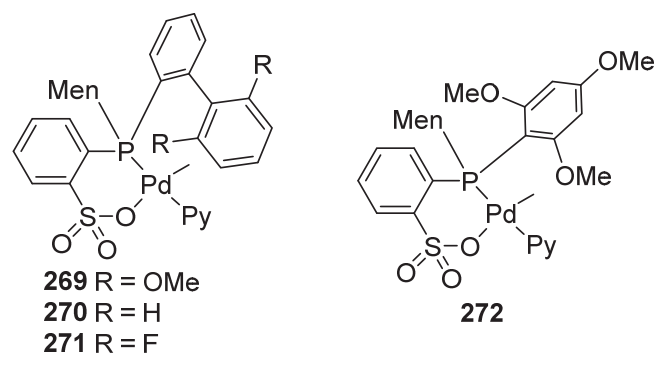

272

\section{$5.5 P d$ 催化剂骨架调整}

在典型膦磺酸型催化剂中, 电子不对称配位点通过 苯环或取代苯环骨架连接. 新型催化剂骨架则引入了其 他共轭骨架(如荎)或非共轭骨架(如环戊基), 并改变了 电子不对称配位点与骨架的连接方式. 与典型催化剂相 比, 新型骨架催化剂催化极性共聚通常会降低的催化活 性和共聚物分子量.

陈昶乐等 ${ }^{[165]}$ 将苯基骨架拓展为萗基, 273 和 274 在 $85{ }^{\circ} \mathrm{C}$ 和 $0.5 \sim 0.9 \mathrm{MPa}$ 乙烯压力时, 催化乙烯一丙烯酸甲 酯共聚活性均低于典型催化剂 204, 但极性基团插入率 高于 204; 273 和 274 催化共聚极性基团插入率分别为 $17 \% \sim 40 \%$ 和 7\% 31\%; 273 得到的共聚物分子量高于 204 (3600 6900), 而 274 得到的共聚物分子量则低于 204 (2800 3900). 改变萗基上 $\mathrm{P}$ 和 $\mathrm{S}$ 的连接位置, 275 277 催化乙烯一丙烯酸甲酯共聚[166], 极性基团插入率 (3\% 27\%)、共聚物分子量(1000 5500)和催化活性 $\left(1 \times 10^{4} \sim 4.7 \times 10^{4}\right)$ 按 275、276 和 277 的顺序升高. 陈 昶乐等[167]还尝试将配位环从六元环扩大为七元环, 但 是大环打破了催化剂的刚性结构, 278 和 279 在催化乙 烯一丙烯酸甲酯共聚时, 共聚活性、产率、极性基团插入 率和共聚物分子量均低于典型催化剂 204.
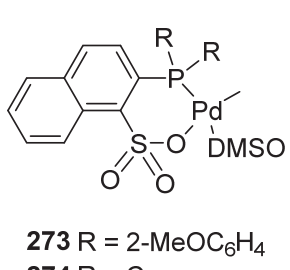
$274 \mathrm{R}=\mathrm{Cy}$
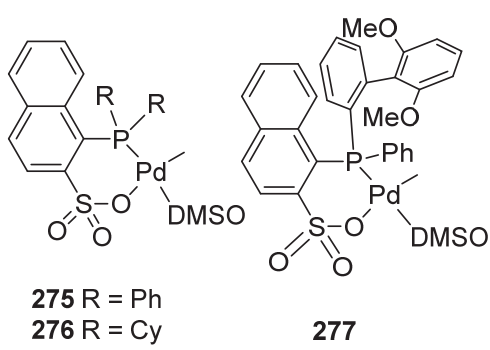

277
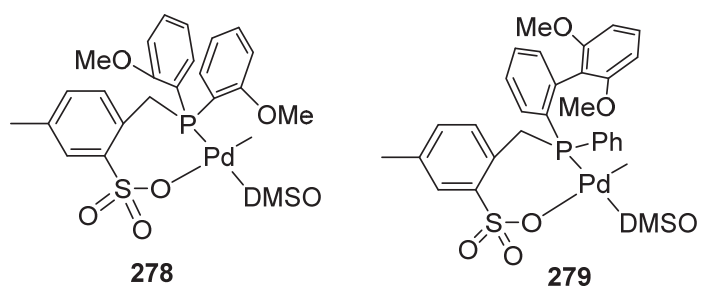

Jordan 等 ${ }^{[168]}$ 将苯基骨架改变为非共轭环戊基, 280 和 281 催化乙烯一丙烯酸甲酯共聚形成线型共聚物, 极 性基团插入率为 $11.7 \%$, 其中 $80 \%$ 嵌入链中, $8 \%$ 位于饱 和链端，12\%位于不饱和链端. 但是, 280 和 $\mathbf{2 8 1}$ 共聚活 性和共聚物分子量均较低. 催化乙烯-氟乙烯共聚[169]可 形成插入率 $0.41 \%$ 的线型共聚物, 其中 $80 \%$ 嵌入链中, $13 \%$ 位于链端, 其他 7\%位于 $\beta-\mathrm{F}$ 消除后极性单体 1,2 形 式插入形成的 $\mathrm{CH}_{2} \mathrm{CF}_{2} \mathrm{H}$ 结构链端. 


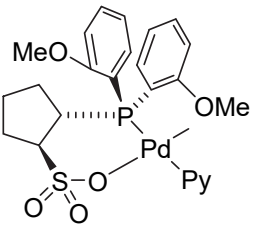

280

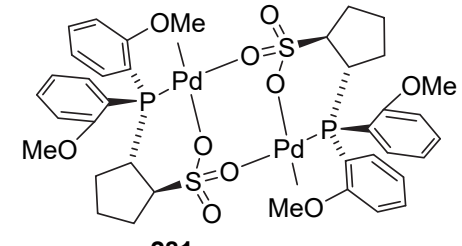

281

\section{6 膦磺酸型 $\mathrm{Ni}$ 催化剂}

$\mathrm{Ni}$ 催化剂一般热稳定性较差, 催化共聚常得到低 分子量共聚物, 且多用于烯烃与阻隔型极性单体, 特别 是多亚甲基阻隔型极性单体共聚, 较难催化烯烃与简单 工业大宗极性单体共聚. 2012 年, Nozaki 等 ${ }^{[170]}$ 首次报道 了膦磺酸型 $\mathrm{Ni}$ 催化剂催化的极性共聚反应, 其催化效 果远差于相应 Pd 催化剂. 282 284 催化乙烯分别与醋 酸烯丙基酯、烯丙基三甲基硅烷和烯丙氧基三甲基硅烷 在二氯甲烷中 $35{ }^{\circ} \mathrm{C}$ 时, 分别共聚形成高度线型低聚物, 分子量小于 1000 , 插入率较低 $(0.19 \% \sim 0.75 \%)$.

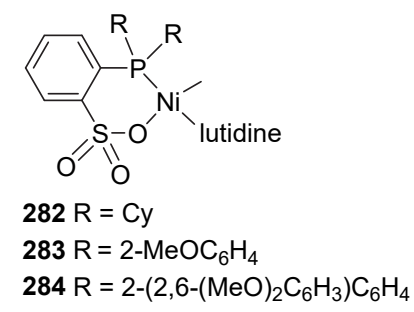

为提高 $\mathrm{Ni}$ 催化剂稳定性和催化性能, 陈昶乐等[171] 通过增加金属中心平面轴向位阻, 在磺酸端邻位引入基 团增加 $\mathrm{S}$ 空间位阻, 调节 $\mathrm{P}$ 上取代基电子效应和替换辅 助配位基团等手段, 设计了一系列膦磺酸 $\mathrm{Ni}$ 催化剂 285 289 可催化多种极性单体与乙烯共聚. 乙烯与乙 烯基三甲氧基硅烷、烯丙基三甲氧基硅烷、烯丙基正丁 基醚、烯丙基腈、极性降冰片烯以及含有长链阻隔的不 饱和氯、溴、醇和酯等在 $80{ }^{\circ} \mathrm{C}$ 和 $0.8 \mathrm{MPa}$ 乙烯压力下 分别共聚, 催化活性最高可达 $1.9 \times 10^{5}$, 极性基团插入 率为 $0.7 \% \sim 7.6 \%$, 共聚物分子量得到提升(1600 19600). 丙烯酸甲酯和乙烯基正丁基醚无法在该体系中 与乙烯共聚.

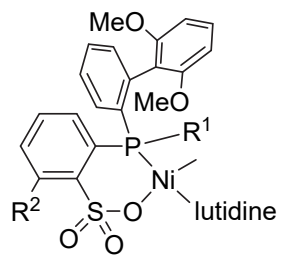

$285 \mathrm{R}^{1}=\mathrm{Ph}, \mathrm{R}^{2}=\mathrm{H}$

$286 \mathrm{R}^{1}=\mathrm{Cy}, \mathrm{R}^{2}=\mathrm{H}$

$288 R^{1}=P h, R^{2}=C_{6} F_{5}$

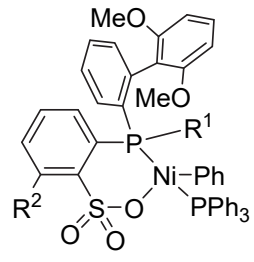

$287 \mathrm{R}^{1}={ }^{t} \mathrm{Bu}, \mathrm{R}^{2}=\mathrm{H}$

$289 \mathrm{R}^{1}=\mathrm{Ph}, \mathrm{R}^{2}=\mathrm{SiMe}_{3}$

配体电子效应可对膦磺酸型 $\mathrm{Ni}$ 催化剂极性共聚性
能产生影响. 膦端含有苯基与 2-(2',6'-二氟)联苯基的 $\mathrm{Ni}$ 催化剂 290 可催化乙烯与一系列极性降冰片烯单体的共

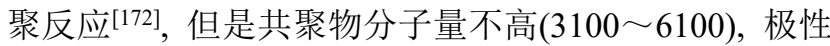
基团插入率为 $0.2 \% \sim 3.6 \%$. 膦端苯基对位含有给电子 基团 $\mathrm{NMe}_{2}$ 的 291 可催化乙烯与十一烯酸甲酯、烯己基 氯和乙烯基三甲基硅烷分别共聚 ${ }^{[173]}$, 共聚物分子量为 $4100 \sim 7800$; 聚合温度从 $80{ }^{\circ} \mathrm{C}$ 降低至 $25{ }^{\circ} \mathrm{C}$, 共聚物分 子量大幅提升 $\left(3.2 \times 10^{4} \sim 6.2 \times 10^{4}\right)$, 但极性基团插入率 同时明显降低; 带有吸电子基团 $\mathrm{CF}_{3}$ 的 292 催化乙烯十一烯酸甲酯共聚的活性和共聚物分子量较 291 低; 该 催化体系不能实现乙烯与简单工业大宗单体(如丙烯酸 甲酯、醋酸乙烯酯和乙烯基丁基醚)的共聚反应.

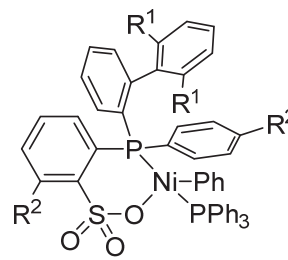

$290 R^{1}=F, R^{2}=H$ $291 R^{1}=\mathrm{OMe}, \mathrm{R}^{2}=\mathrm{NMe}_{2}$ $292 \mathrm{R}^{1}=\mathrm{OMe}, \mathrm{R}^{2}=\mathrm{CF}_{3}$

薄荷基在膦磺酸型 Pd 催化剂中是一种可有效提高 共聚物分子量的大位阻配体, 配体取代基效应在膦端含 有薄荷基以及对取代苯基或取代联苯基 $\mathrm{Ni}$ 催化剂中也 体现出影响. 简忠保等 ${ }^{[174]}$ 报道了类似的 $\mathrm{Ni}$ 催化剂 293 296, 在 $50{ }^{\circ} \mathrm{C}$ 和 $0.14 \mathrm{MPa}$ 乙烯压力条件下, 含有 给电子型甲氧基的 294 和含有吸电子性氟原子的 296 催 化乙烯-乙烯基三甲氧基硅烷共聚分别得到低支化度结 构和高度线型结构共聚物，两者极性基团插入率也存在 较大差别(分别为 $0.1 \% \sim 0.4 \%$ 和 $0.8 \% \sim 2.4 \%$ ). 该催化 体系不能催化乙烯-丙烯酸甲酯共聚，但可以催化有亚 甲基阻隔的烯丙基丁基醚、醋酸烯丙酯和烯丙基氯分别 与乙烯共聚，也可有效催化有多个亚甲基阻隔的烯己基 氯、烯己基澳和十一烯酸甲酯分别与乙烯共聚，轴向位 阻对极性单体插入的阻碍导致共聚物中极性单体插入 率较低.
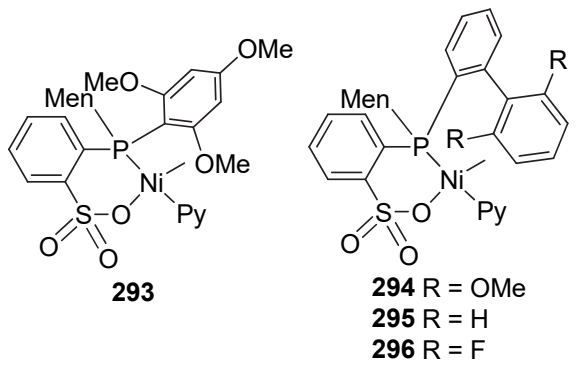

电子不对称结构膦磺酸型催化剂与 $\alpha$-二亚胺型催 
化剂相比具有很多优点, 如较好的极性基团耐受能力、 较好的催化剂热稳定性、较高的共聚反应温度 $(80 \sim$ $100{ }^{\circ} \mathrm{C}$, 接近工业应用温度)、得到的共聚物为高度线型 结构以及极性基团嵌入主链形成统计共聚物等. 研究者 们对不同催化剂结构进行了详尽研究, 拓宽了共聚极性 单体范围, 阐明了共聚反应途径. 结构优化策略以金属 中心空间位阻的调控为主, Nozaki 等使用量化方法较为 明确地展示了各种体积配体对共聚反应的影响. 大体积 联芳基配体和薄荷基配体催化剂可得到高分子量共聚 物, 但是此时极性基团插入率较低. 当极性基团插入率 升高时, 共聚物分子量急剧下降. 共聚物分子量低是膦 磺酸型催化剂应用面临的主要挑战.

\section{$6 \mathrm{~N}$-杂环卡宾型催化剂}

与膦磺酸型催化剂不对称电子结构类似, 有针对性 将强 $\sigma$-给电子体 $(\mathrm{N}$-杂环卡宾 $\mathrm{NHC}$ ) 和弱 $\sigma$-给电子体 $(\mathrm{O})$ 结合形成电子不对称结构以抑制 $\beta-\mathrm{H}$ 消除; 在 $\mathrm{NHC}$ 配 体 $\mathrm{N}$ 上引入大体积取代基造成拥挤空间以促进极性单 体 1,2 形式插入; 选用刚性 NHC 骨架使 NHC 平面与金 属中心共平面, 金属氢化物与 $\mathrm{NHC}$ 空 $\mathrm{p}$ 轨道重叠最小, 抑制由于金属氢化物进攻卡宾空 $\mathrm{p}$ 轨道造成的不可逆还 原消除形成咪唑盐而导致的 NHC 催化剂失活. 由此, Nozaki 等首次设计并实现了 NHC 型 Pd 催化剂 297 299 催化的乙烯/丙烯与乙烯基极性单体和烯丙基型极性单 体的共聚反应, 并在此后对这类催化剂结构调变和催化 性能进行了拓展研究.
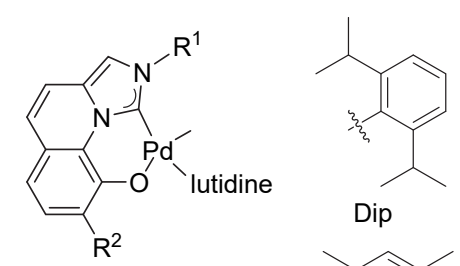

$297 \mathrm{R}^{1}=\operatorname{Dip}, \mathrm{R}^{2}=\mathrm{H}$ $298 R^{1}=$ Mes, $R^{2}=H$ $299 R^{1}=$ Dip, $R^{2}=$ Mes

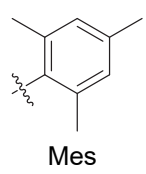

乙烯极性共聚反应中, 乙烯基单体形成线型共聚 物, 烯丙基单体主要以 1,2 形式插入, 而烯丁基单体无 共聚发生. 丙烯极性共聚反应中, 极性单体大多以 1,2 形式插入, 但共聚物立构规整性较差. NHC 型 Pd 催化剂 具有较好的稳定性, 共聚反应在 $100{ }^{\circ} \mathrm{C}$ 时进行. 丙烯分 别与醋酸烯丙酯、三甲基乙酸烯丙酯和丙烯酸甲酯共 聚[175], 催化剂活性不高(1000), 极性基团插入率分别为 $2 \% 、 1.2 \%$ 和 $1.5 \%$.

随后, Nozaki 等 ${ }^{[176]}$ 在 $\mathrm{NHC}$ 的 $\mathrm{N}$ 原子上引入更大空 间体积取代基设计制备了 $\mathrm{Ni}$ 催化剂 300 302, 期望得
到高分子量共聚物. 添加 $\mathrm{Ni}(\mathrm{COD})_{2}$, 乙烯一醋酸烯丙酯 在 $3 \mathrm{MPa}$ 乙烯压力和 $60{ }^{\circ} \mathrm{C}$ 时共聚, 具有大位阻的 $\mathbf{3 0 2}$ 可以得到更高的共聚物分子量(8500), 但是极性基团插 入率却从 $0.83 \%$ 降低到 $0.2 \% .300$ 催化乙烯-二烯丙基醚 和乙烯一乙烯基乙醚共聚得到共聚物分子量分别为 2800 和 1200 , 极性基团插入率为 $1.9 \%$ 和 $0.68 \%, 302$ 催化时 则得到更高分子量(14000 和 10000)和更低极性基团插 入率 $(0.98 \%$ 和 $0.39 \%)$. 丙烯酸甲酯和丙烯腈不能在该体 系中实现共聚.

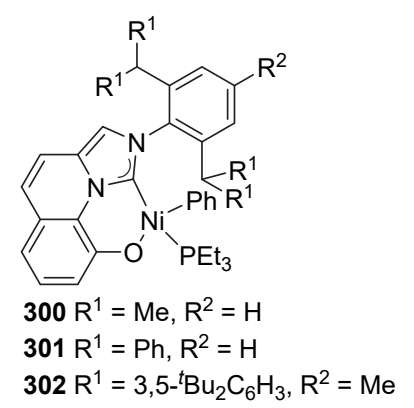

在[C,O]型催化剂骨架基础上, Nozaki 等还对 NHC 型催化剂骨架进行调整. 将 NHC 与氧化膦骨架进行结 合, 303 在 $30{ }^{\circ} \mathrm{C}$ 和 $3 \mathrm{MPa}$ 乙烯压力时, 催化乙烯与醋酸 烯丙酯、丙烯酸甲酯和烯丙基氯分别共聚 ${ }^{[177]}$, 插入率分 别为 $0.58 \% 、 0.61 \%$ 和 $0.47 \%$, 共聚物分子量为 4800 9400 ; 醋酸乙烯酯不能在该体系中与乙烯共聚。含 NHC-磺酰胺骨架的 304 在 $80{ }^{\circ} \mathrm{C}$ 和 $4 \mathrm{MPa}$ 乙烯压力加并 入 BHT 时, 催化乙烯一丙烯酸甲酯共聚[178], 共聚活性仅 为 2800 , 分子量仅为 350 , 极性基团插入率为 $2.8 \%$.
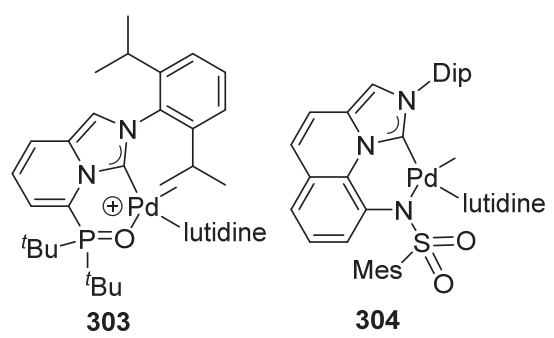

甲基丙烯酸甲酯的插入活性比乙烯和丙烯酸甲酯 低, 极性共聚较为困难. 很多共聚研究都以失败告终, 有些研究得不到共聚物, 有些则得到嵌段共聚物或烯烃 均聚物, 在机理研究中也很难清楚地描述其共聚过程属 于自由基聚合、离子聚合还是配位聚合. Nozaki 等 ${ }^{[143]}$ 于 2018 年首次实现了乙烯与甲基丙烯酸甲酯、醋酸甲 基烯丁基酯和甲基烯丙基苯基醚分别配位共聚得到统 计共聚物. 在 $120{ }^{\circ} \mathrm{C}$ 和 $1 \sim 2 \mathrm{MPa}$ 乙烯压力条件下, 加入 自由基抑制剂 BHT, 使用 NHC 型 Pd 催化剂 297 催化反 应, 共聚物分子量为 $800 \sim 27000$, 共聚物中没有连续极 
性单体插入单元, 极大部分极性单体位于链中. 极性单 体以 1,2 形式插入，最高极性基团插入率分别为 $2.5 \%$ 、 $0.23 \%$ 和 $0.41 \%$.

Nozaki 等根据电子不对称结构设计的全新 N-杂环 卡宾型催化剂与膦磺酸钯型催化剂同样具有较好的热 稳定性, 共聚反应温度一般较高 $\left(60 \sim 120{ }^{\circ} \mathrm{C}\right)$. 尽管可 实现乙烯/丙烯与一系列极性单体直接共聚, 也可通过 增大金属中心空间位阻提升共聚物分子量，但与其他类 型催化剂相比, $\mathrm{N}$-杂环卡宾型催化剂整体催化活性和共 聚物分子量均偏低, 特别是催化简单大宗工业单体参与 共聚时，分子量甚至小于 1000 .

\section{7 膦-氧化膦型催化剂及新型骨架催化剂}

典型膦磺酸型催化剂可以通过增加膦配体上取代 基团的空间位阻抑制链转移，进而提高共聚物分子量. 但是, 大体积取代基催化剂会增加极性单体插入能垒, 导致共聚物分子量和极性单体插入率之间的固有矛盾 关系. 膦磺酸型催化剂中磺酸端结构调变可能性较少, 如何通过单纯调节膦端取代基来解决这个先天存在的 问题答案并不明朗. 引入更多可调控位点, Nozaki 等发 展的新型膦-膦型催化剂体系得到了较多关注, 而陈永 乐等通过理性催化剂设计发展了许多新颖结构的催化 体系, 这些都为解决这一难题提供了新的途径.

\section{1 膦-氧化膦型催化剂}

符合电子不对称性要求的催化剂也可能催化极性 共聚, 形成高度线型的无规共聚物 ${ }^{[179]}$. 为了充分利用 与金属配位的氧原子周围的可调变性, Carrow 和 Nozaki ${ }^{[24]} 2012$ 年首次报道了膦-氧化膦骨架阳离子 $\operatorname{Pd}$ 催化剂 305 和 306 催化的乙烯分别与乙烯基单体醋酸 乙烯酯、醋酸烯丙基酯、烯丙氯、丙烯腈和乙烯基丁基 醚的共聚反应, 催化剂活性最高为 7600 , 极性单体插入 率为 $1 \% \sim 4 \%$, 得到的共聚物为高度线型结构.

膦-氧化膦型催化剂与其他类型催化剂相比有很多 独特性能. 305 和 306 催化的乙烯一烯丙基氯共聚, 在插 入率和膦磺酸型催化剂类似的情况下, 共聚物分子量较 膦磺酸型催化剂有约 2 倍提升. 305 和 306 催化乙烯一丙 烯腈共聚，丙烯腈插入率为 $2 \% \sim 2.5 \%$, 极性基团嵌入 链中、链起始端和链终端, 链终端同时具有烯基和丙烯 腈基团, 而膦磺酸型催化剂得到的链终端全部是极性基 团 ${ }^{[127]}$.

需要注意的是, 305 和 306 在高极性单体浓度(体积 分数为 $50 \%$ ) 反应体系中不能有效催化乙烯-丙烯酸甲酯 共聚, 当极性单体浓度降低至体积分数为 $20 \%$ 才展示出 较低的催化活性(分别为 200 和 100) ${ }^{[180]}$, 于是 Nozaki 等 ${ }^{[80}$ 制备了一系列带有不同氧化膦端空间效应和膦端

电子效应的 307 316 进一步研究不同催化剂对乙烯-丙 烯酸甲酯共聚反应的影响，其中膦端带有二苯基取代基 的 307 由于快速链转移不显示催化活性, 膦端带有给电 子甲氧基的 308 和 313 相比吸电子三氟甲基的 309 和 314 得到更高分子量和极性基团插入率的共聚物，但催 化活性低于后者. 氧化膦端位阻依次减小, 314、315 和 316 催化活性依次升高(最高 $5.4 \times 10^{5}$ ), 但共聚物分子量 从 $1.7 \times 10^{4}$ 下降到 $6.9 \times 10^{3}$. 极性基团插入率为 $0.5 \%$ 3.4\%. 使用 308、314 和 316 催化乙烯-醋酸烯丙基酯共 聚，极性基团插入率和共聚物分子量接近，但 316 共聚 产率是 314 的 5 倍, 是 308 的 9 倍. 此外, 308 还可催化 乙烯-乙烯叔丁基醚和乙烯一丙烯腈共聚, 314 和 316 则 不显示催化活性.

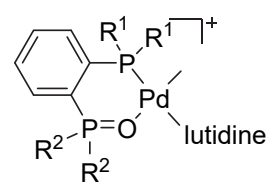

$305 \mathrm{R}^{1}={ }^{i} \mathrm{Pr}, \mathrm{R}^{2}={ }^{t} \mathrm{Bu}$

$307 \mathrm{R}^{1}=\mathrm{Ph}, \mathrm{R}^{2}={ }^{t} \mathrm{Bu}$

$308 \mathrm{R}^{1}=2-\mathrm{MeOC}_{6} \mathrm{H}_{4}, \mathrm{R}^{2}={ }^{t} \mathrm{Bu}$

$309 \mathrm{R}^{1}=2-\mathrm{CF}_{3} \mathrm{C}_{6} \mathrm{H}_{4}, \mathrm{R}^{2}={ }^{t} \mathrm{Bu}$

$310 \mathrm{R}^{1}=2-\mathrm{CF}_{3} \mathrm{C}_{6} \mathrm{H}_{4}, \mathrm{R}^{2}={ }^{i} \mathrm{Pr}$

$311 \mathrm{R}^{1}=2-\mathrm{CF}_{3} \mathrm{C}_{6} \mathrm{H}_{4}, \mathrm{R}^{2}=\mathrm{Me}$

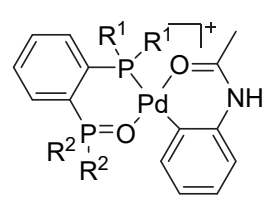

$306 \mathrm{R}^{1}={ }^{i} \mathrm{Pr}, \mathrm{R}^{2}={ }^{t} \mathrm{Bu}$ $312 \mathrm{R}^{1}=\mathrm{Ph}, \mathrm{R}^{2}={ }^{t} \mathrm{Bu}$

$313 \mathrm{R}^{1}=2-\mathrm{MeOC}_{6} \mathrm{H}_{4}, \mathrm{R}^{2}={ }^{t} \mathrm{Bu}$

$314 \mathrm{R}^{1}=2-\mathrm{CF}_{3} \mathrm{C}_{6} \mathrm{H}_{4}, \mathrm{R}^{2}={ }^{t} \mathrm{Bu}$ $315 \mathrm{R}^{1}=2-\mathrm{CF}_{3} \mathrm{C}_{6} \mathrm{H}_{4}, \mathrm{R}^{2}={ }^{i} \mathrm{Pr}$ $316 \mathrm{R}^{1}=2-\mathrm{CF}_{3} \mathrm{C}_{6} \mathrm{H}_{4}, \mathrm{R}^{2}=\mathrm{Me}$

与膦磺酸型催化剂相比, 氧化膦端的存在使得催化 剂结构调控手段更加丰富, 多种取代基被引入氧化膦端 以考察其对共聚性能的影响[181].

在氧化膦端引入双乙氧基 ${ }^{[182]}, 317$ 有利于抑制丙烯 酸甲酯插入后的链转移而有利于链增长，极性基团插入 率为 $1.5 \%$, 其中链中和链端极性基团比例为 $95: 5.318$ 在丙烯酸甲酯插入后以接近的可能性发生链增长和链 转移, 极性基团插入率达 $2.6 \%$, 链中和链端极性基团比 例为 $60: 40$. 与典型催化剂相比, 317 和 318 催化活性得 到提高 (分别为 $5.8 \times 10^{4}$ 和 $1.5 \times 10^{5}$ ), 但共聚物分子量 偏低(分别为 1500 和 770). 乙烯一丙烯酸共聚也可实现, 共聚物分子量较低( $700 \sim 1450)$.

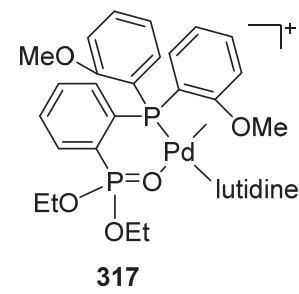

317

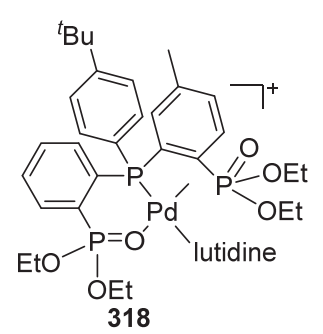

在氧化膦端引入给电子性单胺基 ${ }^{[183]}$, 膦端芳基取 代的 Pd 催化剂 319 可催化乙烯-丙烯酸甲酯、乙烯基丁 基醚和醋酸丙烯酯共聚; 乙烯-丙烯酸甲酯共聚物分子 
量约 $10^{4}$, 最高可得到 $33 \%$ 的极性基团插入率; 膦端烷 基取代的 320 催化反应极性基团插入率和共聚物分子量 均约为 319 的 $1 / 3$. 相似结构的 $\mathrm{Ni}$ 催化剂 321 323 只能 催化乙烯与多阻隔型极性单体(如十一烯酸甲酯、烯己 基氯和醋酸烯己基酯)的共聚 [184]; 随着膦端取代基位阻 增大，催化活性、分子量、插入率和熔点同时升高, 323 催化共聚极性基团插入率 $0.6 \% \sim 2.6 \%$, 共聚物分子量 不高(1200～5100), 催化乙烯一烯已基氯共聚活性最高 $\left(1.5 \times 10^{5}\right)$.
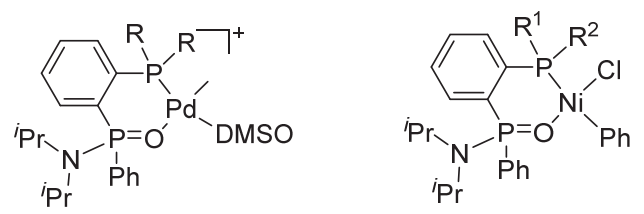

$$
\begin{array}{ll}
319 \mathrm{R}=2-\mathrm{MeOC}_{6} \mathrm{H}_{4} & 321 \mathrm{R}^{1}=\mathrm{Ph}, \mathrm{R}^{2}=\mathrm{Ph} \\
320 \mathrm{R}=\mathrm{Cy} & 322 \mathrm{R}^{1}=\mathrm{Cy}, \mathrm{R}^{2}=\mathrm{Cy} \\
& \left.323 \mathrm{R}^{1}=\mathrm{Ph}, \mathrm{R}^{2}=2-\left(2,6-(\mathrm{MeO})_{2}\right) \mathrm{C}_{6} \mathrm{H}_{3}\right) \mathrm{C}_{6} \mathrm{H}_{4}
\end{array}
$$

在氧化膦端引入强给电子性双胺基, 324 和 325 催 化乙烯一丙烯酸甲酯等简单工业大宗极性单体共聚 ${ }^{[13]}$, 在 $3 \mathrm{MPa}$ 乙烯压力和 $90{ }^{\circ} \mathrm{C}$ 时, 形成高度线型的统计共 聚物(支化度小于 6 ), 分子量得到提升. 共聚反应中没有 发生来自休眠态的 $\beta-\mathrm{H}$ 消除和链转移, 新链启动时, 丙 烯酸甲酯插入 $\mathrm{Pd}-\mathrm{H}$ 键，94\%极性基团位于链中，6\%位 于饱和链端, 在不饱和链端和支链链端无极性基团存 在. 丙烯酸丁酯、丙烯酸异冰片酯、丙烯酸和乙烯基丁 基醚都可以实现共聚. 235 催化乙烯一丙烯酸丁酯共聚所 得共聚物分子量为 $2.2 \times 10^{5}$, 此时极性基团插入率为 $0.7 \%$; 当升高丙烯酸丁酯浓度可将插入率提高至 $9.6 \%$, 此时共聚物分子量虽然降低但仍然保持 $6.2 \times 10^{4}$.

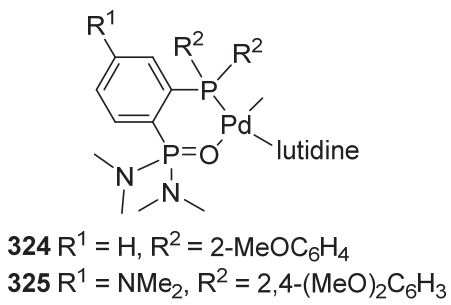

除氧化膦端取代基结构调控外，Jian 等通过一系列 骨架调整策略, 如变换电子不对称端连接骨架和连接点 位, 研究了膦-氧化膦型催化剂的极性共聚行为.

将苯基骨架调整为苯并噻吩骨架, 2,3-连接的 326 328 催化乙烯一丙烯酸甲酯共聚[185]得到高度线型结构共 聚物, 催化效果优于类似结构的膦磺酸骨架 Pd 催化剂; 带有大体积联芳基的 328 具有较高的催化活性 $\left(4.28 \times 10^{5}\right)$ 和较高共聚物分子量 $\left(3.27 \times 10^{4}\right)$, 极性基团 插入率仅为 $0.1 \% \sim 0.9 \%$. 互换膦-氧化膦与苯并噻吩连

接位点, 3,2-连接的 330 332 也可得到高度线型共聚物, 但催化活性和共聚物分子量降低 ${ }^{[186]}$.

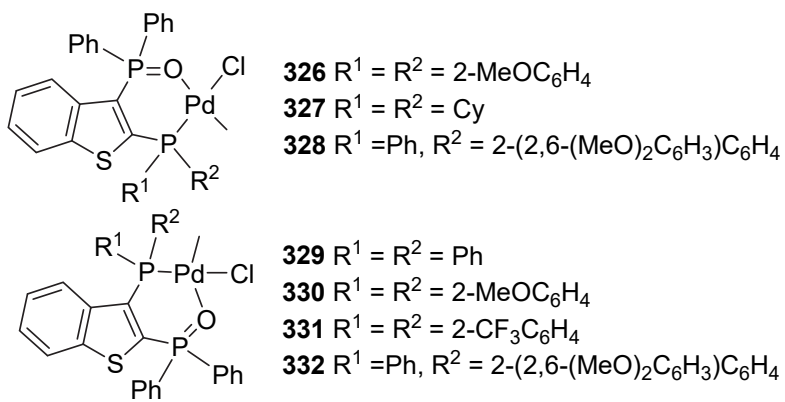

苯并噻吩骨架的催化剂 326、330 和 333 336 催化 极性共聚 ${ }^{[187]}$, 氧化膦端双烷氧基结构 2,3-连接的 333 得 到低分子量共聚物，双胺基结构 3,2-连接的 336 则得到 最高分子量共聚物. 336 催化乙烯与丙烯酸甲酯和丙烯 酸分别共聚, 分子量分别可达 $3.24 \times 10^{5}$ 和 5300 . 此外, 336 还可以催化乙烯与乙烯基丁基醚、醋酸乙烯酯、丙 烯腈、醋酸烯丙酯、烯丙基氯和烯己基氯分别共聚，全 部得到高度线型结构共聚物.
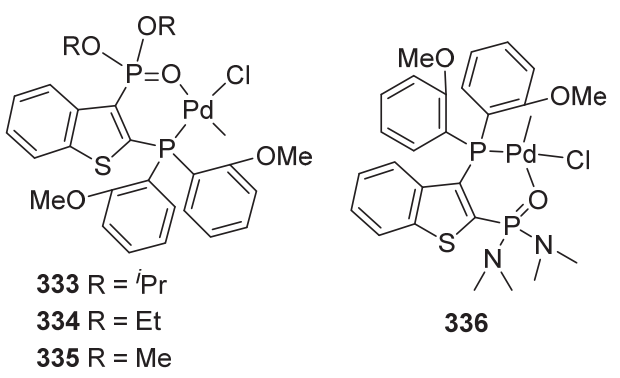

简忠保等 ${ }^{[188]}$ 最近设计制备了吲哚骨架配合物 337 339, 在极性共聚反应中, 337 几乎不显示催化活 性, 338 和 339 可催化乙烯与丙烯酸甲酯和丙烯酸丁酯 分别共聚，催化活性为 $1.3 \times 10^{4} \sim 2.3 \times 10^{4}$, 极性基团插 入率为 $2.3 \% \sim 2.9 \%$, 共聚物分子量为 $1500 \sim 4500$. 乙 烯与丙烯腈、乙烯基丁基醚和醋酸烯丙酯分别共聚，极 性基团插入率较低 $(0.3 \% \sim 1.1 \%)$. 阻隔型烯己基氯与乙 烯共聚活性高达 $5.7 \times 10^{5}$, 极性基团插入率为 $3.3 \%$, 分 子量只有 2300 .

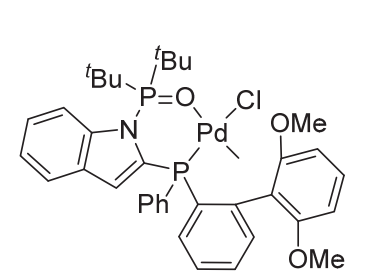

337

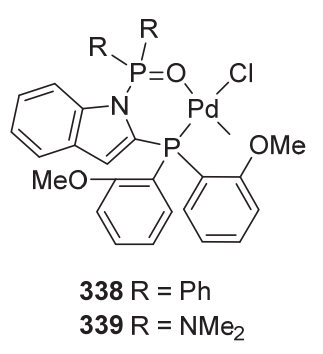

与 $\mathrm{N}$-杂环卡宾型催化剂一样, 膦-氧化膦型催化剂 也是 Nozaki 等根据电子不对称结构设计的全新类型催 
化剂. 而且由于氧化膦端的存在, 膦-氧化膦型催化剂 结构调整较膦磺酸型催化剂更加灵活. 在现有的学术研 究中, 膦-氧化膦型催化剂热稳定性好, 共聚反应可在 $90{ }^{\circ} \mathrm{C}$ 时进行, 形成高度线型共聚物, 极性基团分布于链 中和链端; 膦端给电子基团、氧化膦端给电子基团或氧 化膦端大空间位阻基团的存在有利于共聚物分子量的 提高, 但共聚物分子量依然偏低; 简忠保等进行的苯并 噻吩和吲哚电子不对称位点连接方式互换的研究提供 了共聚反应调控的新途径.

\section{2 新型骨架催化剂}

在 Brookhart 等报道了 $\alpha$-二亚胺型催化剂这一突破 性进展后很长一段时间内, 只有少数几种适合于烯烃 极性单体直接共聚的催化体系被报道出来. 在过去十年 中, 新型骨架催化剂的研究也取得了不少关键进展. 其 中一些催化体系已在前面章节中进行了介绍, 如 $\mathrm{N}$-杂 环卡宾型催化剂和膦-氧化膦型催化剂. 这两类催化剂 已经得到了该领域研究者的关注, 其结构优化研究也取 得了初步进展. 本节主要介绍除此之外近五年来持续被 设计研究的新型骨架催化剂.

Nozaki 等 ${ }^{[189]}$ 将共轭苯环骨架简化为亚甲基, 设计 合成了新型膦-氧化膦型 $P d$ 催化剂 340 和 341, 成功催 化了乙烯分别与醋酸烯丙酯、醋酸乙烯酯、乙烯基丁基 醚、丙烯腈、丙烯酸甲酯和甲基丙烯酸甲酯在 $80{ }^{\circ} \mathrm{C}$ 和 1 3 MPa 乙烯压力下的共聚. 晶体数据显示, 与相应苯 环连接的膦-氧化膦型催化剂相比, 342 中 $\mathrm{P}-\mathrm{Pd}-\mathrm{O}$ 夹 角变小, 氧化膦 $\mathrm{P}-\mathrm{O}$ 键长边长, 而 $\mathrm{P}-\mathrm{Pd}-\mathrm{C}(\mathrm{Me})$ 夹角 和 $\mathrm{P}-\mathrm{Pd}$ 键长相当, 而 $\mathrm{P}-\mathrm{Pd}-\mathrm{C}(\mathrm{Me})$ 之间的夹角和 $\mathrm{P}$ -Pd 键长与典型膦苯磺酸催化剂相当, 因此骨架的改 变相当于改变了 $\mathrm{O}$ 原子周围的电子和空间结构. 相同条 件下, 341 可高活性催化共聚得到较高的分子量共聚物, 340 可催化共聚得到较高的极性基团插入率.

亚甲基骨架 $\mathrm{Ni}$ 催化剂 344 在 $50 \sim 80{ }^{\circ} \mathrm{C}$ 时, 催化乙

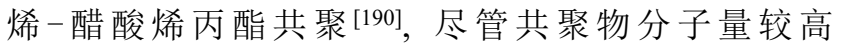
$\left(1.4 \times 10^{4} \sim 4.7 \times 10^{4}\right)$, 但极性基团插入率非常低 $(0.04 \% \sim 0.09 \%)$, 催化活性也不高(190 440); 增大极 性单体浓度和助催化剂用量, 活性和极性基团插入率提 高, 共聚物分子量急剧下降. 使用 343 首次实现了丙烯醋酸烯丙基酯共聚, 但活性仅有 68 和 34. 该体系不能 催化乙烯-丙烯酸甲酯共聚.
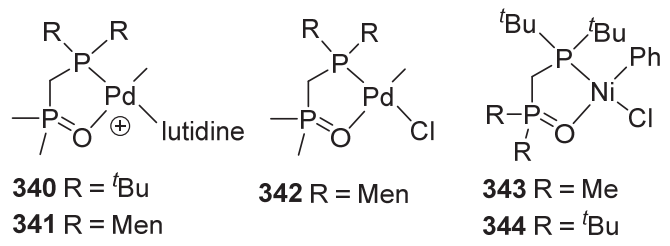

陈昶乐等 ${ }^{1911}$ 设计合成了 $\mathrm{N}$ 原子桥连的拥有刚性配 体、电子不对称特性和更多调控位点的全新骨架膦-氧 化膦型配合物 $345 \sim 354$. 在 $80{ }^{\circ} \mathrm{C}$ 和 $0.8 \mathrm{MPa}$ 乙烯压力 下 345 催化乙烯一丙烯酸甲酯拥有最高活性 $\left(1.67 \times 10^{4}\right)$ 和插入率(6.8\%), 346 得到最高分子量(7400), 但插入率 为 $2 \% .345$ 和 346 还可以催化乙烯分别与丙烯酸和乙烯 基丁基醚共聚，共聚物分子量为 $2800 \sim 9200$.
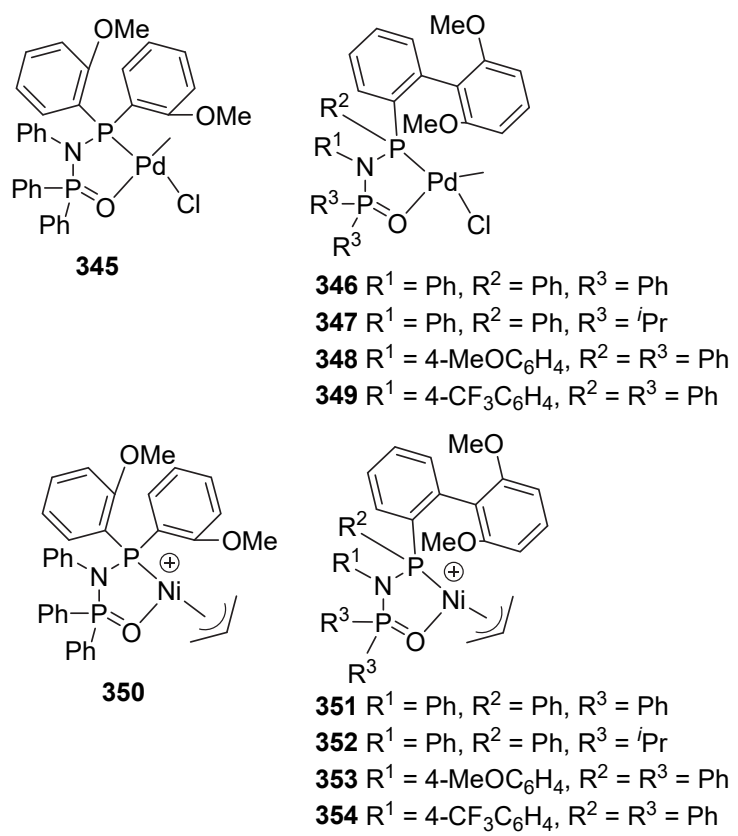

$\mathrm{Ni}$ 催化剂催化乙烯一丙烯酸甲酯, 353 催化活性最高 (9200), 351 得到最高共聚物分子量(9900); 催化乙烯-丙 烯酸丁基酯共聚, 352 可以同时得到最高分子量(6300)和 最高插入率(4.7\%), 但催化活性最低(仅 800). 此外 353 还可以催化丙烯酸-2-甲氧基乙酯、乙烯基丁基醚和丙烯 酸七氟丁基酯参与共聚.

345 还可以催化乙烯一甲基丙烯酸甲酯共聚 ${ }^{[192]}$, 催 化活性为 1700 , 但极性基团插入率低 $(0.2 \%)$, 共聚物分 子量为 5700, 进一步研究发现甲基丙烯酸甲酯以 2,1 形 式插入，几何变形较小, 但是由于单体中甲基与正在插 入的乙烯基团间的空间排斥作用易发生 $\beta-\mathrm{H}$ 消除，导致 极性基团位于链终止端.

弱给电子端使用 $\mathrm{N}$ 原子, 强给电子端使用芳基膦. Pd 催化剂 355 催化乙烯与丙烯酸甲酯、乙烯基丁基醚、 乙烯基三甲氧基硅烷、醋酸烯丙酯和烯丙基氯分别共聚, 得到低分子量高度线型共聚物 ${ }^{[193]}$, 催化活性(50 $2400)$ 和共聚物分子量较低( $890 \sim 1300)$, 极性基团位于 链中和链终止端, 插入率为 $0.4 \% \sim 1.5 \%$.

强给电子端使用 $\mathrm{N}$ 原子, 弱给电子端使用氧化膦. 碳桥五元环 Ni 催化剂 356 催化乙烯与阻隔型烯己基氯 和十一烯酸甲酯分别共聚得到高度线型共聚物 ${ }^{[194]}$, 催 
化活性为 $0.5 \times 10^{4} \sim 2.8 \times 10^{4}$, 共聚物分子量为 $2200 \sim$ 13400 , 极性基团插入率为 $0.9 \% \sim 3.4 \%$. 氮桥六元环 $\mathrm{Ni}$ 催化剂 357 359 催化乙烯与十一烯酸甲酯和乙烯基三 甲氧基硅烷分别共聚 ${ }^{[195]}$, 催化活性为 $1.4 \times 10^{4} \sim$ $4.8 \times 10^{4}$, 共聚物分子量分别可达 5500 和 13600 , 极性 基团插入率分别为 $3.5 \%$ 和 $0.7 \%$. 丙烯酸甲酯和醋酸乙 烯酯均不能在这些体系中与乙烯共聚.

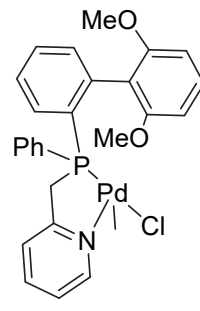

355

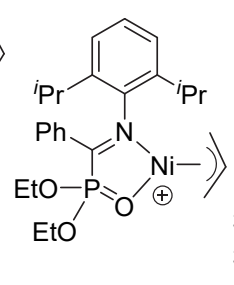

356

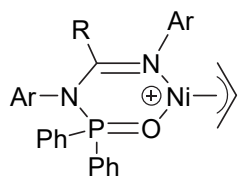

$357 \mathrm{R}=\mathrm{H}, \mathrm{Ar}=2,6-{ }^{i} \mathrm{Pr}_{2}-\mathrm{C}_{6} \mathrm{H}_{3}$ $358 \mathrm{R}=\mathrm{H}, \mathrm{Ar}=2,6-\mathrm{F}_{2}-\mathrm{C}_{6} \mathrm{H}_{3}$ $359 \mathrm{R}={ }^{t} \mathrm{Bu}, \mathrm{Ar}=2,6-{ }^{i} \mathrm{Pr}_{2}-\mathrm{C}_{6} \mathrm{H}_{3}$
2002 年, Brookhart 等 ${ }^{[196]}$ 在专利中公开了部分亚胺酮骨架 $\mathrm{Ni}$ 催化剂(如 360)的结构、合成方法及其对乙烯 均聚和极性共聚的催化效果. 最近, 陈昶乐等 ${ }^{[197]}$ 进一 步拓展了这类催化剂配体结构, 在亚胺端引入 $\alpha$-二亚胺 配体中常用的大体积二苯甲基结构 设计合成了 $\mathrm{Ni}$ 催化 剂 361 363. $50{ }^{\circ} \mathrm{C}$ 时 361 可催化乙烯一丙烯酸甲酯共聚, 具有较低的共聚活性(2500) 和极性基团插入率 $(0.6 \%)$, 共聚物分子量为 $1.8 \times 10^{4}$; 乙烯-乙烯基三甲氧基硅烷 共聚极性基团插入率可达 $10.8 \%$ ，但分子量仅为 8300 ; 乙烯-醋酸降冰片烯酯共聚活性很低; 乙烯与阻型隔烯己 基氯和十一烯酸甲酯分别在 50 和 $20{ }^{\circ} \mathrm{C}$ 共聚活性提升明 显 $\left(5 \times 10^{4} \sim 10 \times 10^{4}\right)$, 极性基团插入率为 $2.2 \% \sim 3.4 \%$, 共聚物分子量最高可达 $3.07 \times 10^{5}, 50{ }^{\circ} \mathrm{C}$ 时乙烯一十一烯 酸甲酯共聚分子量下降至 $5 \times 10^{4} \sim 7 \times 10^{4} .363$ 催化乙烯 一十一烯酸甲酯共聚分子量最高可达 $1.65 \times 10^{5}$.

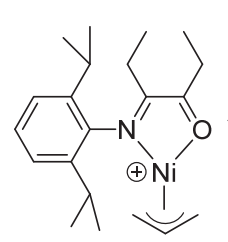

360

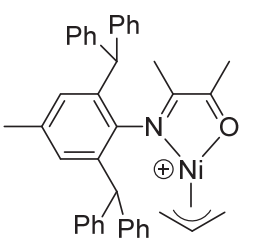

361

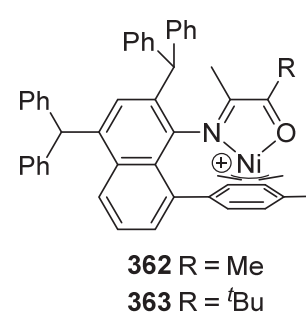

\section{8 下一代高性能材料}

少数已商业化的乙烯-极性单体直接共聚物主要由 自由基聚合反应制得(图 5). 后过渡金属催化的直接极 性共聚反应极大拓展了可引入非极性聚烯烃链中的极 性基团种类(图 2,3,4), 在实现对聚合物分子量、极性基 团插入率和微观结构的精确调控的同时, 各种类型极性 基团的存在不仅可以提升极性共聚物的力学性能、流变 性能和表面性能, 还能带来许多新的应用可能, 如转化
为其他类型的极性基团，或者鳌合金属离子、结合路易 斯酸性位点形成可逆或不可逆的共价键，从而制备出一 些有别于传统聚合物类型的具有独特性能和全新应用 的功能聚烯烃材料 ${ }^{[15]}$.

但极性基团的存在所导致的 “极性单体问题” 使得 可控制备极性共聚物材料非常具有挑战性，迄今为止尚 无真正具有商业价值的后过渡金属可控极性共聚催化 剂及共聚物材料出现 ${ }^{[131,198]}$. 由于所得的共聚物往往分 子量低导致力学性能差, 仅有少量关于后过渡金属配合 物催化的极性共聚物性能与微观结构关系的详尽研究. 近年来研究者们通过配体修饰和新型催化剂设计, 已经 获得了满足力学性能要求的高分子量极性共聚物, 促进 极性共聚物材料性能的研究逐渐增多.

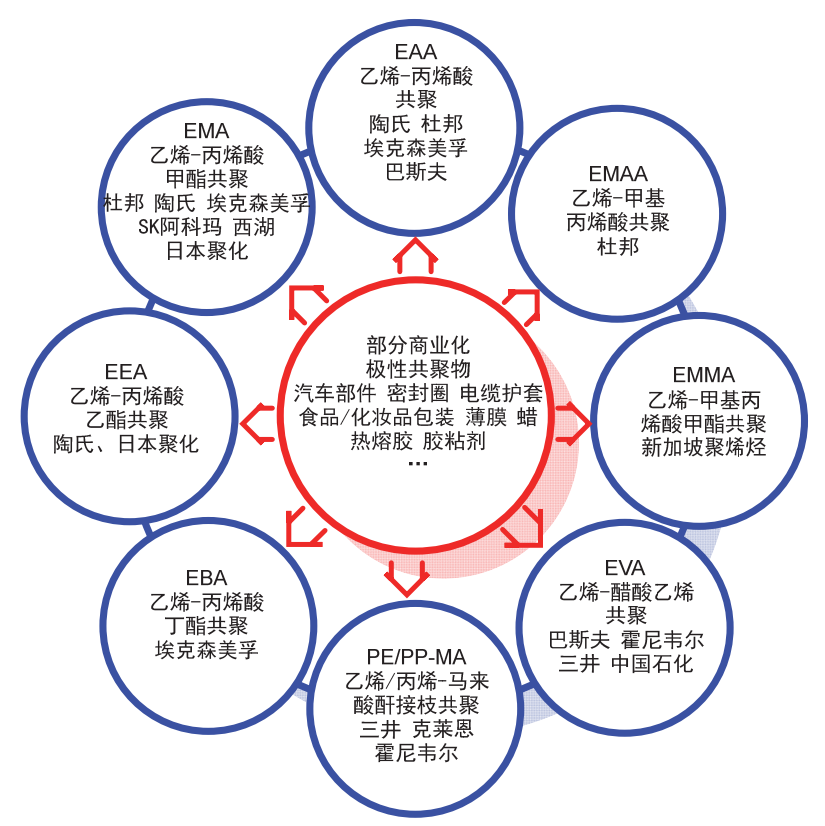

图 5 商业化极性共聚物

Figure 5 Commercial polar copolymers

\section{1 极性共聚物微观结构}

聚烯烃微观结构会显著影响其宏观性能 [7f,114,199], 不同后过渡金属催化剂所形成的共聚物微观结构也不 尽相同 ${ }^{[7 d, 154]}$. 典型 $\alpha$-二亚胺催化剂得到的乙烯一丙烯酸 甲酯超支化共聚物极性基团主要位于链端(图 6,A), 玻 璃化转变温度为 $-84 \sim-87{ }^{\circ} \mathrm{C}$; 双金属催化乙烯-丙烯 酸叔丁基酯高支化共聚物极性基团可大部分位于链中 (图 6, B), 熔点和杨氏模量分别为 $8 \sim 29{ }^{\circ} \mathrm{C}$ 和 $1.6 \mathrm{MPa}$, 水解为羧酸基团后进一步提升为 $16 \sim 35{ }^{\circ} \mathrm{C}$ 和 $4.6 \mathrm{MPa}$. 这种结构特性体现在材料性能上, 双金属催化共聚物形 成柔软的可拉伸膜, 而双金属催化的乙烯均聚物过于柔 软无法成膜 (熔点为 $6.5{ }^{\circ} \mathrm{C}$ ). 典型膦磺酸催化剂催化乙 烯一丙烯酸甲酯共聚物为高度线型结构，极性基团嵌入 主链(图 6, C), 聚合物为半结晶结构; 但也可通过一锅 
法串联反应使嵌入极性基团的线型主链同时拥有短烷 基支链(乙基和丁基)(图 6,D).

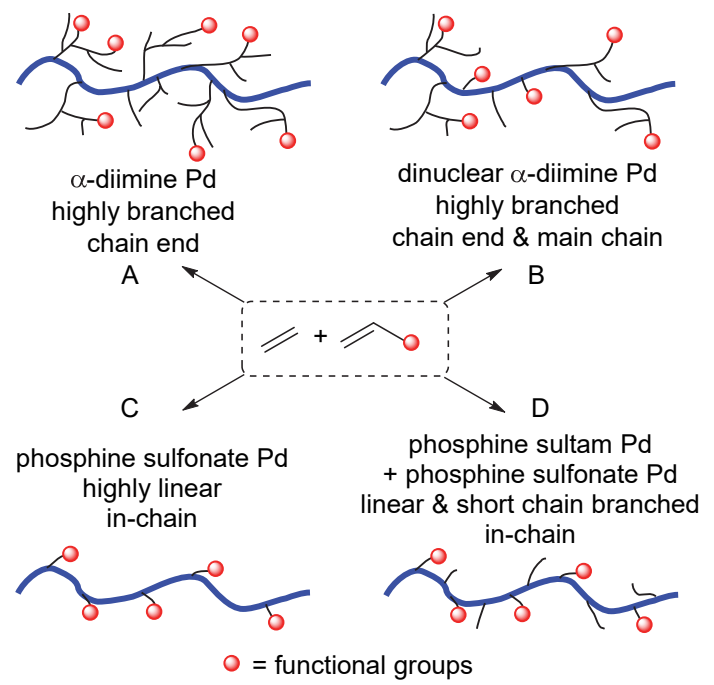

图6 具有不同微观结构的后过渡金属催化乙烯-极性单体共 聚物

Figure 6 Copolymers of ethylene and polar monomers with different microstructures

\section{2 极性弹性体}

2014 年, Mecking 等[7f]首次从材料性质的角度出发 详细研究了乙烯一乙烯基极性单体直接共聚物的材料性 能. 通过单体设计、204 催化以及第三单体(如丙烯酸三 甲氧基硅基丙酯、丙烯酸缩水甘油酯和降冰片烯二酸 䣶)产生交联，他们制备了一系列功能化弹性体(Scheme 7). 无交联乙烯-丙烯酸全氟 1-辛酯-丙烯酸三甲氧基硅 基丙酯三元共聚物玻璃化转变温度 $\left(T_{\mathrm{g}}\right)$ 为 $-31{ }^{\circ} \mathrm{C}$, 在体 积比为 $1000: 1$ 的甲苯/水中交联的弹性体以及 $100{ }^{\circ} \mathrm{C}$ 水蒸汽交联弹性体 $T_{\mathrm{g}}$ 分别为 -1 和 $-27{ }^{\circ} \mathrm{C}$, 显示出不 同交联方式对一 $\mathrm{Si}-\mathrm{O}-\mathrm{Si}$-交联键的影响. 降冰片烯 的引入可增加聚合物链的刚性, 玻璃化转变温度也随之
升高，交联乙烯-丙烯酸全氟 1-辛酯-降冰片烯二酸酐三 元共聚物 $T_{\mathrm{g}}$ 为 $9{ }^{\circ} \mathrm{C}$. 丙烯酸全氟 1 -辛酯的引入可降低 弹性体溶胀，在正丁醇和石油醚中，交联乙烯一丙烯酸 全氟 1 -辛酯-丙烯酸三甲氧基硅基丙酯三元共聚物 $(6.9 \%$ 丙烯酸全氟 1-辛酯插入率，以质量分数计为 $42 \%)$ 分别增重 $6 \%$ 和 $10 \%$, 而三元乙丙橡胶分别增重 $6 \%$ 和 $73 \%$, 氢化丁腈橡胶分别增重 $37 \%$ 和 $6 \%$. 极性单体全部 以 2,1 形式插入，但共聚物分子量较低(3600 8500), 其 力学性能受到影响.

热塑性弹性体通常由茂金属催化乙烯/丙烯与高级 $\alpha$-烯烃共聚制备, 在汽车部件和家居用品中广泛应用. 2020 年,陈昶乐等 ${ }^{[200]}$ 通过 $\alpha$-二亚胺 Pd 催化剂 364 催化 乙烯与十一烯酸(UA) 或十一烯酸甲酯(MU)直接共聚, 成功制备出了表面性能、力学性能和弹性回复性能良好 的极性热塑性弹性体. 插入率分别为 $1.3 \% \mathrm{UA}$ 和 $1.4 \%$ MU 的共聚物水接触角比相同条件下的聚乙烯 $\left(105^{\circ}\right)$ 分 别减小 $20^{\circ}$ 和 $14^{\circ}$; 高分子量 $\left(6.1 \times 10^{4} \sim 34.1 \times 10^{4}\right)$ 极性 共聚物具有中等支化度 $(53 \sim 76)$ 、低熔点 $\left(14 \sim 24{ }^{\circ} \mathrm{C}\right)$ 、 中等拉伸断裂应力 $(3.3 \mathrm{MPa} \sim 17.6 \mathrm{MPa})$ 、高拉伸断裂应 变(450\% 1850\%)和高回弹率(图 $7, \mathrm{SR}=77 \% \sim 80 \%$ ). 需要注意的是，首次拉伸回弹造成部分不可逆聚合物结 构改变, 随后的拉伸回弹实验则显示出较好的弹性回复 性能.

\section{3 极性聚乙烯(极性 LDPE 和 LLDPE)}

目前低密度聚乙烯(LDPE)和商用极性 $\operatorname{LDPE}$ (如乙 烯一醋酸乙烯共聚物 EVA)由高温高压自由基聚合生产, 共聚物支化度为 $20 \sim 40$. 线型低密度聚乙烯(LLDPE)由 乙烯与 $\alpha$-烯烃共聚生产，根据催化剂和共聚单体的不同 而具有不同的支链结构. 使用后过渡金属催化制备这些 聚烯烃材料面临如何引入短和长支链的难题，具有独特 “链行走” 特性的 $\alpha$-二亚胺型催化剂则提供了可行途径, 且共聚物支化度可以更高(达到 80 以上), 还可以在非常

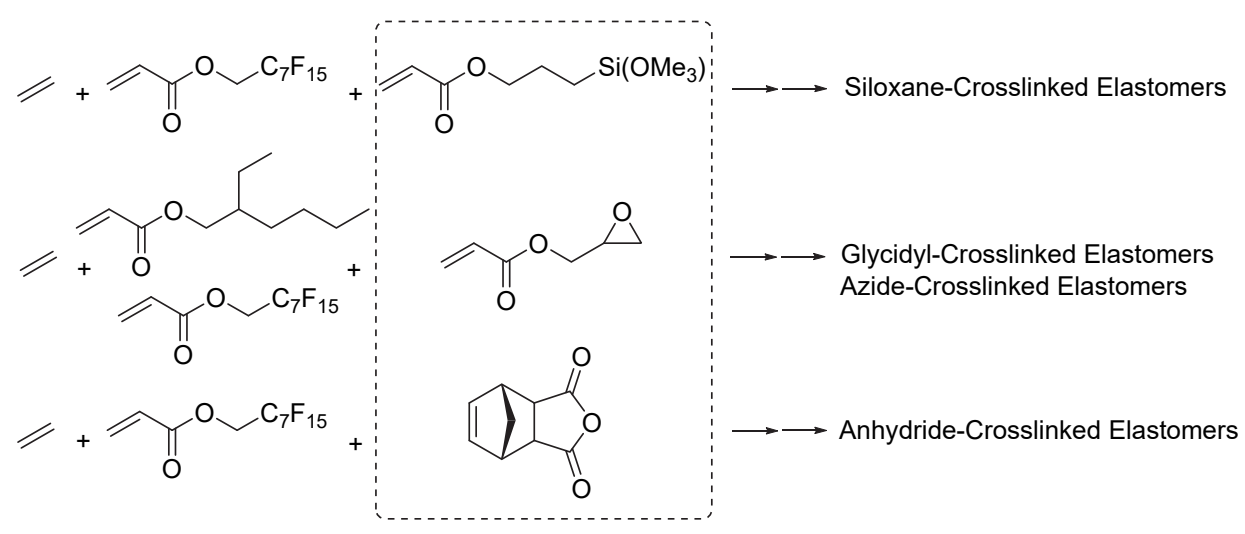

图式 7 乙烯与极性单体直接共聚制备极性聚乙烯弹性体

Scheme 7 Polar-substituted polyethylene elastomers from ethylene copolymerization with polar monomers 

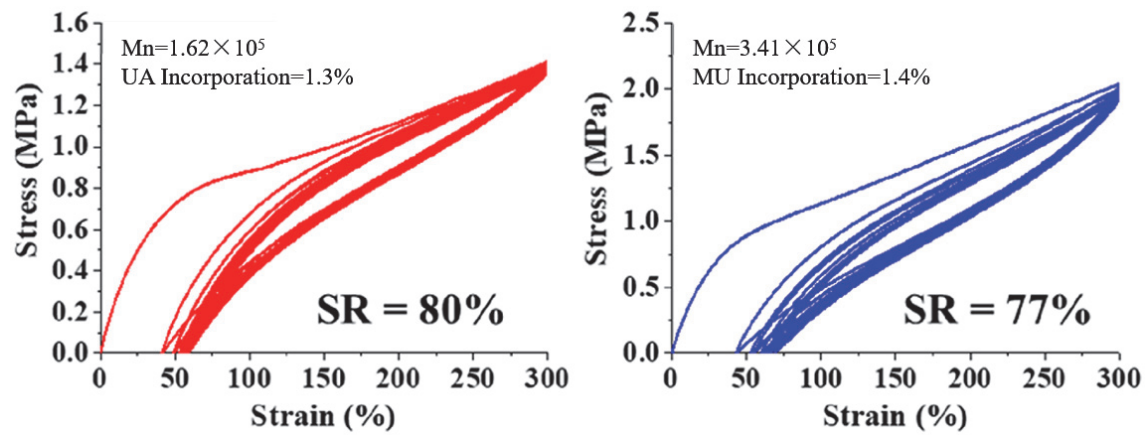

图 7 共聚物十次 $300 \%$ 拉伸回弹测试应力-应变曲线图

Figure 7 Plots of hysteresis experiments of ten cycles at a strain of $300 \%$ for copolymer samples Reprinted (adapted) with permission from Ref. [200]. Copyright (2020) American Chemical Society

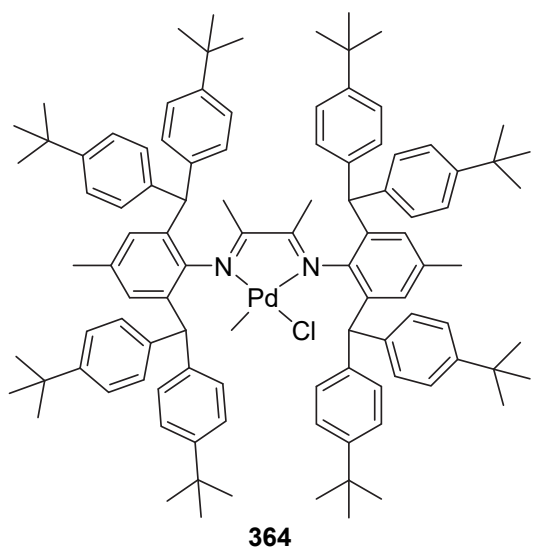

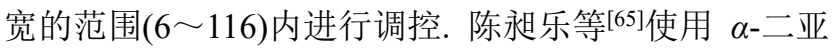
胺型 Pd 催化剂 52 催化阻隔型十一烯酸甲酯、十一烯酸、 十一烯醇和烯己基氯与乙烯的二元共聚制备了极性
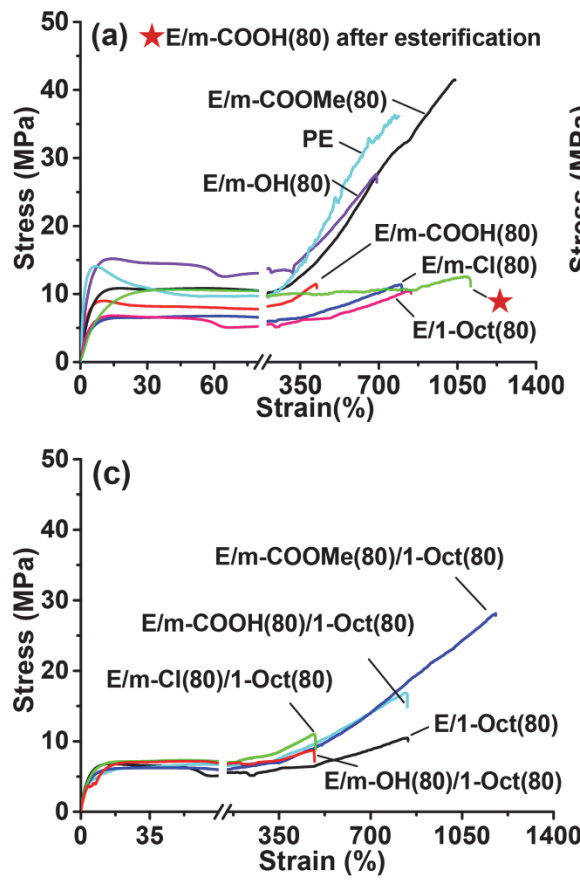

图 852 和 241 催化的聚乙烯和乙烯共聚物应力-应变曲线图

Figure 8 Stress vs strain curves for the polymer and copolymer products generated using $\mathbf{5 2}$ and $\mathbf{2 4 1}$

$(\mathrm{a} \sim \mathrm{c}) \mathbf{2 4 1}$, (d) 52. Reprinted (adapted) with permission from Ref. [65]. Copyright (2018) American Chemical Society 

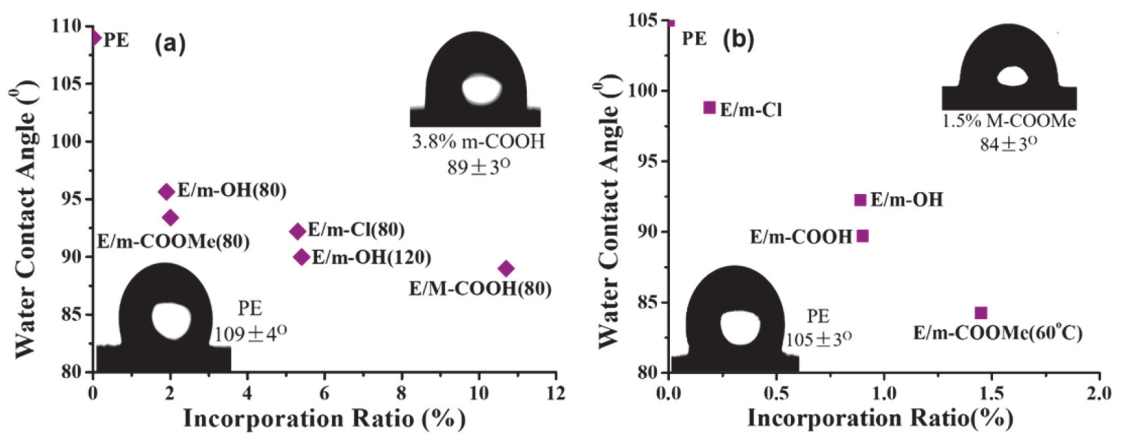

图 952 和 241 催化的聚乙烯和乙烯共聚物的水接触角

Figure 9 Water contact angles of the polyethylene and copolymer products generated using $\mathbf{5 2}$ and $\mathbf{2 4 1}$

(a) 52, (b) 241. Reprinted (adapted) with permission from Ref. [65]. Copyright (2018) American Chemical Society

\section{4 阻燃材料}

烯烃阻燃性能可通过加入磷、嗍和石墨等进行提升, 但非极性聚烯烃难以与阻燃剂有效相容，两相机械混合 往往达不到理想效果. 陈昶乐等[7c]利用 241 催化乙烯极性基团二元和三元共聚, 直接在共聚物链中引入 $\mathrm{P} 、 \mathrm{~B}$ 和 $\mathrm{Si}$ 等原子(Scheme 8). 少量极性基团的引入(插入率 $0.8 \% \sim 2.6 \%$ )提升了共聚物的表面性能、热性能和阻燃 性能，抑制共聚物易燃物释放. 极性共聚物 $10 \%$ 失重温 度和 $50 \%$ 失重温度高于聚乙烯, 热释放速率(HRR)和总 释放热 (THR) 比非极性聚乙烯分别下降 $24.5 \%$ 和 4.6\% (图 10). 共聚物分子量为 $6000 \sim 36900$, 力学性能 差, 于是他们通过后修饰方法引入甲基磷酸二甲酯, 或 者使用聚乙烯 $(\mathrm{PE})$ 、多聚磷酸铵 $(\mathrm{APP})$ 或季戊四醇 (PER)、乙烯-十一烯酸甲酯(poly(E-co-O1))共混, 在保持
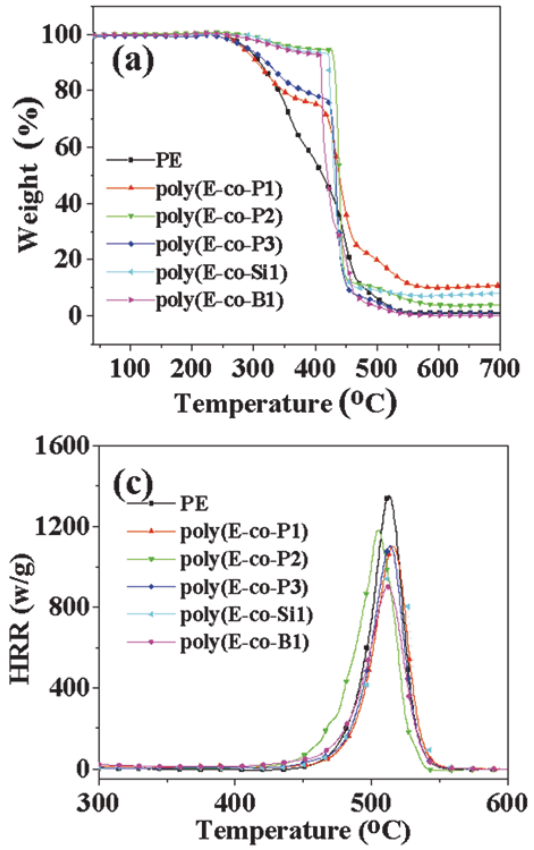

力学性能的基础上进一步证实了极性共聚物对阻然性 能的提升作用. 值得注意的是, $(\mathrm{poly}(\mathrm{E}-\mathrm{co}-\mathrm{O} 1))$ 作为添加 剂可有效促进聚乙烯与传统阻燃成分(如 APP)共混, 得 到近似于均相的分散体系(图 11).

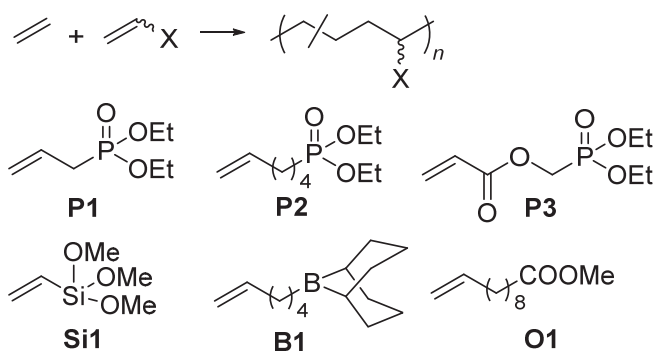

图式 8 乙烯共聚使用的极性单体

Scheme 8 Comonomers used in the copolymerization of ethylene
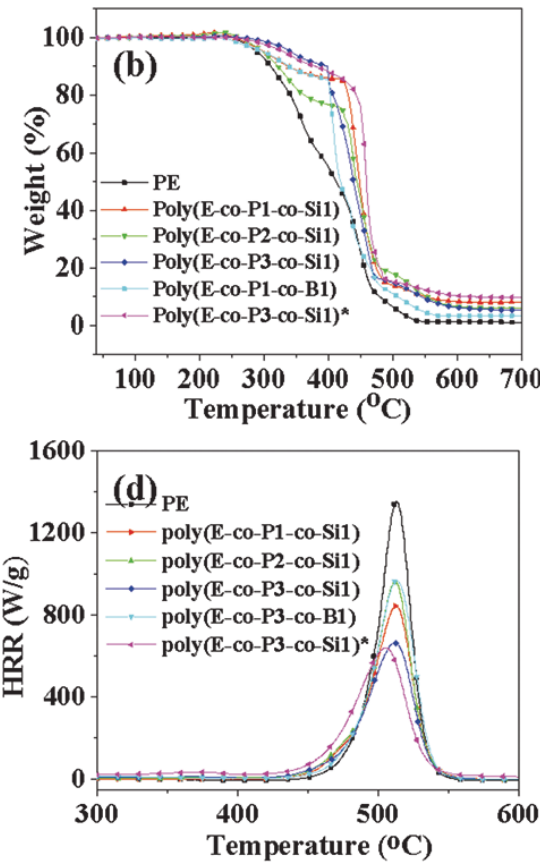

图 10 热重分析(TGA)曲线和热释放速率(HRR)曲线

Figure 10 Thermal gravimetric analysis (TGA) curves and heat release rate (HRR) curves TGA curves of the copolymers (a) and terpolymers (b), HRR curves of copolymers (c) and terpolymers (d). Reproduced from Ref. [7c] with permission from The Royal Society of Chemistry. 


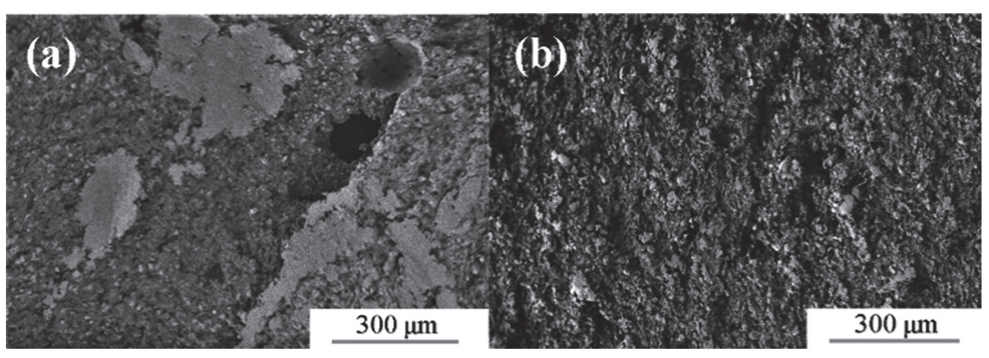

图 11 共混材料扫描电镜(SEM)图

Figure 11 Scanning electron microscope (SEM) images

(a) PE/APP $(m: m=70: 30)$ and (b) PE/poly(E-co-O1)/APP $(m: m: m=60: 10: 30)$ composites. Reproduced from Ref. [7c] with permission from The Royal Society of Chemistry.

\section{5 自修复材料和光敏材料}

亚乙基降冰片烯(ENB)是三元乙丙橡胶生产中普遍 使用的第三单体. 最近, 陈昶乐等[7]利用 241 催化乙烯十一烯酸/十一烯酸甲酯-亚乙基降冰片烯三元共聚, 将 一定量的亚乙基降冰片烯引入极性聚乙烯中; 逐渐增大 亚乙基降冰片烯浓度, 共聚催化活性 $\left(1.3 \times 10^{5}\right.$ $\left.1.7 \times 10^{5}\right)$ 以及十一烯酸和十一烯酸甲酯插入率变化不 大( $1 \% \sim 2 \%)$, 但分子量自 $17.6 \times 10^{4}$ 降低到 $9.8 \times 10^{4}$; 调节亚乙基降冰片烯插入率 $(5.7 \%$ 2 $2.6 \%$ )可调节聚合 物结晶度, 共聚物从半结晶态热塑性塑料 $\left(T_{\mathrm{m}}=\right.$ $\left.110.7{ }^{\circ} \mathrm{C}\right)$ 转变为无定形弹性体 $\left(T_{\mathrm{g}}=-8{ }^{\circ} \mathrm{C}\right)$; 此外, 亚乙 基降冰片烯还为橡胶硫化引入了可形成永久交联的双 键(图 12).

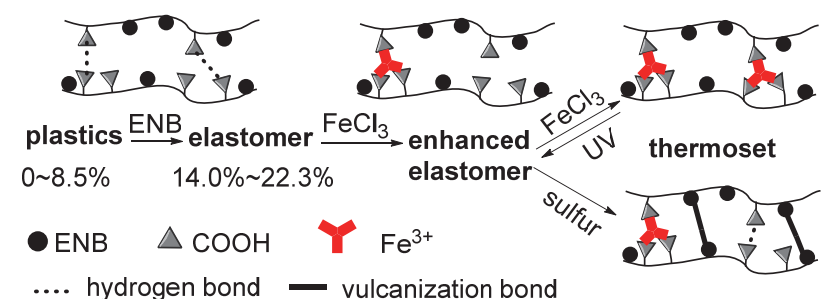

图 12 通过 $\mathrm{ENB}$ 插入率、氢键、 $\mathrm{Fe}^{3^{+}}$交联、硫化交联调节材 料性能

Figure 12 Modulation of material properties through ENB incorporation, hydrogen bonding, $\mathrm{Fe}^{3+}$-induced crosslinking and sulfur-induced vulcanization

含有极性基团的共聚物水接触角可由乙烯均聚物 的 $100^{\circ}$ 降低至最低 $63^{\circ}$, 且 $\mathrm{COOH}$ 对表面性能的影响比 $\mathrm{COOMe}$ 更大 ${ }^{[62]}$. 功能性羧酸基团的引入及与 $\mathrm{Fe}^{3+}$ 结合 可提供动态交联活性位点, 进一步调控聚合物力学性 能、弹性体性能及自修复功能. 共聚物拉伸断裂应力和 拉伸断裂应变分别在 $0.4 \sim 26.7 \mathrm{MPa}$ 和 $700 \% \sim 940 \%$ 范 围内, $\mathrm{COOH}$ 部分与 $\mathrm{Fe}^{3+}$ 结合后拉伸断裂应力从 26.6 $\mathrm{MPa}$ 上升至 $31.6 \mathrm{MPa}$. 得益于 $\mathrm{COOH}$ 共聚物中氢键的 影响, 断裂的 $\mathrm{OOH}$ 与 $\mathrm{Fe}^{3+}$ 结合共聚物在 $80{ }^{\circ} \mathrm{C}$ 时, 牢固 接触 12 24 h, 断裂值时的伸长率得到 $95 \%$ 恢复. 紫外
光照射下柠檬酸将 $\mathrm{Fe}^{3+}$ 还原为 $\mathrm{Fe}^{2+}$, 进而减弱 $\mathrm{COOH}$ 与 $\mathrm{Fe}^{2+}$ 的结合, 降低交联密度并降低力学性能; 在空气中 加热可以将 $\mathrm{Fe}^{2+}$ 氧化为 $\mathrm{Fe}^{3+}$, 这种氧化还原调控为循环 利用热固性材料提供了一种途径(图 12).

生物来源单体丁香酚可用于抗菌及香精配方中, 乙 烯-丁香酚可使用 206 催化共聚成具有一定抗菌性能的 共聚物 ${ }^{[201]}$, 但分子量较低(3400 21000), 影响其力学 性能. 最近, 陈昶乐等 $[76]$ 拓宽了这一共聚反应范围及共 聚物性能. 241 催化丁香酚、对烯丙基邻苯二酚和三乙基 硅烷保护的对烯丙基邻苯二酚与乙烯二元共聚，以及与 乙烯/1-已烯三元共聚(Eq. 3). 1-已烯(插入率 6\%～12\%) 可以增加链的灵活性, 促进与 $\mathrm{Fe}^{3+}$ 的相互作用. 共聚物 分子量为 $3.8 \times 10^{4} \sim 4.9 \times 10^{4}$, 具有较好的力学性能、表 面性能、粘接性能和相容性, 还可与金属离子动态作用 产生自修复特性 $\left(\mathrm{Fe}^{3+}\right.$ 和 $\left.\mathrm{Ti}^{4^{+}}\right)$.

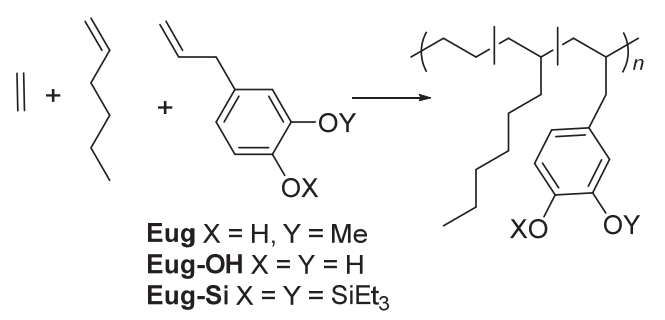

\section{9 总结与展望}

后过渡金属催化烯烃-极性单体直接共聚制备极性 聚烯烃领域在近十年时间里形成了丰富的催化体系, 特 别是近五年来, 研究方向拓展到了催化剂理性设计及高 效新型骨架催化剂和材料应用研究, 致力于解决极性单 体问题. 大量的研究促使共聚反应和共聚物性能可在一 定程度上精细精确调控. 后过渡金属配合物已经从最初 的 $\alpha$-二亚胺型和水杨醛亚胺型发展到酮胺型、膦酚型、 膦磺酸型、 $\mathrm{N}$-杂环卡宾型、膦-氧化膦型以及最近不断 被报道出来的新型骨架结构. 在热稳定性、共聚物分子 量、极性基团插入率和可共聚单体范围等方面, 每种催 化剂都有其优点和缺点. 
在全面介绍这些催化剂研究进展的基础上, 还重点 关注了后过渡金属催化剂极性共聚物在材料性能方面 的研究进展. 与商业化乙烯-极性单体自由基直接共聚 物相比, 后过渡金属催化极性共聚物微观结构可调控性 好，通过灵活选用第二共聚单体或第三共聚单体，可以 得到更多性能独特或具有全新性能的极性共聚物和功 能材料.

尽管取得了许多瞩目的成果, 但进行极性聚烯烃材 料开发时依然较难获得既符合力学性能要求又满足应 用性能要求的直接共聚物, 在分子层面上则反映为得到 高分子量共聚物的同时较难有效调控极性基团插入率, 这严重影响后过渡金属催化剂直接极性共聚物在功能 材料方向上的发展. 后过渡金属催化极性共聚主要得到 统计共聚物, 较少有嵌段共聚物或类似共聚物生成, 共 聚物链结构类型受限. 此外, 材料性能研究正处于起步 阶段, 尚无法解决高效、低成本催化体系构建和满足市 场需求的共聚物篮选这两大难题.

走向商业化应用, 除了加速传统极性共聚树脂的开 发应用、具有独特性能和全新应用场景的功能聚烯烃的 开发或者与其他类型聚合方法和手段结合开发新型功 能材料, 这一领域存在许多基础问题需要关注. 第一, 深化对直接极性共聚反应的认识. 极性共聚反应中可能 同时存在数个竞争性反应, 每一种催化剂都可能存在多 个失活和分解途径, 需要深入进行共聚反应机理探讨, 明确反应途径、类型和共聚物微观结构形成机制, 阐明 实现共聚物性能调控的真正影响因素, 使聚合过程更加 可控. 第二, 直面 $\mathrm{Ni}$ 催化剂挑战. $\mathrm{Ni}$ 的亲氧性高于 $\mathrm{Pd}$, 受极性基团影响大, 一般只能适用于阻隔型甚至多阻隔 型极性单体, 得到低分子量共聚物; 且一般 $\mathrm{Ni}$ 催化剂温 度耐受性差, 对放热聚合中反应温度平稳控制的要求更 高; 但是 $\mathrm{Pd}$ 金属近年来的市场价格不断上涨, $\mathrm{Ni}$ 催化剂 在生产成本控制上具有潜在优势, 使其成为商业化应用 中一种可能途径. 第三, 高效热稳催化剂的开发. 由于 极性单体问题的存在, 要适应目前已有工业装置要求, 达到商业化应用水平, 需要持续开发更高效、更稳定的 催化体系调和共聚物分子量和极性基团插入率之间的 内在矛盾, 进一步优化共聚条件(如温度和压力), 提升 共聚物力学性能和表面性能, 增强实用性.

\section{References}

[1] (a) Hlatky, G. G. Coord. Chem. Rev. 2000, 199, 235.

(b) Severn, J. R.; Chadwick, J. C.; Duchateau, R.; Friederichs, N. Chem. Rev. 2005, 105, 4073.

(c) Hlatky, G. G. Chem. Rev. 2000, 100, 1347.

(d) Chen, E. Y. X. Chem. Rev. 2009, 109, 5157

[2] Coates, G. W. Chem. Rev. 2000, 100, 1223.

[3] Gibson, V. C.; Spitzmesser, S. K. Chem. Rev. 2003, 103, 283.

[4] Makio, H.; Terao, H.; Iwashita, A.; Fujita, T. Chem. Rev. 2011, 111,
2363.

[5] Ittel, S. D.; Johnson, L. K.; Brookhart, M. Chem. Rev. 2000, 100, 1169.

[6] (a) Chen, Z. K.; Mao, Y. H.; Cao, Y. C.; Liang, S. B.; Song, S.; Ni, C.; Liu, Z. Y.; Ye, X. F.; Shen, A.; Zhu, H. P. Chin. J. Org. Chem. 2018, 38, 2937 (in Chinese)

(陈志康, 毛远洪, 曹育才, 梁胜彪, 宋莎, 倪晨, 刘振宇, 叶晓 峰, 沈安, 朱红平, 有机化学, 2018, 38, 2937.)

(b) Liu, R.; Xiao, S. M.; Zhong, X. H.; Cao, Y. C.; Liang, S. B.; Liu, Z. Y.; Ye, X. F.; Shen, A.; Zhu, H. P. Chin. J. Org. Chem. 2015, 35,1861 (in Chinese)

(刘睿，肖树萌，钟向宏，曹育才，梁胜彪，刘振宇，叶晓峰，沈 安, 朱红平, 有机化学, 2015, 35, 1861.)

(c) Li, B. G.; Zhang, M. X.; Liu, W. F.; Wang, W. J. Chem. Ind. Eng. Prog. 2017, 36, 3135 (in Chinese). (李伯耿, 张明轩, 刘伟峰, 王文俊, 化工进展, 2017, 36, 3135.)

[7] (a) Zou, C.; Chen, C. Angew. Chem., Int. Ed. 2020, 59, 395.

(b) Na, Y.; Chen, C. Angew. Chem., Int. Ed. 2020, 59, 7953.

(c) Gao, J. X.; Cai, W.; Hu, Y.; Chen, C. L. Polym. Chem. 2019, 10, 1416.

(d) Takano, S.; Takeuchi, D.; Osakada, K.; Akamatsu, N.; Shishido, A. Angew. Chem., Int. Ed. 2014, 53, 9246.

(e) Yao, H. L.; He, X. H.; Chen, L.; Chen, Y. W.; Chen, D. F. J. Appl. Polym. Sci. 2013, 128, 3540.

(f) Rünzi, T.; Mecking, S. Adv. Funct. Mater. 2014, 24, 387.

[8] (a) Novák, I.; Borsig, E.; Hrčková, L. U.; Fiedlerová, A.; Kleinová, A.; Pollák, V. Polym. Eng. Sci. 2007, 47, 1207.

(b) Dai, S. Y.; Zhou, S. X.; Zhang, W.; Chen, C. L. Macromolecules 2016, 49,8855 .

[9] (a) Mazzolini, J.; Boyron, O.; Monteil, V.; Gigmes, D.; Bertin, D.; D'agosto, F.; Boisson, C. Macromolecules 2011, 44, 3381. (b)Boaen, N. K.; Hillmyer, M. A. Chem. Soc. Rev. 2005, 34, 267.

[10] Wu, H. T.; Lv, C.; Jiang, T.; Cui, K.; Ma, Z. Chem. Ind. Eng. Prog. 2015, 34, 1699 (in Chinese).

(吴昊天，吕弛，姜涛，崔崑，马志，化工进展，2015，34, 1699.)

[11] Franssen, N. M. G.; Reek, J. N. H.; De Bruin, B. Chem. Soc. Rev. 2013, 42, 5809.

[12] (a) Shanmugam, S.; Boyer, C. Science 2016, 352, 1053.

(b) Parkatzidis, K.; Wang, H. S.; Truong, N. P.; Anastasaki, A. Chem 2020, 6, 1575.

(c) Tasdelen, M. A.; Kahveci, M. U.; Yagci, Y. Prog. Polym. Sci. 2011, 36, 455.

(d) Zhang, H. C.; Liu, Z. N.; Xi, F. F.; Li, Y. M.; Kong, L.; Hao, A. Y. Chin. J. Org. Chem. 2011, 31, 1761 (in Chinese). (张华承, 刘召娜，辛飞飞，李月明，孔丽，郝爱友，有机化学， 2011, 31, 1761.)

[13] Zhang, W.; Waddell, P. M.; Tiedemann, M. A.; Padilla, C. E.; Mei, J. J.; Chen, L. Y.; Carrow, B. P. J. Am. Chem. Soc. 2018, 140, 8841.

[14] Chen, G. H.; Ma, X. S.; Guan, Z. B. J. Am. Chem. Soc. 2003, 125, 6697.

[15] Marks, T. J.; Chen, J.; Gao, Y. Angew. Chem., Int. Ed. 2020, 59, 14726.

[16] Zhu, Y. Q.; Li, S. H.; Liang, H. Q.; Xie, X. L.; Zhu, F. M. RSC $A d v$. 2019, 9, 26582.

[17] Hong, M.; Wang, Y. X.; Mu, H. L.; Li, Y. S. Organometallics 2011, 30, 4678 .

[18] Chen, Z.; Li, J. F.; Tao, W. J.; Sun, X. L.; Yang, X. H.; Tang, Y. Macromolecules 2013, 46, 2870.

[19] (a) Chen, R. F.; Qian, C. T.; Li, Y.; Zou, F. L. Chin. J. Org. Chem. 2000, 20, 712 (in Chinese).

(陈瑞芳, 钱长涛, 李杨, 邹丰楼, 有机化学, 2000, 20,712.)

(b) Su, B. Y.; Jia, P. Y.; Wang, Y. Z.; Li, Y. N.; Huang, H.; Li, Q. D. Chin. J. Org. Chem. 2016, 36, 2344 (in Chinese).

(苏碧云, 㚘佩瑜, 王彦昭, 李亚宁, 黄鹤, 李谦定, 有机化学, 2016, 36, 2344.)

[20] (a) Nakamura, A.; Anselment, T. M. J.; Claverie, J.; Goodall, B.; Jordan, R. F.; Mecking, S.; Rieger, B.; Sen, A.; Van Leeuwen, P. W. N. M.; Nozaki, K. Acc. Chem. Res. 2013, 46, 1438. 
(b) Chen, C. L. Nat. Rev. Chem. 2018, 2, 6 .

(c) Mitchell, N. E.; Long, B. K. Polym. Int. 2019, 68, 14.

(d) Tan, C.; Chen, C. L. Angew. Chem., Int. Ed. 2019, 58, 7192.

(e) Wang, F. Z.; Chen, C. L. Polym. Chem. 2019, 10, 2354.

[21] Klabunde, U.; Itten, S. D. J. Mol. Catal. 1987, 41, 123.

[22] Johnson, L. K.; Mecking, S.; Brookhart, M. J. Am. Chem. Soc. 1996, 118, 267.

[23] Younkin, T. R.; Connor, E. F.; Henderson, J. I.; Friedrich, S. K.; Grubbs, R. H.; Bansleben, D. A. Science 2000, 287, 460

[24] Carrow, B. P.; Nozaki, K. J. Am. Chem. Soc. 2012, 134, 8802.

[25] Drent, E.; Van Dijk, R.; Van Ginkel, R.; Van Oort, B.; Pugh, R. I. Chem. Commun. 2002, 744.

[26] Friedberger, T.; Wucher, P.; Mecking, S. J. Am. Chem. Soc. 2012, $134,1010$.

[27] Zhao, Y.; Gao, H. Y.; Zhang, L.; Wu, Q. Chin. Polym. Bull. 2009, 27 (in Chinese). (赵烨，高海洋，张玲，伍青，高分子通报，2009, 27.)

[28] Chen, M.; Chen, C. L. Acta Polym. Sin. 2018, 1372 (in Chinese). (陈敏，陈昶乐，高分子学报, 2018, 1372.)

[29] Jian, Z. B. Acta Polym. Sin. 2018, 1359 (in Chinese) (简忠保，高分子学报, 2018, 1359.)

[30] Cui, D. M. Acta Polym. Sin. 2020, 1 (in Chinese). (崔冬梅, 高分子学报, 2020, 1.)

[31] Mu, H.; Pan, L.; Song, D.; Li, Y. Chem. Rev. 2015, 115, 12091.

[32] Yuan, S.-F.; Yan, Y.; Solan, G. A.; Ma, Y.; Sun, W.-H. Coord. Chem. Rev. 2020, 411, 213254.

[33] Dai, S.; Li, S. Polymer 2020, 200, 122607.

[34] Li, M. Y.; Cai, Z. G.; Eisen, M. S. Organometallics 2018, 37, 4753.

[35] Chen, Z.; Brookhart, M. Acc. Chem. Res. 2018, 51, 1831.

[36] (a) Chen, M.; Yang, B. P.; Chen, C. L. Synlett 2016, 27, 1297. (b) Chen, C. L. ACS Catal. 2018, 8, 5506.

(c) Kaiser, J. M.; Long, B. K. Coord. Chem. Rev. 2018, 372, 141.

[37] (a) Guo, L. H.; Dai, S. Y.; Sui, X. L.; Chen, C. L. ACS Catal. 2016, $6,428$.

(b) Flisak, Z.; Sun, W.-H. ACS Catal. 2015, 5, 4713.

[38] Nakamura, A.; Ito, S.; Nozaki, K. Chem. Rev. 2009, 109, 5215.

[39] Camacho, D. H.; Guan, Z. Chem. Commun. 2010, 46, 7879.

[40] (a) Zhang, Y. P.; Mu, H. L.; Pan, L.; Wang, X. L.; Li, Y. S. ACS Catal. 2018, 8, 5963.

(b) Nomura, K. J. Synth. Org. Chem. Jpn. 2010, 68, 1150.

(c) Gaikwad, S. R.; Deshmukh, S. S.; Koshti, V. S.; Poddar, S.; Gonnade, R. G.; Rajamohanan, P. R.; Chikkali, S. H. Macromolecules 2017, 50, 5748 .

[41] (a) Radlauer, M. R.; Day, M. W.; Agapie, T. J. Am. Chem. Soc. 2012, 134, 1478.

(b) Runzi, T.; Frohlich, D.; Mecking, S. J. Am. Chem. Soc. 2010, 132,17690

(c) Keyes, A.; Alhan, H. E. B.; Ordonez, E.; Ha, U.; Beezer, D. B.; Dau, H.; Liu, Y.-S.; Tsogtgerel, E.; Jones, G. R.; Harth, E. Angew. Chem., Int. Ed. 2019, 58, 12370.

[42] Schuster, N.; Runzi, T.; Mecking, S. Macromolecules 2016, 49, 1172.

[43] Huo, P.; Liu, W. Y.; He, X. H.; Wang, H. M.; Chen, Y. W. Organometallics 2013, 32, 2291.

[44] Mecking, S.; Johnson, L. K.; Wang, L.; Brookhart, M. J. Am. Chem. Soc. 1998, 120, 888.

[45] Park, S.; Takeuchi, D.; Osakada, K. J. Am. Chem. Soc. 2006, 128, 3510.

[46] Luo, S.; Jordan, R. F. J. Am. Chem. Soc. 2006, 128, 12072.

[47] (a) Guo, L. H.; Zou, C.; Dai, S. Y.; Chen, C. L. Polymers 2017, 9, 122.

(b) Li, M.; Wang, X. B.; Luo, Y.; Chen, C. L. Angew. Chem., Int. Ed. 2017, 56, 11604.

[48] (a) Popeney, C. S.; Camacho, D. H.; Guan, Z. B. J. Am. Chem. Soc. 2007, 129, 10062

(b) Liu, F.-S.; Hu, H.-B.; Xu, Y.; Guo, L.-H.; Zai, S.-B.; Song, K.-M.; Gao, H.-Y.; Zhang, L.; Zhu, F.-M.; Wu, Q. Macromolecules 2009, 42, 7789 . (c) Guo, L. H.; Gao, H. Y.; Guan, Q. R.; Hu, H. B.; Deng, J. A.; Liu, J.; Liu, F. S.; Wu, Q. Organometallics 2012, 31, 6054.

[49] Avar, S.; Mortazavi, S. M. M.; Ahmadjo, S.; Zohuri, G. H. Appl. Organomet. Chem. 2018, 32, e4238.

[50] Takeuchi, D.; Yamada, T.; Nakamaru, Y.; Osakada, K.; Aratani, I.; Suzuki, Y. Organometallics 2019, 38, 2323.

[51] Rosar, V.; Meduri, A.; Montini, T.; Fini, F.; Carfagna, C.; Fornasiero, P.; Balducci, G.; Zangrando, E.; Milani, B. ChemCatChem 2014, 6, 2403.

[52] (a) Allen, K. E.; Campos, J.; Daugulis, O.; Brookhart, M. ACS Catal. 2015, 5, 456.

(b) Chen, Z.; Liu, W. J.; Daugulis, O.; Brookhart, M. J. Am. Chem. Soc. 2016, 138, 16120.

[53] Chen, Z.; Leatherman, M. D.; Daugulis, O.; Brookhart, M. J. Am. Chem. Soc. 2017, 139, 16013.

[54] Matos, I.; Fernandes, S. N.; Liu, H. R.; Tevtia, A. K.; Singh, R. P.; Manda, L.; Lemos, F.; Marques, M. M. J. Appl. Polym. Sci. 2013, $129,1820$.

[55] Meduri, A.; Montini, T.; Ragaini, F.; Fornasiero, P.; Zangrando, E.; Milani, B. ChemCatChem 2013, 5, 1170

[56] Rosar, V.; Meduri, A.; Montini, T.; Fornasiero, P.; Zangrando, E.; Milani, B. Dalton Trans. 2018, 47, 2778.

[57] Pan, H. J.; Zhu, L.; Li, J. W.; Zang, D. D.; Fu, Z. S.; Fan, Z. Q. J. Mol. Catal. A: Chem. 2014, 390, 76.

[58] Popeney, C. S.; Guan, Z. B. J. Am. Chem. Soc. 2009, 131, 12384.

[59] Rhinehart, J. L.; Brown, L. A.; Long, B. K. J. Am. Chem. Soc. 2013, $135,16316$.

[60] Dai, S. Y.; Sui, X. L.; Chen, C. L. Angew. Chem., Int. Ed. 2015, 54, 9948.

[61] Dai, S. Y.; Chen, C. L. Angew. Chem., Int. Ed. 2016, 55, 13281.

[62] Dai, S. Y.; Chen, C. L. Macromolecules 2018, 51, 6818.

[63] Gong, Y.; Li, S.; Gong, Q.; Zhang, S.; Liu, B.; Dai, S. Organometallics 2019, 38, 2919.

[64] Muhammad, Q.; Tan, C.; Chen, C. Sci. Bull. 2020, 65, 300.

[65] Na, Y. N.; Dai, S. Y.; Chen, C. L. Macromolecules 2018, 51, 4040.

[66] Sui, X. L.; Hong, C. W.; Pang, W. M.; Chen, C. L. Mat. Chem. Front. 2017, 1, 967.

[67] Na, Y. N.; Zhang, D.; Chen, C. L. Polym. Chem. 2017, 8, 2405.

[68] Fang, J.; Sui, X. L.; Li, Y. G.; Chen, C. L. Polym. Chem. 2018, 9, 4143.

[69] Guo, L. H.; Liu, Y. L.; Sun, W. T.; Du, Q.; Yang, Y. L.; Kong, W. Y.; Liu, Z.; Chen, D. R. J. Organomet. Chem. 2018, 877, 12.

[70] Liao, Y.; Zhang, Y.; Cui, L.; Mu, H.; Jian, Z. Organometallics 2019 38, 2075.

[71] Kanai, Y.; Foro, S.; Plenio, H. Organometallics 2019, 38, 544

[72] Hu, X.; Zhang, Y.; Zhang, Y.; Jian, Z. ChemCatChem 2020, 12, 2497.

[73] Wang, R. K.; Zhao, M. H.; Chen, C. L. Polym. Chem. 2016, 7, 3933.

[74] Zhai, F.; Solomon, J. B.; Jordan, R. F. Organometallics 2017, 36, 1873 .

[75] Zou, W. P.; Chen, C. L. Organometallics 2016, 35, 1794.

[76] Dall'anese, A.; Rosar, V.; Cusin, L.; Montini, T.; Balducci, G.; D'auria, I.; Pellecchia, C.; Fornasiero, P.; Felluga, F.; Milani, B. Organometallics 2019, 38, 3498.

[77] Zhong, S. H.; Tan, Y. X.; Zhong, L.; Gao, J.; Liao, H.; Jiang, L.; Gao, H. Y.; Wu, Q. Macromolecules 2017, 50, 5661.

[78] Du, C.; Zhong, L.; Gao, J.; Zhong, S. H.; Liao, H.; Gao, H. Y.; Wu, Q. Polym. Chem. 2019, 10, 2029.

[79] Zhong, L.; Li, G. L.; Liang, G. D.; Gao, H. Y.; Wu, Q. Macromolecules 2017, 50, 2675.

[80] Huo, P.; Li, J.; Liu, W.; Mei, G.; He, X. RSC Adv. 2017, 7, 51858.

[81] He, X.; Deng, Y.; Jiang, X.; Wang, Z.; Yang, Y.; Han, Z.; Chen, D. Polym. Chem. 2017, 8, 2390.

[82] Huo, P.; Liu, W. Y.; He, X. H.; Wei, Z. H.; Chen, Y. W. Polym. Chem. 2014, 5, 1210

[83] Tian, J.; He, X.; Liu, J.; Deng, X.; Chen, D. RSC Adv. 2016, 6, 22908. 
[84] Long, B. K.; Eagan, J. M.; Mulzer, M.; Coates, G. W. Angew. Chem., Int. Ed. 2016, 55, 7106.

[85] Hu, H.; Chen, D.; Gao, H.; Zhong, L.; Wu, Q. Polym. Chem. 2016, 7, 529.

[86] Zheng, T.; Liao, H.; Gao, J.; Zhong, L.; Gao, H. Y.; Wu, Q. Polym Chem. 2018, 9, 3088.

[87] Kawakami, T.; Ito, S.; Nozaki, K. Dalton Trans. 2015, 44, 20745.

[88] Zhu, L.; Fu, Z. S.; Pan, H. J.; Feng, W.; Chen, C. L.; Fan, Z. Q. Dalton Trans. 2014, 43, 2900.

[89] Na, Y. N.; Wang, X. B.; Lian, K. B.; Yun, Z.; Li, W. M.; Yi, L.; Chen, C. L. ChemCatChem 2017, 9, 1062.

[90] Huo, P.; Liu, W. Y.; He, X. H.; Chen, Y. W. J. Polym. Sci., Part A: Polym. Chem. 2014, 52, 3213.

[91] Tafazolian, H.; Culver, D. B.; Conley, M. P. Organometallics 2017, 36,2385 .

[92] Culver, D. B.; Tafazolian, H.; Conley, M. P. Organometallics 2018 , 37, 1001.

[93] Radlauer, M. R.; Buckley, A. K.; Henling, L. M.; Agapie, T. J. Am. Chem. Soc. 2013, 135, 3784

[94] Cheng, H. L.; Wang, H. J.; Li, Y. Q.; Hu, Y. M.; Zhang, X. Q.; Cai, Z. G. J. Catal. 2018, 368, 291.

[95] Takeuchi, D.; Chiba, Y.; Takano, S.; Osakada, K. Angew. Chem., Int. Ed. 2013, 52, 12536.

[96] Chen, Z. T.; Yao, E. D.; Wang, J. C.; Gong, X. Y.; Ma, Y. G. Macromolecules 2016, 49, 8848 .

[97] Chen, Y.; Mandal, S.; Sen, A. Organometallics 2010, 29, 3160.

[98] He, F.; Chen, Y.; He, X.; Chen, M.; Zhou, W.; Wu, Q. J. Polym. Sci., Part A: Polym. Chem. 2009, 47, 3990.

[99] Huang, R.; He, X. H.; Chen, Y. W.; Nie, H. R.; Zhou, W. H. Polym. Adv. Technol. 2012, 23, 483.

[100] Xing, Y.; Chen, Y.; He, X. J. Polym. Sci., Part A: Polym. Chem. 2011, 49, 4425 .

[101] Tian, J. W.; Zhu, H. Y.; Liu, J. Y.; Chen, D. F.; He, X. H. Appl. Organomet. Chem. 2014, 28, 702.

[102] Xing, Y. P.; He, X. H.; Chen, Y. W.; Nie, H. R.; Wu, Q. Polym. Bull. 2011, 66, 1149 .

[103] Zhou, W.; He, X.; Chen, Y.; Chen, M.; Shi, L.; Wu, Q. J. Appl. Polym. Sci. 2011, 120, 2008.

[104] Wang, K.; Chen, Y.; He, X.; Liu, Y.; Zhou, W. J. Polym. Sci., Part A: Polym. Chem. 2011, 49, 3304.

[105] He, X.; Liu, Y.; Chen, L.; Chen, Y.; Chen, D. J. Polym. Sci., Part A: Polym. Chem. 2012, 50, 4695.

[106] Wang, X. F.; He, X. H.; Chen, D. F.; Chen, Y. W. J. Polym. Eng. 2012, 32, 415 .

[107] Chen, L.; Zhong, Z. C.; Chen, C.; He, X. H.; Chen, Y. W. J. Organomet. Chem. 2014, 752, 100.

[108] He, X. H.; Liu, J. Y.; Chen, L.; Zhu, H. Y.; Wang, J. Chem. J. Chin Univ. 2015, 36, 575 (in Chinese) (贺晓慧，刘菁)㳙，陈璐，朱宏宇，王娟，高等学校化学学报， 2015, 36, 575.)

[109] He, X. H.; Yang, Y. P.; Wang, S. L.; Han, Z. L.; Tu, G. S.; Zhang, F.; Huang, S. M.; Wang, Z. J.; Chen, D. F. RSC Adv. 2017, 7, 48745.

[110] Tian, J. W.; He, X. H.; Liu, J. Y.; Deng, X. D.; Chen, D. F. RSC Adv 2015, 5, 61851.

[111] Fu, X.; Zhang, L. J.; Tanaka, R.; Shiono, T.; Cai, Z. G. Macromolecules 2017, 50, 9216.

[112] Ding, L.; Cheng, H. L.; Li, Y. Q.; Tanaka, R.; Shiono, T.; Cai, Z. G. Polym. Chem. 2018, 9, 5476.

[113] Cheng, H. L.; Su, Y.; Hu, Y. M.; Zhang, X. Q.; Cai, Z. G. Polymers 2018, 10, 10 .

[114] Zou, C.; Dai, S. Y.; Chen, C. L. Macromolecules 2018, 51, 49.

[115] (a) Mu, H. L.; Li, Y. G.; Li, Y. S. Chin. J. Appl. Chem. 2012, 29, 1381 (in Chinese) (穆红亮, 李彦国, 李悦生, 应用化学, 2012, 29, 1381.) (b) Gibson, V. C.; Tomov, A. Chem. Commun. 2001, 1964.

[116] Guo, C.-Y.; Peulecke, N.; Basvani, K. R.; Kinderman, M. K.; Heinicke, J. Macromolecules 2010, 43, 1416.

[117] Konishi, Y.; Tao, W. J.; Yasuda, H.; Ito, S.; Oishi, Y.; Ohtaki, H.;
Tanna, A.; Tayano, T.; Nozaki, K. ACS Macro Lett. 2018, 7, 213.

[118] Xin, B. S.; Sato, N.; Tanna, A.; Oishi, Y.; Konishi, Y.; Shimizu, F. J. Am. Chem. Soc. 2017, 139, 3611.

[119] Zhang, Y. P.; Mu, H. L.; Wang, X. L.; Pan, L.; Li, Y. S. ChemCatChem 2019, 11, 2329.

[120] Zhang, Y.-P.; Li, W.-W.; Li, B.-X.; Mu, H.-L.; Li, Y.-S. Dalton Trans. 2015, 44, 7382

[121] Zhang, Y. P.; Mu, H. L.; Li, Y. G.; Li, Y. S. Appl. Organomet. Chem 2018, 32, 9 .

[122] Zhang, Y.; Zhang, Y.; Chi, Y.; Jian, Z. Dalton Trans. 2020, 49, 2636.

[123] Zhang, Y.; Jian, Z. Polymer 2020, 194, 122410

[124] Skupov, K. M.; Marella, P. R.; Simard, M.; Yap, G. P. A.; Allen, N.; Conner, D.; Goodall, B. L.; Claverie, J. P. Macromol. Rapid Commun. 2007, 28, 2033.

[125] Luo, S.; Vela, J.; Lief, G. R.; Jordan, R. F. J. Am. Chem. Soc. 2007 $129,8946$.

[126] Ito, S.; Munakata, K.; Nakamura, A.; Nozaki, K. J. Am. Chem. Soc. 2009, 131, 14606

[127] Kochi, T.; Noda, S.; Yoshimura, K.; Nozaki, K. J. Am. Chem. Soc. 2007, 129, 8948

[128] Weng, W.; Shen, Z.; Jordan, R. F. J. Am. Chem. Soc. 2007, 129, 15450

[129] Neuwald, B.; Oelscher, F.; Goettker-Schnetmann, I.; Mecking, S. Organometallics 2012, 31, 3128.

[130] Jian, Z. B.; Wucher, P.; Mecking, S. Organometallics 2014, 33, 2879.

[131] Piche, L.; Daigle, J.-C.; Rehse, G.; Claverie, J. P. Chem.-Eur. J. 2012, 18, 3277.

[132] Kryuchkov, V. A.; Daigle, J.-C.; Skupov, K. M.; Claverie, J. P.; Winnik, F. M. J. Am. Chem. Soc. 2010, 132, 15573.

[133] Daigle, J.-C.; Piche, L.; Claverie, J. P. Macromolecules 2011, 44 1760 .

[134] Neuwald, B.; Falivene, L.; Caporaso, L.; Cavallo, L.; Mecking, S. Chem.-Eur. J. 2013, 19, 17773

[135] Wucher, P.; Goldbach, V.; Mecking, S. Organometallics 2013, 32 , 4516.

[136] Guironnet, D.; Roesle, P.; Rünzi, T.; Göttker-Schnetmann, I.; Mecking, S. J. Am. Chem. Soc. 2009, 131, 422.

[137] Zhang, D.; Chen, C. L. Angew. Chem., Int. Ed. 2017, 56, 14672.

[138] Daigle, J.-C.; Piche, L.; Arnold, A.; Claverie, J. P. ACS Macro Lett. 2012, 1,343

[139] Jian, Z.; Baier, M. C.; Mecking, S. J. Am. Chem. Soc. 2015, 137 2836.

[140] Jian, Z.; Mecking, S. Angew. Chem., Int. Ed. 2015, 54, 15845

[141] Jian, Z.; Mecking, S. Macromolecules 2016, 49, 4395.

[142] Gaikwad, S. R.; Deshmukh, S. J. S.; Gonnade, R. G.; Rajamohanan, P. R.; Chikkali, S. H. ACS Macro Lett. 2015, 4, 933.

[143] Yasuda, H.; Nakano, R.; Ito, S.; Nozaki, K. J. Am. Chem. Soc. 2018, 140, 1876.

[144] Ölscher, F.; Göttker-Schnetmann, I.; Monteil, V.; Mecking, S. J. Am. Chem. Soc. 2015, 137, 14819.

[145] (a) Li, S.; Liu, D.; Wang, Z.; Cui, D. ACS Catal. 2018, 8, 6086. (b) Liu, B.; Qiao, K.; Fang, J.; Wang, T.; Wang, Z.; Liu, D.; Xie, Z.; Maron, L.; Cui, D. Angew. Chem., Int. Ed. 2018, 57, 14896. (c) Wang, T. T.; Liu, D. T.; Cui, D. M. Macromolecules 2019, 52, 9555.

[146] Borkar, S.; Newsham, D. K.; Sen, A. Organometallics 2008, 27, 3331.

[147] Cui, L.; Chen, M.; Chen, C. L.; Liu, D. T.; Jian, Z. B. Macromolecules 2019, 52, 7197

[148] Shen, Z.; Jordan, R. F. Macromolecules 2010, 43, 8706

[149] Lanzinger, D.; Giuman, M. M.; Anselment, T. M. J.; Rieger, B. ACS Macro Lett. 2014, 3, 931.

[150] Bouilhac, C.; Rünzi, T.; Mecking, S. Macromolecules 2010, 43 , 3589.

[151] Ravasio, A.; Boggioni, L.; Tritto, I. Macromolecules 2011, 44, 4180 . 
[152] Jian, Z. B.; Leicht, H.; Mecking, S. Macromol. Rapid Commun. 2016, 37, 934.

[153] Chen, M.; Chen, C. L. Angew. Chem., Int. Ed. 2020, 59, 1206.

[154] Jian, Z. B.; Mecking, S. Macromolecules 2016, 49, 4057.

[155] Liang, T.; Chen, C. L. Organometallics 2017, 36, 2338.

[156] Yang, B. P.; Xiong, S. Y.; Chen, C. L. Polym. Chem. 2017, 8, 6272.

[157] Tan, C.; Qasim, M.; Pang, W.; Chen, C. Polym. Chem. 2020, 11, 411.

[158] Anselment, T. M. J.; Anderson, C. E.; Rieger, B.; Boeddinghaus, M. B.; Fassler, T. F. Dalton Trans. 2011, 40, 8304.

[159] Leicht, H.; Göttker-Schnetmann, I.; Mecking, S. Angew. Chem., Int. Ed. 2013, 52, 3963.

[160] Wucher, P.; Schwaderer, J. B.; Mecking, S. ACS Catal. 2014, 4, 2672.

[161] Ito, S.; Kanazawa, M.; Munakata, K.; Kuroda, J.-I.; Okumura, Y.; Nozaki, K. J. Am. Chem. Soc. 2011, 133, 1232.

[162] Ota, Y.; Ito, S.; Kuroda, J.-I.; Okumura, Y.; Nozaki, K. J. Am. Chem. Soc. 2014, 136, 11898.

[163] Ota, Y.; Ito, S.; Kobayashi, M.; Kitade, S.; Sakata, K.; Tayano, T.; Nozaki, K. Angew. Chem., Int. Ed. 2016, 55, 7505.

[164] Xia, J.; Zhang, Y. X.; Hu, X. Q.; Ma, X.; Cui, L.; Zhang, J. F.; Jian, Z. B. Polym. Chem. 2019, 10, 546.

[165] Wu, Z. X.; Chen, M.; Chen, C. L. Organometallics 2016, 35, 1472.

[166] Wu, Z. X.; Hong, C. W.; Du, H. X.; Pang, W. M.; Chen, C. L. Polymers 2017, 9, 168.

[167] Zou, C.; Pang, W. M.; Chen, C. L. Sci. China: Chem. 2018, 61, 1175.

[168] Black, R. E.; Jordan, R. F. Organometallics 2017, 36, 3415.

[169] Wada, S.; Jordan, R. F. Angew. Chem., Int. Ed. 2017, 56, 1820.

[170] Ito, S.; Ota, Y.; Nozaki, K. Dalton Trans. 2012, 41, 13807.

[171] Chen, M.; Chen, C. ACS Catal. 2017, 7, 1308.

[172] Song, G. Z.; Pang, W. M.; Li, W. M.; Chen, M.; Chen, C. L. Polym. Chem. 2017, 8, 7400 .

[173] Liang, T.; Chen, C. L. Inorg. Chem. 2018, 57, 14913.

[174] Xia, J.; Zhang, Y. X.; Zhang, J. F.; Jian, Z. B. Organometallics 2019, 38, 1118 .

[175] Nakano, R.; Nozaki, K. J. Am. Chem. Soc. 2015, 137, 10934.

[176] Tao, W. J.; Nakano, R.; Ito, S.; Nozaki, K. Angew. Chem., Int. Ed. 2016, 55,2835

[177] Tao, W.; Akita, S.; Nakano, R.; Ito, S.; Hoshimoto, Y.; Ogoshi, S.;
Nozaki, K. Chem. Commun. 2017, 53, 2630.

[178] Tao, W.; Wang, X.; Ito, S.; Nozaki, K. J. Polym. Sci., Part A: Polym. Chem. 2019, 57, 474.

[179] Carrow, B. P.; Nozaki, K. Macromolecules 2014, 47, 2541.

[180] Mitsushige, Y.; Carrow, B. P.; Ito, S.; Nozaki, K. Chem. Sci. 2016, $7,737$.

[181] Cai, Z. Z.; Do, L. H. Organometallics 2018, 37, 3874.

[182] Contrella, N. D.; Sampson, J. R.; Jordan, R. F. Organometallics 2014, 33, 3546.

[183] Sui, X. L.; Dai, S. Y.; Chen, C. L. ACS Catal. 2015, 5, 5932.

[184] Hong, C. W.; Sui, X. L.; Li, Z. Q.; Pang, W. M.; Chen, M. Dalton Trans. 2018, 47, 8264 .

[185] Ye, J. H.; Mu, H. L.; Wang, Z.; Jian, Z. B. Organometallics 2019, $38,2990$.

[186] Mu, H.-L.; Ye, J.-H.; Zhou, G.-L.; Li, K.-K.; Jian, Z.-B. Chin. J. Polym. Sci. 2019, 38, 579.

[187] Zhou, G.; Mu, H.; Jian, Z. J. Catal. 2020, 383, 215.

[188] Li, K.; Ye, J.; Wang, Z.; Mu, H.; Jian, Z. Polym. Chem. 2020, 11, 2740.

[189] Mitsushige, Y.; Yasuda, H.; Carrow, B. P.; Ito, S.; Kobayashi, M.; Tayano, T.; Watanabe, Y.; Okuno, Y.; Hayashi, S.; Kuroda, J.; Okumura, Y.; Nozaki, K. ACS Macro Lett. 2018, 7, 305.

[190] Jung, J.; Yasuda, H.; Nozaki, K. Macromolecules 2020, 53, 2547.

[191] Chen, M.; Chen, C. L. Angew. Chem., Int. Ed. 2018, 57, 3094.

[192] Sun, J. J.; Chen, M.; Luo, G.; Chen, C. L.; Luo, Y. Organometallics 2019, 38, 638 .

[193] Si, G. F.; Na, Y. N.; Chen, C. L. ChemCatChem 2018, 10, 5135.

[194] Gao, J. X.; Yang, B. P.; Chen, C. L. J. Catal. 2019, 369, 233.

[195] Zou, C.; Tan, C.; Pang, W. M.; Chen, C. L. ChemCatChem 2019, $11,5339$.

[196] Brookhart, M.; Kunitsky, K.; Malinoski, J.; Wang, L, Wang, Y.; Liu, W.; Johnson, L.; Kreutzer, K.; Ittel, S. WO 2002059165, 2002.

[197] Liang, T.; Goudari, S. B.; Chen, C. Nat. Commun. 2020, 11, 372.

[198] Franssen, N. M. G.; Reek, J. N. H.; De Bruin, B. Dalton Trans. 2013, 42, 9058.

[199] Walsh, D. J.; Hyatt, M. G.; Miller, S. A.; Guironnet, D. ACS Catal. 2019, 9, 11153 .

[200] Dai, S.; Li, S.; Xu, G.; Chen, C. Macromolecules 2020, 53, 2539.

[201] Parisi, L. R.; Scheibel, D.; Lin, S.; Bennett, E. M.; Lodge, J. M.; Miri, M. Polymer 2017, 114, 319. 